\title{
The Effects of Obesity, Chronic Stress, and Exercise on Pancreatic Health
}

Abigail Tice

West Virginia University, altice@mix.wvu.edu

Follow this and additional works at: https://researchrepository.wvu.edu/etd

Part of the Medicine and Health Sciences Commons

\section{Recommended Citation}

Tice, Abigail, "The Effects of Obesity, Chronic Stress, and Exercise on Pancreatic Health" (2019). Graduate Theses, Dissertations, and Problem Reports. 4034.

https://researchrepository.wvu.edu/etd/4034

This Thesis is protected by copyright and/or related rights. It has been brought to you by the The Research Repository @ WVU with permission from the rights-holder(s). You are free to use this Thesis in any way that is permitted by the copyright and related rights legislation that applies to your use. For other uses you must obtain permission from the rights-holder(s) directly, unless additional rights are indicated by a Creative Commons license in the record and/ or on the work itself. This Thesis has been accepted for inclusion in WVU Graduate Theses, Dissertations, and Problem Reports collection by an authorized administrator of The Research Repository @ WVU. For more information, please contact researchrepository@mail.wvu.edu. 


\title{
The Effects of Obesity, Chronic Stress, and Exercise on Pancreatic Health
}

\author{
Abigail Lynn Tice \\ Thesis to be submitted to the School of Medicine at West Virginia University in partial \\ fulfillment of the requirements of the degree: \\ Masters of Science in Exercise Physiology \\ Randall W. Bryner, Ed.D., Committee Chair/Research Advisor \\ Paul D. Chantler, Ph.D. \\ I. Mark Olfert, Ph.D.
}

Division of Exercise Physiology

Morgantown, West Virginia

July 2019

Key Words: Obesity, metabolic syndrome, chronic stress, depression, pancreas, inflammation, Oxidative stress, apoptosis, thioredoxin-interacting protein (TXNIP)

Copyright 2019 Abigail Tice 


\title{
Abstract \\ The Effects of Obesity, Chronic Stress, and Exercise on Pancreatic Health
}

\begin{abstract}
Abigail L. Tice
Obesity is concomitant with hyperglycemic conditions, increased proinflammatory cytokines, and increased oxidative stress. Under hyperglycemia, thioredoxin interacting protein (TXNIP) is increased and causes increased oxidative stress and pancreatic $\beta$-cell apoptosis. Chronic stress is associated with increased glucocorticoid levels and a proinflammatory environment. The purpose of this study was to examine the effects of obesity, chronic stress, and exercise on pancreatic health.

Lean Zucker Rats (LZRs) and Obese Zucker Rats (OZRs) were randomly assigned to four groups: 1) sedentary controls (C: $\mathrm{n}=8$ per); 2) unpredictable chronic mild stress (UCMS) (S: $n=8) ; 3$ ) exercise (E: $n=8)$; and 4) combined UCMS and exercise (ExS: $n=8)$. Exercise rats underwent 8 weeks of treadmill running for 60 minutes. Stress rats were subjected to UCMS that included cage tilt, no bedding, damp bedding, bath, social stress, and altered light-dark cycles for 8 hours a day, 5 days a week for 8 weeks. Pancreas tissue was obtained from rats around 20 weeks of age. Total pancreatic TXNIP protein was quantified, including total pancreatic cytokine expression for IL-1 $\beta$, TNF- $\alpha$, IL-4, and IL-10. Using immunohistochemistry, $\beta$-cell and $\alpha$-cell counting, islet area measurements, and $\beta$-cell to $\alpha$-cell ratio were examined. TUNEL staining, to determine apoptosis, was examined in pancreatic lysates.

OZRs had higher insulin, glucose, and body mass compared to LZRs, as wells as higher $\beta$-cell and $\alpha$-cell number and islet area $(\mathrm{p}<0.05)$. TXNIP in pancreas had an increasing trend in OZR-C compared to LZR-C ( $\mathrm{p}=0.10)$; TNF- $\alpha$ and IL-4 were higher in OZR-C compared to LZR-C $(\mathrm{p}<0.05)$. Little to no differences in morphology or TXNIP in either genotype of stressed animal. OZR-S had lower TNF- $\alpha$, IL-4, and IL-6 when compared to OZR-C $(\mathrm{p}<0.05)$. Islet area and $\alpha$-cell numbers were lower with exercise in obese animals, while $\beta$-cell to $\alpha$-cell ratio was higher $(\mathrm{p}<0.05)$. TXNIP was not different, but IL-4 and IL-6 were lower in OZR-EX compared to OZR-C $(p<0.05)$. $\beta$-cell and $\alpha$-ell numbers and islet area were higher in LZR-EXS compared to LZR-S $(p<0.05)$, but no differences were seen in the obese model of stress and exercise. TXNIP was lower in LZR-EXS compared to LZR-S $(\mathrm{p}<0.05)$, and TXNIP trended to decrease in OZR-EXS compared to OZR-S ( $p=0.10$ ). No differences were observed in cytokines in these groups. No differences were observed in any groups with apoptosis.

In a model of obesity and metabolic syndrome, the pancreas appeared to be stimulated to grow as indicated by greater numbers of $\beta$ - and $\alpha$-cells and larger islets even in the presence of slightly higher pancreatic TXNIP and TNF- $\alpha$. Obesity resulted in an increased level of inflammation and reduced antioxidant potential within the pancreas as indicated by significantly higher TXNIP, IL-1 $\beta$, and TNF- $\alpha$. Eight weeks of treadmill running reversed this effect. Exercise training was also able to reduced TXNIP within the pancreas as a result of stress.
\end{abstract}




\section{Dedication}

To my family, lab mates, teammates, and many mentors for guiding me every step of the way in and out of the lab and classroom. 


\section{Acknowledgements}

In the six years I have spent at WVU and in the Exercise Physiology program, I have had the privilege of having many distinguished mentors and making some of the greatest friends. Within the Exercise Physiology family, I have had the opportunity to be guided by many intelligent minds, such as Randy, Paul, Mark, Ed, Lori, Emily, Danny, Jim, and many others. I was inspired by Dr. Pistilli's lectures in EXPH 386 to try out research, and thanks to the efforts of my committee, I have fallen in love with this path. I have many thanks to give to Guy and my weightlifting family for being my home away from home and helping me workout through the stresses of my masters to become a stronger (mostly physically, but a little bit mentally) person. I have learned the importance of discipline and time management... and not waiting until two days before a meet to try to cut six kilos.

I consider myself a very blessed person for having someone like Dr. Bryner as my chair. He always had my back, answered all my texts and emails, and never let his candy bowl get too empty. The best thing that could have happened to me was getting a PI that was my opposite. Dr. B has done his absolute best at teaching me to "chill out", though we both know I will always be a spaz through and through. I am grateful for Dr. Chantler and Dr. Olfert and their patience with me as I learned how to write and actually get my hands dirty in lab. I know that I am leaving WVU a better and smarter person because these professors took a chance on me and helped me grow as a student and as a person.

I will never be able to put into words the amount of gratitude and love I have for my labmates, some of the greatest human beings on this planet. I am blessed to have gotten the chance to work with such an amazing group of people, and I know there will always be a place in my heart for all of them. 


\section{ABBREVIATIONS}

T2D Type 2 diabetes

GC Glucocorticoid

HPA-axis Hypothalamus pituitary adrenal axis

SNS Sympathetic nervous system

GLUT4 Glucose transporter 4

TXNIP Thioredoxin-interacting protein

Trx Thioredoxin

ASK-1 Apoptosis signaling kinase-1

Cyt-C Cytochrome-C

NLRP3 Nod-like receptor protein 3

UCMS Unpredictable chronic mild stress

ROS Reactive oxygen species

NO Nitric oxide

OZR Obese Zucker rat

LZR Lean Zucker rat

C Control

EX Exercise

EXS Exercise and stress 
Table of Contents

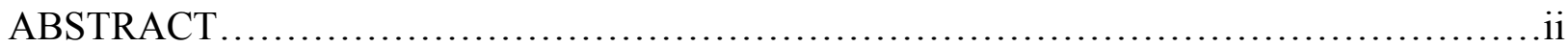

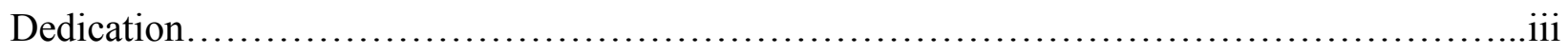

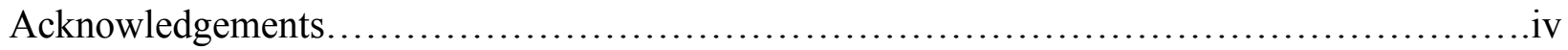

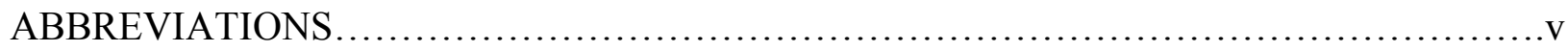

CHAPTER 1: BACKGROUND AND SIGNIFICANCE ..................................

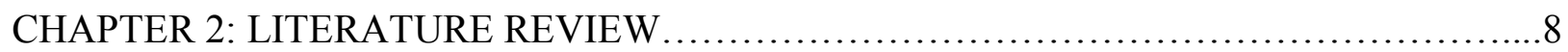

CHAPTER 3: MATERIALS AND METHODS ........................................ 32

CHAPTER 4: RESULTS .......................................................45

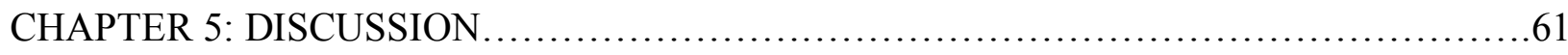

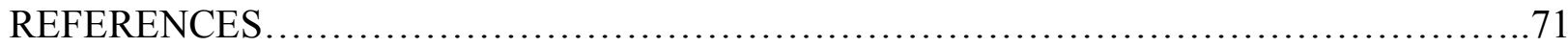




\section{CHAPTER 1: BACKGROUND AND SIGNIFICANCE}

Metabolic Syndrome, which affects approximately 23 percent of adults in the United States, is comprised of a cluster of risk factors that can lead to many chronic diseases, including cardiovascular diseases, cancer, and diabetes ${ }^{1,2,3}$. The criteria for the Metabolic Syndrome includes increased waist circumference (obesity), hypertension, high circulating triglycerides, low high-density lipoprotein-cholesterol (HDL-C), and high fasting glucose. ${ }^{2}$ The risk factors for Metabolic Syndrome are similar to risk factors related to the development of type 2 diabetes (T2D), such as obesity, high circulating triglycerides, and high fasting glucose, and the condition often leads to insulin resistance and hyperinsulinemia., ${ }^{4,5}$ There are various modifiable risk factors that can lead to insulin resistance, including physical inactivity, poor nutrition, obesity, and stress. ${ }^{1}$ Obesity is an epidemic affecting nearly one-third of the adult population in the US, and it is proposed that by 2030 , there will be 65 million more obese adults in the US. ${ }^{6,7}$ Obesity is the accumulation of excess adipose tissue, an active endocrine tissue, which is a major storage site for triglycerides, and a major site of pro-inflammatory cytokine production. ${ }^{7,8}$ Initially, obesity and a high fat diet is associated with an increase in pancreatic islet mass due to hypertrophy of the $\beta$-cells and the $\alpha$-cells to compensate for the hyperglycemic state caused by increased levels of circulating free-fatty acids (FFA). ${ }^{9}$ Chronically high levels of circulating FFA are associated fatty acid and ceramide accumulation in peripheral tissues such as the liver and skeletal muscle which can result in insulin resistance and hyperinsulinemia, a process known as lipid toxicity. ${ }^{9}$ It can also result in $\beta$-cell dysfunction and eventual decreased insulin secretion, as a result of an interference with the insulin peptide folding causing an impairment of proper insulin processing. ${ }^{9}$ Obesity-induced adipocyte hypertrophy leads to altered visceral adipose tissue (VAT) homeostasis which causes an elevation of circulating proinflammatory cytokines, 
such as IL-6 and TNF- $\alpha$, through the proliferation of proinflammatory cells within the VAT. ${ }^{10}$ These proinflammatory cytokines are also seen to promote insulin resistance and place the body in a proinflammatory state by negatively affecting the insulin cascade. . $^{7,8,11,12,13}$

Stress, another modifiable risk factor for obesity, can lead to the hypersecretion of glucocorticoids (GCs) and proinflammatory cytokines, such as IL6 and TNF- $\alpha .{ }^{14}$ An upregulation of proinflammatory cytokines can lead to insulin resistance and an increased risk for the development of T2D. ${ }^{15}$ When the body senses stress, the hypothalamus-pituitary-adrenal (HPA) axis and sympathetic nervous system (SNS) are activated to release GCs and catecholamines (norepinephrine and epinephrine), respectively. ${ }^{16}$ In the presence of chronic stress, the HPA axis is subject to dysregulation, which in turn dysregulates inflammation with an associated increase in proinflammatory cytokines. Immune cells become desensitized to GCs that normally terminate an immune response, inducing a proinflammatory environment. ${ }^{17}$ Chronically elevated levels of circulating GCs promote increased adiposity and increase stress on pancreatic islet cell function. ${ }^{9}$ Upregulated GC exposure over time leads to increased insulin secretion and induces an increase in caloric intake, preference for calorically-dense foods, and circulating FFAs, promoting insulin resistance. ${ }^{9}$ The excessive secretion of GCs that is seen with chronic stress can lead to depression. ${ }^{14}$ Depression has been associated with poor health behaviors, including physical inactivity, smoking, and excessive caloric intake which can lead to obesity. ${ }^{15}$ Therefore, the co-morbidities are often linked in humans.

Physical inactivity is another modifiable risk factor of T2D, yet 80 percent of the US adult population does not meet recommendations for physical activity. ${ }^{18}$ A single bout of moderately intense exercise is associated with increased insulin sensitivity for 12-48 hours post exercise bout. ${ }^{19}$ Insulin sensitivity and $\beta$-cell function homeostasis are maintained through the 
balance of $\beta$-cell replication, neogenesis, and apoptosis, and regular exercise stimulates $\beta$-cell neogenesis. Chronic, daily, physical activity not only improves insulin sensitivity and action, but also works to improve GLUT4 translocation in skeletal muscle. This in turn reduces insulin requirements and improves peripheral insulin action. Regular physical activity preserves $\beta$-cell mass through the prevention of $\beta$-cell exhaustion that is seen through overuse in T2D. Acute exercise increases the release of GCs through the stimulation of the HPA axis, but with regular exercise, HPA axis activity can be normal or even reduced at rest. ${ }^{20}$ In addition, regular exercise lowers elevated GCs, mainly cortisol, brought about by chronic stress, therefore increasing insulin sensitivity and reducing insulin resistance. ${ }^{21}$

The thioredoxin system is a key component of the cellular anti-oxidant mechanism. ${ }^{22}$ Thioredoxin-interacting protein (TXNIP), a proapoptotic factor stimulated by hyperglycemia, acts as an inhibitor of thioredoxin (Trx), interfering with the anti-oxidant response and promoting oxidative stress. $^{22,23,24,25}$ Hyperglycemia enhances the interaction between TXNIP and Trx, and TXNIP is essential for glucose toxicity-induced $\beta$-cell apoptosis. ${ }^{22,23,24}$ TNXIP interferes with Trx through a variety of pathways, including mitochondrial interaction, cytoplasmic interference, and nuclear mechanisms. ${ }^{22,23,24,25,26}$ Within the mitochondria, TXNIP binds to Trx2, releasing apoptosis signal regulating kinase-1 (ASK1) from its inhibited state, increasing the release of Cytochrome $\mathrm{C}(\mathrm{Cyt}-\mathrm{C})$ and cleaved caspase-3, which leads to $\beta$-cell apoptosis. ${ }^{23,25,26}$ The TXNIP/Trx interaction in the cytoplasm causes the anti-oxidative mechanisms of Trx1 to be inhibited, increasing oxidative stress and leading to $\beta$-cell apoptosis. ${ }^{25,26}$. Through increased TXNIP expression, insulin transcription and $\beta$-cell function are reduced through the increased expression of microRNAs that interfere with the expression of target genes. ${ }^{24,25}$ Along with these increases in apoptosis, increased TXNIP expression also leads to the activation of the nod-like 
receptor protein 3 (NLRP3) inflammasome, a major producer of IL-1 $\beta$, a proinflammatory cytokine associated with insulin resistance..$^{22,27,28}$ ER stress induces increased TXNIP expression through unfolded protein response pathways IRE1- $\alpha$ and PERK, and therefore ER stress regulated NLRP3 production of IL-1 $\beta$ through TXNIP pathway, increasing the proinflammatory environment in the pancreas and other parts of the body. ${ }^{28}$

\section{PURPOSE AND SPECIFIC AIMS}

The purpose of this study was to assess the effects of obesity, chronic stress and exercise training on pancreatic health in a model of metabolic syndrome. We hypothesized that obesity would cause a decrease in pancreatic $\beta$-cell number and islet area because of an increase in TXNIP, the proinflammatory environment, and overall apoptosis-related proteins in the pancreas. We also hypothesized that stress would further increase and exercise training decrease these effects, through altered TXNIP and pro- and anti-inflammatory cytokines within the pancreas.

Specific Aim 1.1: To determine the effects of obesity on pancreatic morphology Hypothesis 1. Obesity alone (OZR-C) will decrease the number of pancreatic $\beta$-cells, the $\beta$-cell to $\alpha$-cell ratio, and islet area when compared with lean animals (LZR-C).

Specific Aim 1.2: To determine the effects of stress alone and in combination with obesity on pancreatic morphology

Hypothesis 1. Eight weeks of UCMS (LZR-S) will decrease the number of pancreatic $\beta$-cells, the $\beta$-cell to $\alpha$-cell ratio, and islet area when compared with lean animals (LZR-C). 
Hypothesis 2. Eight weeks of UCMS in combination with obesity (OZR-S) will augment the obesity-related decreases in the number of pancreatic $\beta$-cells, the $\beta$-cell to $\alpha$-cell ratio, and islet area when compared with obese (OZR-C) animals.

Specific Aim 1.3: To determine the effects of exercise training on the obesity and stress related changes to pancreatic morphology.

Hypothesis 1. Eight weeks of treadmill running in combination with obesity (OZR-EX) will attenuate the obesity-related decreases in pancreatic $\beta$-cell number, the $\beta$-cell to $\alpha$-cell ratio, and islet area compared with obese animals (OZR-C).

Hypothesis 2. Eight weeks of treadmill running in combination with eight weeks of UCMS (LZR-EXS) will attenuate the stress-related decreases in pancreatic $\beta$-cell number, the $\beta$-cell to $\alpha$-cell ratio, and islet area compared with lean stressed animals (LZR-S).

Hypothesis 3. Eight weeks of treadmill running will attenuate the combined effects of obesity and UCMS (OZR-EXS) on pancreatic decreases in $\beta$-cell number, the $\beta$-cell to $\alpha$-cell ratio, and islet area compared with obsess stressed animals (OZR-S).

Specific Aim 2.1: To determine the effects of obesity on the pancreatic pro-inflammatory environment and level of apoptosis

Hypothesis 1. Obesity alone (OZR-C) will result in an increase in pancreatic TXNIP, proinflammatory cytokines (e.g., IL-1 $\beta$, IL-6, and TNF $\alpha$ ) and apoptosis and a decrease in antinflammatory cytokines (IL-4 and IL-10) compared with lean animals (LZR-C). 
Specific Aim 2.2: To determine the effects of stress alone and in combination with obesity on the pancreatic pro-inflammatory environment and level of apoptosis Hypothesis 1. Eight weeks of UCMS (LZR-S) will result in an increase in pancreatic TXNIP, pro-inflammatory cytokines (e.g., IL-1 $\beta$, IL-6, and TNF $\alpha$ ) and apoptosis and a decrease in antiinflammatory cytokines (IL-4 and IL-10) compared with lean animals (LZR-C).

Hypothesis 2. Eight weeks of UCMS in combination with obesity (OZR-S) will augment the obesity-related increase in pancreatic TXNIP, pro-inflammatory cytokines (e.g., IL-1 $\beta$, IL-6, and $\mathrm{TNF} \alpha$ ) and apoptosis and a decrease in anti-inflammatory cytokines (IL-4 and IL-10) compared with obese animals (OZR-C).

Specific Aim 2.3: To determine the effects of exercise training on the obesity and stress related changes to the pancreatic pro-inflammatory environment and level of apoptosis Hypothesis 1. Eight weeks of treadmill running in combination with obesity (OZR-EX) will attenuate the obesity-related increase in pancreatic TXNIP, pro-inflammatory cytokines (e.g., IL$1 \beta$, IL-6, and TNF $\alpha$ ) and apoptosis and a decrease in anti-inflammatory cytokines (IL-4 and IL10) compared with obese animals (OZR-C).

Hypothesis 2. Eight weeks of treadmill running in combination with eight weeks of UCMS (LZR-EXS) will attenuate the stress-related increase in pancreatic TXNIP, pro-inflammatory cytokines (e.g., IL-1 $\beta$, IL-6, and TNF $\alpha$ ) and apoptosis and a decrease in anti-inflammatory cytokines (IL-4 and IL-10) compared with lean stressed animals (LZR-S).

Hypothesis 3. Eight weeks of treadmill running will attenuate the combined effects of obesity and UCMS (OZR-EXS) on pancreatic increases in TXNIP, pro-inflammatory cytokines (e.g., IL- 
$1 \beta$, IL-6, and TNF $\alpha$ ) and apoptosis and a decreases in anti-inflammatory cytokines (IL-4 and IL10) compared with obese stressed animals (OZR-S). 


\section{CHAPTER 2: LITERATURE REVIEW}

\section{Pancreas}

The pancreas is an organ in the body responsible for maintaining glucose homeostasis through the counter-regulatory actions of insulin and glucagon. ${ }^{29,30}$ There are many types of cells in the pancreas that make up the islet of Langerhans, including $\beta$-cells that produce insulin, $\alpha$ cells that produce glucagon, somatostatin, ghrelin, and polypeptide-secreting endocrine cell types that each produce a unique hormone. Eight-five percent of the pancreatic tissue is made up of exocrine cell types, such as acinar cells that produce digestive enzymes and duct cells that produce a conduit to the gut for digestive enzymes. ${ }^{31,32}$ The remaining fifteen percent is made up of the pancreatic islets, which consist of approximately seventy-five percent $\beta$-cells and twenty percent $\alpha$ cells. $^{33}$

Blood glucose is important for the stimulation of $\beta$-cell growth in fetal and adult life. ${ }^{34}$ Blood glucose levels modulate the release of insulin from the pancreatic $\beta$-cells when blood glucose is high, a process known as glucose-stimulated insulin secretion. ${ }^{29,35}$ When glucose levels are low, glucagon is released from the pancreatic $\alpha$-cells, and this triggers glycogenolysis and gluconeogenesis by the liver to increase glucose levels. ${ }^{30}$ A rise in blood glucose level triggers glucose oxidation via glycolysis and the Krebs cycle within the pancreas and an increase in cytosolic ATP/ADP ratio that leads to an influx of free $\mathrm{Ca}^{2+}$, triggering a signal for insulin secretion from pancreatic $\beta$-cells (Figure 1). ${ }^{29,35,36}$ 


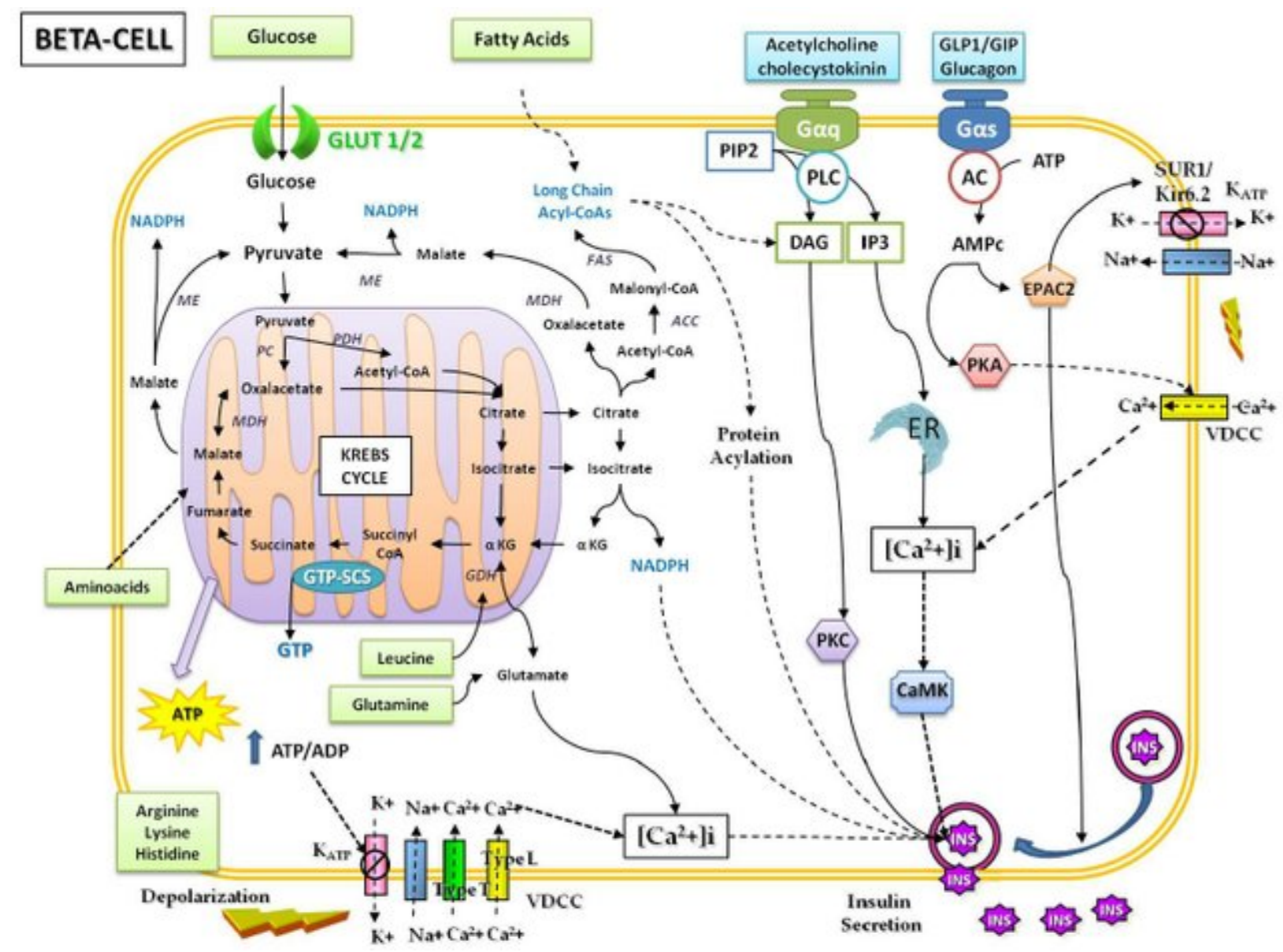

Figure 1 shows the process of glucose entering the human $\beta$-cell through the GLUT 1 (GLUT 2 in rodent) receptor and proceeding through the Krebs cycle to produce ATP. Potassium channels then close off, depolarizing the membrane to allow calcium channels to open, triggering the release of insulin from the $\beta$-cells. ${ }^{36}$

The development of pancreas tissue involves apoptosis, replication, and neogenesis.

During the neonatal period, the pancreas undergoes substantial remodeling, and apoptosis is a major process determining the final $\beta$-cell mass. ${ }^{37}$ There are two process by which pancreatic $\beta$ cells develop: differentiation and proliferation. ${ }^{34,38,37}$ Neoformation of pancreatic $\beta$-cells occurs from the differentiation of precursor cells. ${ }^{34}$ Proliferation of pre-existing pancreatic $\beta$-cells is a key component in regeneration. ${ }^{38}$ It has been suggested that pancreatic $\beta$-cells derive from $\alpha$ cells, in that $\alpha$-cells develop first in the embryo. Figure 2 shows the process of development of the cells in the pancreatic islets. ${ }^{39}$ When insulin resistance leads to T2D, it is suggested to be a 
bi-hormonal disease with hypoinsulinemia ( $\beta$-cells) and hyperglucagonaemia ( $\alpha$-cells). Though this could suggest changes to $\alpha$-cell mass in the pancreas with the progression to T2D, the $\alpha$-cell to $\beta$-cell ratio increases with T2D when compared to non-diabetic pancreas islets due to decreases in $\beta$-cell numbers, with no significant changes occurring to the $\alpha$-cell number. ${ }^{40}$

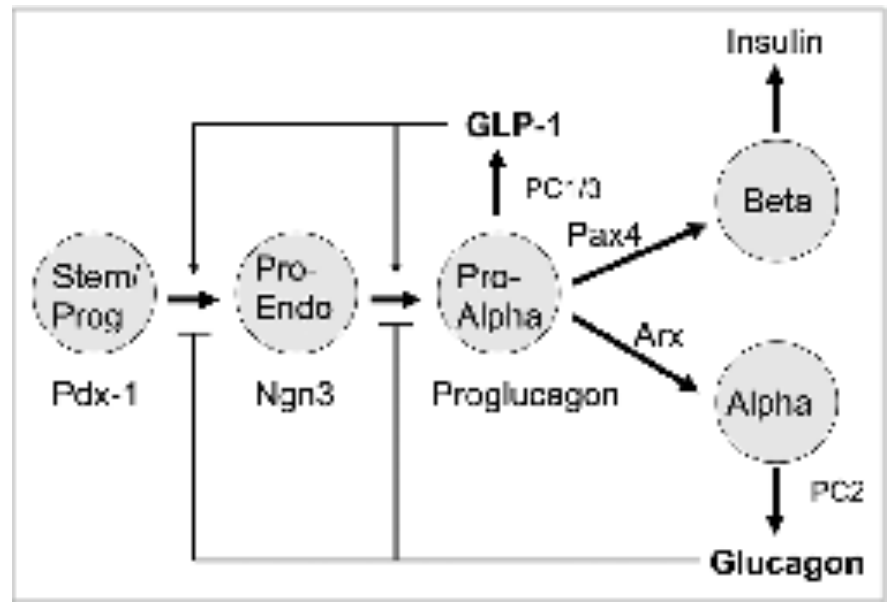

Figure 2 shows the development of pancreatic $\beta$-cells and $\alpha$-cells. ${ }^{39}$

Insulin resistance is a process that develops gradually as pancreatic $\beta$-cells overproduce insulin to compensate for the onslaught of blood glucose until these cells begin to experience cell death. The periphery becomes resistant to the effects of insulin after circulating insulin remains consistently elevated. ${ }^{41}$ This is characterized by diabetes, which is subdivided into two pathways of dysfunction: type 1 diabetes (T1D) and type 2 diabetes (T2D). T1D is an autoimmune disease that results in complete exogenous insulin dependence due to pancreatic $\beta$-cells being destroyed and unable to sufficiently produce insulin. T2D is a progressive disease that is also known as insulin-independent diabetes. Under extreme conditions, like morbid obesity, T2D can progress into total insulin-dependence, though this is rare. ${ }^{42,43,44}$ 
There are five stages to the development of insulin resistance: compensation, stable adaptation, unstable early decompensation, stable decompensation, and severe decompensation. ${ }^{42}$ The compensation stage is found to be highly associated with obesity and involves upregulated insulin secretion and increased GSIS following a glucose challenge. ${ }^{42,43}$ This increase in insulin is suggested to be brought about by increased $\beta$-cell mass as has been observed postmortem in obese patients. ${ }^{42,45}$ The stable adaptation stage involves pancreatic $\beta$-cells unable to compensate for the high glucose levels. This stage is considered stable because those individuals who adhere to a healthy diet and regular exercise regimen progress at a much slower rate to T2D. ${ }^{42,46}$ Stage 2 is characterized by fasting glucose levels between 5.0 and $7.3 \mathrm{mmol} / 1$, the loss of GSIS, and changes in $\beta$-cell differentation. ${ }^{42,47}$ Patients can remain in stage two for years, but once $\beta$-cells can no longer compensate and $\beta$-cell mass declines, glucose levels rise substantially over a short period of time. This has been characterized as the unstable early decompensation stage (stage three). Stage four will most likely be maintained throughout the lifetime of a patient of T2D. Those individuals with T1D have a rapid autoimmune destruction of $\beta$-cells that lead to stage five, which is severe decompensation. Stage five is rarely reached with T2D. ${ }^{42}$

Two contributors to the development of T2D include chronic stress and obesity. ${ }^{48,49,50}$ Both of these processes promote inflammation, increased oxidative stress, and apoptosis, including but not limited to pancreatic $\beta$-cell death. Chronic stress has been associated with an increase in obesity, and obesity can promote chronic stress. ${ }^{51}$ Both of these comorbidities are associated with increased GCs, hyperglycemia, hyperinsulinemia, and increased FFA, along with others, all of which can be associated with insulin resistance. ${ }^{4,7,8,9,11,12,13,15}$ 


\section{Metabolic Syndrome}

The Metabolic Syndrome is a noninfectious pandemic that involves organs such as the heart, liver, adipose tissue, pancreas, etc. ${ }^{52}$ Of the estimated 200 million overweight Americans, over 50 million are estimated to be affected by the Metabolic Syndrome. ${ }^{52}$ This disease is a cluster of factors that are linked to increased risk for diseases such as diabetes, cardiovascular disease, cancer, etc. These factors include abdominal obesity, high blood glucose levels (insulin resistance), dyslipidemia, high cholesterol or low HDL-C levels, and hypertension. ${ }^{3}$ It is suggested to be due mostly to the environment, with little influence from genetics. ${ }^{53,54,55}$ From 1970 to 2003 , the caloric intake in the United States increased by 523 calories, while advances in technology have led to a more sedentary lifestyle. ${ }^{54,55}$ Proinflammatory markers have been shown to positively correlate with features of the Metabolic Syndrome, like insulin resistance with no correlation to the degree of obesity. These proinflammatory markers include TNF- $\alpha$, IL6 , IL-1 $\beta$, and other chemokines. ${ }^{56}$ Vozarova and colleagues ${ }^{57}$ showed a correlation with high white blood cell (WBC) count, an indicator that the immune system is activated, and the development of diabetes. Phillips and Perry $^{58}$ showed a positive correlation with metabolically healthy individuals and lower levels of IL-6 and WBCs and higher levels of adiponectin.

\section{Obesity}

Obesity is the accumulation of adipocytes in the form of adipose tissue. Adipocytes are cells that store fat in the form of triglycerides (TGs) as energy for times of starvation. ${ }^{53}$ In order to avoid lipids from accumulating in non-adipose tissue, adipocytes not only serve as the storage for TGs, but these cells also secrete leptin to signal the brain that satiety is reached and stimulate fatty-acid oxidation in those non-adipose tissues. ${ }^{53}$ 
As energy intake increases and energy expenditure decreases, adipose tissue accumulates via hypertrophy, or in serve conditions, hyperplasia. ${ }^{59}$ Organs involved in the Metabolic Syndrome, like the pancreatic islets, accumulate ectopic fat in both humans and rodents. ${ }^{60}$ It was shown in overweight humans using magnetic resonance spectroscopy (MRS) that the pancreas accumulates TG deposits. ${ }^{61}$ When glucose tolerance is impaired, or in the presence of diabetes, fat accumulation in the pancreas is significantly even greater. ${ }^{61}$ This is suggested to be glucolipotoxicity, where increased glucose further promotes lipogenesis and lipotoxicity. ${ }^{62}$ Adipose tissue is an active endocrine organ known to secrete free-fatty acids (FFA) and adipokines, such as cytokines and chemokines. ${ }^{59}$ This action may contribute to the development of metabolic diseases through hyperglycemia, dyslipidemia, and inflammation. ${ }^{59}$ It has also been shown that obesity stimulates the production of reactive oxygen species (ROS) via increased FFA being released by adipose tissue into circulation. ${ }^{63}$ All of these actions can lead to the development of insulin resistance.

\section{Inflammation and Obesity}

Macrophage content of adipose tissue is positively correlated with body mass and adipocyte size, and these macrophages secrete cytokines like TNF- $\alpha$, IL-6, and IL-8, which are associated with insulin resistance. ${ }^{7}$ Macrophages are the key immune cells involved in adipose tissue inflammation in obese individuals, and during chronic exposure to inflammation, macrophages within the adipose tissue impair adipocyte function. ${ }^{64,65,66}$ Macrophages are cells of the innate immune system and serve as a link between the innate immune system and the adaptive immune system. ${ }^{13,64}$ Obesity has been shown to induce a phenotypic change in macrophage polarization, from $\mathrm{M}_{2}$ to $\mathrm{M}_{1}\left(\mathrm{M}_{\text {anti }}\right.$ to $\left.\mathrm{M}_{\text {pro }}\right) .{ }^{13,65} \mathrm{M}_{1}$ are macrophages that are crucial 
for fighting bacterial infections and tumors, but excess activation leads to a proinflammatory environment that can cause tissue damage. In order to fight off infections, $\mathrm{M}_{1}$ secrete ROS, nitric oxide (NO), and proinflammatory cytokines, such as TNF- $\alpha$, IL-1 $1 \beta$, and IL- $6 .{ }^{13} \mathrm{TNF}-\alpha$ is one of the first cytokines produced in this process, and along with the proinflammatory cytokine IL-1 $\beta$, it can induce the production of IL-6, which can be both a proinflammatory cytokine and an antiinflammatory cytokine, depending on its origin (i.e. skeletal muscle produces IL-6 in an antiinflammatory fashion, while adipose tissue produces a proinflammatory IL-6). ${ }^{13,67,68,69} \mathrm{The} \mathrm{M}_{2}$ pathway is an anti-inflammatory pathway that produces anti-inflammatory cytokines such as IL10 to suppress inflammation. ${ }^{13,70}$

Macrophages have been suggested to be linked to insulin resistance, more specifically through the release of proinflammatory cytokines such as TNF $\alpha{ }^{64,66} \mathrm{TNF}-\alpha$ is thought to be a major cause of the development of insulin resistance, and it has been shown that obese mice that lack either TNF- $\alpha$ or TNF- $\alpha$ receptors are protected from developing insulin resistance. ${ }^{71,69}$ In rodent models, mice deficient in TNF- $\alpha$ show decreased levels of FFA and TGs when compared to control mice, and rodents subjected to TNF- $\alpha$ showed impaired action of glucose uptake by the skeletal muscle. ${ }^{72}$ Advances in insulin sensitivity were not mimicked in humans with antiTNF- $\alpha$ treatments. ${ }^{73}$ TNF- $\alpha$ increases lipolysis in adipose tissue to release FFA into systemic circulation. FFA are then able to deposit in non-adipose tissues, like skeletal muscle. ${ }^{71,74,75}$ In humans, $10-35 \%$ of circulating IL-6 is housed in adipose tissue, and so hypertrophy of adipocytes is accompanied by an increased production of adipose tissue IL-6. ${ }^{76,77}$ It has been shown that expression of IL-6 from adipose tissue positively correlates with insulin resistance, and so when neutralization of TNF- $\alpha$ in humans brings about no improvement in insulin 
sensitivity, it can be suggested that IL- 6 makes up for the absence of the effects of TNF- $\alpha{ }^{78,79}$ Hyperglycemia has also been associated with increases in IL-6 levels from adipose tissue. ${ }^{80}$

\section{Oxidative Stress and Obesity}

Obesity has been observed to increase oxidative stress, which is known to cause direct and indirect damage to organs that can result in many pathological processes, including the Metabolic Syndrome. ${ }^{63,81}$ Biomarkers for oxidative stress have been shown to be correlated directly with many factors involved with obesity, including BMI, percent body fat, LDL oxidation, and TG levels, and it has been shown that these biomarkers are increased in diets high in fat and carbohydrates. ${ }^{82,83}$ As stated above, obesity is associated with a proinflammatory environment through the overproduction of cytokines, which are known to increase ROS and NO. TNF- $\alpha$ causes damage to the mitochondria in the mitochondrial chain complex III and activates the production of ROS at the ubiquinone site. ${ }^{84,85}$ This was further investigated by inhibiting mitochondrial oxidative metabolism, which not only lead to the inhibition of TNF- $\alpha$ cytotoxicity, but also reduced TNF- $\alpha$ activation of nuclear-factor kappa- $\beta$ (NF- $\kappa \beta)$ and IL-6. ${ }^{85,86}$ With obesity there is a higher demand on the heart, and therefore an increase in mitochondrial respiration; this leads to the consumption of more oxygen, and the production of more ROS in the form of superoxide and hydrogen peroxide. ${ }^{63}$ It has been shown that hydrogen peroxide is increased in obese mouse adipose tissue, and along with the fact that adipose tissue was the only observed organ that had increased hydrogen peroxide levels, can suggest that adipose tissue is the major producer of this oxidative stress biomarker. ${ }^{63}$

The adipokine, adiponectin, has insulin-sensitizing effects that increase insulin sensitivity. ${ }^{59}$ Adiponectin is shown to be reduced in obese individuals, and it has been shown that 
plasma adiponectin levels are inversely related to oxidative stress biomarkers in nondiabetic human subjects. ${ }^{63,87}$ In rodent models, the absence of adiponectin is shown to induce insulin resistance, whereas overexpression of this adipokine leads to increased insulin sensitivity.

\section{Obesity's Effects on the Pancreas}

Excess circulating lipids are taken up by the pancreas and other organs, leading to lipid accumulation in those organs. ${ }^{88}$ It was shown in obese homozygous $(f a / f a)$ male ZDF rats that apoptosis in the pancreatic islets was increased as prediabetic and diabetic stages progressed. It is suggested that elevated levels of circulating FFA and lipoproteins transport more FFA than the pancreas can oxidize, leading to a lipotoxic effect on islets. ${ }^{89}$ Excess circulating lipids were associated with diminished pancreatic $\beta$-cell function and even apoptosis in in vivo rat models and in vitro human islet cells. ${ }^{90}$ It is suggested that ceramides are a mediator of the FFAinduction of pancreatic $\beta$-cell apoptosis. ${ }^{89}$

Lipotoxicity and glucotoxicity in the pancreas have been shown to increase ER stress through JNK activation, leading to decreases in $\beta$-cell mass in animal studies. ${ }^{91,92}$ On the other hand, Saisho and colleagues ${ }^{93}$ found that in human pancreas autopsies that $\beta$-cell mass was increased with obesity. Oxidative stress is known to cause damages to many organs, including impairment of insulin secretion in pancreatic $\beta$-cells and impairment of glucose transport into muscle and adipose tissue. ${ }^{94,95,96}$ The adverse effects of ROS on insulin production not only leads to insulin resistance, but also may lead to $\beta$-cell apoptosis. ${ }^{88}$ ER stress in the mitochondria of the pancreatic $\beta$-cell can lead to the overproduction of ROS, and obesity has been associated with this increase in ER stress-induced oxidative stress in the mitochondria. ${ }^{88}$ 


\section{General Stress Response}

Chronic stress is a modifiable risk factor for T2D and insulin resistance. ${ }^{14}$ Organisms have a primal instinct to survive, and this requires physiological adaptations that must occur when homeostasis is threatened. ${ }^{97}$ When a stressor is perceived by the brain, a cascade of signals activates the HPA axis, and GCs are released. ${ }^{97,98,99,100,17}$ The stressor promotes corticotropinreleasing hormone $(\mathrm{CRH})$ to initiate the stress response in the hypothalamus and flow through circulation to the anterior pituitary gland to stimulate the release of adrenocorticotrophic hormone (ACTH). ${ }^{97,99,100,16}$ When ACTH reaches the systemic circulation the adrenal glands are stimulated to release GCs (cortisol in humans and corticosterone in rodents) that are then pumped into the systemic circulation..$^{97,99,100,16}$ In an acute stress response, GCs act as a negative feedback mechanism to the hypothalamus to stop the release of CRH to turn off the stress response cascade. ${ }^{97}$ When in circulation, GCs bind to their receptors, GRs to help modulate a number of biological functions due to GRs being expressed in almost all cell types. In immune cells and other organs and tissues, including adipose tissue, GCs are one of the key regulators of energy influx in adipocytes. ${ }^{98,100}$

This release of GCs allows for energy to be mobilized for one of two reasons: 1) a reactive response, in which energy is needed to meet a physical insult, or 2) an anticipatory response, in which energy is assembled to prepare for a predicted need. ${ }^{97}$ Energy is mobilized through the binding of GCs to glucocorticoid receptors (GR) in the hypothalamus and pituitary glands of the brain that promote mobilization of energy stores for the liver, fat, and muscle and increase inflammation and neural function. ${ }^{101} \mathrm{GR}$ receptors are considered to lead the bulk of feedback regulation. ${ }^{97}$ GCs work to increase the liver glucose output and the release of FFA from 
white adipose tissue along with the reduction of insulin secretion so that energy can be available for behavioral reactions to stressors. ${ }^{102}$

\section{Glucocorticoids and Obesity}

When under chronic psychological stress, it has been shown that there is a tendency for overconsumption of energy dense foods. ${ }^{98,103}$ Chronic stress has been shown in both humans and rodents to trigger the desire for high fat, energy dense foods. ${ }^{104}$ Even in instances in which stressed subjects do not gain weight, it is still shown that high fat and/or sweet foods are favored. ${ }^{104}$ It has been shown in animal studies that under chronic mild stress, rodents saw weight gain and increased food consumption when sweet condensed milk was offered in comparison to regular chow. ${ }^{105,106}$ In humans, chronic stress induces an increase in cortisol that may lead to an increased consumption in energy-dense food, which could lead to weight gain. ${ }^{107}$

Some key components of obesity are hyperglycemia, or high blood sugar., hyperinsulinemia, and insulin resistance. In acute stress conditions, GCs exposure can lead to decreased skeletal muscle glucose transport and increase hepatic glucose production. ${ }^{5,108}$ Acute exposure to GCs can improve pancreatic $\beta$-cell function to glucose sensitivity and insulin secretory capacity, but chronic exposure to the stress hormone can lead to dysfunctions including impaired peripheral insulin sensitivity and decreased GSIS. ${ }^{20}$ Chronic exposure of GCs can result in damage to the pancreas that can lead to insulin resistance, hyperinsulinemia, and hyperglycemia when chronically stimulated, which can lead to deteriorated glucose homeostasis. 98,109,5,9 Chronic stress can promote increased abdominal obesity and excess ectopic fat deposition. ${ }^{98,5,108}$ Humans subjected to chronic GC treatment (>14 days) showed decreases in insulin secretion when subjected to a glucose challenge. This impairment in insulin action could 
suggest an indirect loss in pancreatic $\beta$-cell function or suppression of the release of insulin by pancreatic $\beta$-cells. ${ }^{110,111}$ This could suggest that over time, chronic exposure to stress and GCs can lead to insulin-dependent diabetes through the elimination of pancreatic $\beta$-cells. It was also shown that increased endogenous glucose production, as well as lipolysis, increased plasma freefatty levels. ${ }^{110,111}$ This goes along with the belief that GCs cause metabolic and morphological attenuations to the pancreatic $\beta$-cells. ${ }^{20,112}$ Chronic GC exposure has been shown to increase $\beta$ cell mass due to hypertrophy and hyperplasia, which can lead to hyperinsulinemia. ${ }^{20}$ GCs have been observed to favor glycogenolysis activation, gluconeogenesis, lipid mobilization, and protein synthesis inhibition, which can lead to increased blood glucose and in turn hyperinsulinemia. ${ }^{112}$ These different responses in the pancreatic $\beta$-cells to chronic exposure to GCs could be due to differences in the progression of pancreatic damage brought about by the chronic exposure to stress.

\section{Inflammation and Chronic Stress}

The HPA axis is one of the main mechanisms the brain utilizes to control the immune system, and stress has been shown to have deleterious effects on the immune system. ${ }^{99} \mathrm{GCs}$ are known to be primarily an anti-inflammatory defense. ${ }^{17,109}$ In acute situations, GCs combat the immune cells; at a cellular level, GCs induce apoptosis in T lymphocytes, neutrophils, basophils, and eosinophils and modulate macrophage cytokine production by inhibiting p38 MARK at the transcriptional level. ${ }^{100,113,114}$ GCs are known to suppress proinflammatory cytokines such as IL6 and TNF- $\alpha$ and upregulate the secretion of anti-inflammatory cytokines like IL-4, IL-10, and IL-13. ${ }^{16,115}$ GCs have also been shown to downregulate IL-1 $\beta$ transcription. ${ }^{116}$ Corticosterone enters the nucleus to inhibit the transcription control pathways, including NF- $\kappa \beta$, mitogen- 
activated protein kinases (MAPKs), and others. ${ }^{16,117}$ GCs have also been studied to promote the Th1 to Th2 shift, meaning they suppress proinflammatory (Th1) processes and upregulate antiinflammatory (Th2) cytokines. ${ }^{16,118}$ GCs act to suppress the production of IL-12, the main inducer of the Th1, or proinflammatory, response. ${ }^{16,118}$

Although GCs can be used for therapeutic benefits in conditions like rheumatoid arthritis or Addison's Disease where the adrenal glands are not producing GCs, high doses of GCs are associated with diabetes, hypertension, and other diseases risks. ${ }^{100,119,120}$ Cushing's Syndrome is the excess production of GCs, and like chronic stress can overstimulate the HPA axis causing immune cells to become less sensitive to GCs. ${ }^{100,17,121}$ Chronic stress can lead to changes in lymphocyte populations, changes in NK cell number and activity, changes in ratio of helper: suppressor T cells, impaired antibody responses, etc. ${ }^{99}$

Lymphocytes are mediators in cell immunity, and $\mathrm{T}$ lymphocytes are divided into four subgroups: cytotoxic T cells (CD8+ T cells that destroy non-self-cells), helper T cells (CD4+ T cells that secrete cytokines), memory T cells (either CD4+ or CD8+ T cells that are antigenspecific), and regulatory T cells (suppressor T cells that suppress antibody production). ${ }^{99}$ Stressors have been shown to have varying effects on the T lymphocytes, including: decreases in total T lymphocytes, helper T lymphocytes, and suppressor T lymphocytes ${ }^{122,123}$; decreased helper-to-suppressor T lymphocyte ratio ${ }^{122,124}$; increased levels of CD8+ cytotoxic T cells ${ }^{125}$; and poor memory T cell proliferation. ${ }^{126,127}$ Natural killer cells, cytotoxic T lymphocytes that primarily kill viral infections and cancer, experience a decrease in number and activity in response to stressors; this leads to a decrease in the ability to fight infection. ${ }^{99}$ Stress has been shown to have differing effects on immunoglobins in the absence of infection, including increasing plasma IgA without changes in $\operatorname{IgG}$, $\operatorname{IgM}$, and salivary $\operatorname{IgA}$ during examination 
stress, ${ }^{128}$ increases in $\mathrm{IgG}, \operatorname{IgM}$, and IgA during examination stress, ${ }^{99}$ and in mice, decreased serum IgM with footshock. ${ }^{129}$ Also, white blood cells develop a counterregulatory response to downregulate the function of receptors responsible for binding and reacting with GCs. ${ }^{121}$ This allows for a proinflammatory environment to collect with chronic stress. ${ }^{17,121}$

Cytokines are divided into two subsets: Th1 cytokines, or proinflammatory cytokines, which include IL-1, IL-2, IL-6, INF $\gamma$, and TNF- $\alpha$; and Th2 cytokines, or anti-inflammatory cytokines, which include IL-4, IL-5, IL-10, and IL-13. ${ }^{99}$ With chronic stress, studies have shown the development of glucocorticoid-resistance syndrome, where GCs can no longer suppress cytokine production, ${ }^{16}$ or glucocorticoid-receptor resistance, where a decrease in the immune cells sensitivity to GCs allows for increased for chronic inflammation. ${ }^{17}$ Studies have shown that with prolonged stress, the ability to suppress the secretion of IL- 6 , IL- $1 \beta$, and TNF- $\alpha$ is diminished, allowing for the upregulation of proinflammation. ${ }^{99,17,117,130,131}$ GCs have also been shown to induce the activation of the NLRP3 inflammasome, a NOD-like receptor that is a major producer of IL-1 $\beta$, a proinflammatory cytokine. ${ }^{132}$

\section{Oxidative Stress and Chronic Stress}

Apoptosis is programmed cell death that, under normal conditions, helps remove damaged or aged cells and maintain homeostasis. ${ }^{133,134}$ Excess oxidative stress causes cell death through apoptosis. ${ }^{135,136}$ Too much apoptosis can lead to adverse consequences, and hyperglycemia is a pathophysiological component that induces both oxidative stress and apoptosis. ${ }^{29}$ Glucocorticosteroids and TNF- $\alpha$ can both stimulate apoptosis through severe oxidative stress. $^{29}$ 
Oxidative stress is also thought to contribute to glucotoxicity, an effect that can be brought about by over nutrition and the steady increase in high blood glucose levels that can lead to the development of conditions such as type 2 diabetes. ${ }^{29}$ In hyperglycemic conditions, more glucose is circulating through the glycolytic pathways and therefore increasing the amount of pyruvate and acetyl-CoA being produced. This process produces NADH, an electron carrier, and in hyperglycemic conditions, there is a surplus of NADH produced, creating electron pressure on the mitochondria electron transport chain, especially in the pancreatic $\beta$-cells. ${ }^{137,138,139,140}$ The mitochondrial complex I (MC-I) functions to recycle NADH, and when hyperglycemia overproduces NADH, a heavy burden is placed on MC-I. ${ }^{141,142}$ This increased cycling of NADH through the MC-I produces more superoxide, the precursor for all ROS, through the leakage of electrons that can reduce oxygen to superoxide. ${ }^{141,143,144,145}$ The four major sources of ROS are oxidative burst, oxidative processes, lipid peroxidation, and oxidative stress. ${ }^{146}$

In depression, oxidative stress is increased and antioxidant defenses are decreased. ${ }^{147} \mathrm{In}$ patients with depressive disorders, plasma, serum, and urine samples have shown increases in total oxidative status, oxidative stress index, and markers of lipid peroxidation. ${ }^{148}$ It was also shown in peripheral blood samples of depression patients that mitochondrial ROS production, nitric oxide levels, and lipid peroxidation were all increased while the antioxidant markers superoxide dismutase (SOD) and GPx were decreased. ${ }^{149,150,151,152}$ In the postmortem hippocampus of patients that suffered depression or bipolar disorder, there was an increased RNA oxidation observed, as well as decreases in antioxidant marker GPx in the frontal cortex. ${ }^{153,154}$ These results suggest that, while oxidative stress can be a consequence of depression, it also contributes to and increases the progression of depression. ${ }^{155}$ 


\section{UCMS Protocol}

The unpredictable chronic mild stress (UCMS) protocol, also known as CUMS, CMS, etc., can be used to induce stress in the rodents to mimic stress in humans. These protocols induce stress presents similar behaviors to that of depression in rodents, presenting itself such that rodents show anhedonia-like behavior and other behaviors that suggest depression is present. ${ }^{112,146,148}$ The protocols success can be measured in different ways, including coat score assessment, behavior testing, and corticosterone measurements. Rodents undergo a randomized schedule of stressors, including bath, cage tilt, damp bedding, wet bedding, and social stress. These are outlined in detail in the methods section. The schedule is randomized for each day, with different stressors and different durations to make sure that the animals do not grow accustomed to the stressors. Coat scores are assessed at the end of each week by the same individual, and the blood samples taken the day of surgery are used to measure corticosterone levels.

In a study done by López-López and colleges, ${ }^{112}$ the pancreas was examined in relation to oxidative stress caused by chronic, unpredictable, mild stress (CUMS). Corticosterone was increased with the stress protocol, as well as lipoperoxide concentration in the pancreas gradually from day 20 to day 60 . This was shown by the increased levels of lipid peroxidation and oxidative proteins in the pancreas, along with decreases in total antioxidant capacity with the stress protocol. The pancreas is a regulator of the metabolism of carbohydrates, lipids, and proteins, and is not equipped as a major regulator of the redox state of an organism. ${ }^{12}$

The liver is the major site for antioxidant enzyme capacities in the body and is considered the regulatory organ for the redox state. ${ }^{12,148}$ The CUMS protocol resulted in an increase in oxidative stress markers and lipid peroxidation in the liver, though total antioxidant capacity did 
not significantly decrease over the 60 -day duration. ${ }^{12}$ Duda and colleagues ${ }^{148}$ used chronic mild stress (CMS) to show the increase markers of oxidative stress, including ROS, malondialdehyde (MDA), and non-protein sulfhydryl (NPSH), while the antioxidant markers catalase (CAT) and glutathione peroxidase (GPx) increased as well within the liver.

\section{Exercise and Obesity}

Regular exercise is associated with better quality of life and health outcomes. ${ }^{156}$ Exercise has been shown to improve physical attributes of health, including reduced blood pressure, enhanced cardiovascular fitness, increased insulin sensitivity, reduced abdominal adiposity, and prevention of chronic diseases, such as diabetes and obesity. ${ }^{157,158}$ Even short-term exercise has been shown to improve many aspects of the Metabolic Syndrome. ${ }^{156}$ A 12-week exercise program in middle-aged women resulted in decreases in blood pressure, body fat percentage, fast glucose levels, triglycerides, and cholesterol. ${ }^{159}$

Exercise has been shown to enhance the loss of adipose tissue, which can in turn reduce the proinflammatory environment brought about by adipocyte hypertrophy. ${ }^{158} \mathrm{In}$ a study with severely obese human subjects, 15 -weeks of hypocaloric diet and daily exercise resulted in decreased circulating inflammatory markers and decreases in adipose tissue expression of inflammatory markers, such as IL- 6 and TNF- $\alpha$. The lifestyle intervention also produced increases in adiponectin and improvement in metabolic status. ${ }^{160}$ Though a high-fat diet was shown to increase obesity, inflammation, and insulin-resistance, voluntary exercise reduced these parameters. Voluntary exercise not only reduced the inflammation brought about by the HFD, but this intervention also reduced inflammation in the exercise-regular chow diet. ${ }^{161}$ 


\section{Exercise and Stress}

Depression has been associated with low levels of physical activity, and regular exercise has been shown to improve mental health. ${ }^{162,157}$ Individuals with depression spent significantly less time in light and /or moderate physical activity than did non-depressed adults, while adults that lived a physically active lifestyle showed reduced depression symptoms. ${ }^{163,164}$ Sedentary lifestyle has been demonstrated to have a direct relationship with depression. ${ }^{162}$ Exercise has been advocated as a means to improve mood and depressive-type mental disorders through physiological and psychological processes, including improved mood state, enhanced selfesteem, and lower stress and anxiety. ${ }^{157}$ In a study done by DiLorenzo and colleagues, ${ }^{165}$ aerobic exercise showed not only improvements in health parameters, but also in many aspects of psychological well-being, including depression, anxiety, self-concept, and vigor. In obese and overweight individuals, increasing moderate-to-vigorous physical activity and decreasing sedentary time resulted in lower risk for the development of depression. ${ }^{166}$

In animal studies, regular exercise caused alterations in serotonergic and noradrenergic systems, which are targeted by pharmacological treatments for depression. ${ }^{167}$ Treadmill running with rats was shown to increase levels of blood tryptophan, allowing the brain to produce an increased rate of synthesis of serotonin, 5-hydroxyindoleacetic acid (5-HT). ${ }^{168}$ Exercise promoted increases in 5-HT turnover in the hypothalamus in rats. In rats exposed prenatally to high level of GCs, four weeks of swimming exercise resulted in decreased levels of serum corticosterone and depressive behavior. ${ }^{169} \mathrm{HPA}$-axis activity decreased in rats exposed to lowintensity stressors with six-weeks of intermittent, voluntary wheel running. ${ }^{170} 171$

In humans, ten weeks of moderate-intensity exercise produced anxiolytic effects correlated with a downregulation of postsynaptic serotonin receptors and with a blunted cortisol 
response to the $5-\mathrm{HT}_{2 \mathrm{C}}$ agonist, meta-chlorophenylpiperazine (m-CCP). ${ }^{172,173} \mathrm{In}$ a human crosssectional study of 269 adult subjects, regular exercise was shown to reduce anxiety and lower depression, and in 7 randomized controlled studies, regular exercise was associated with reduced stress and decreased anxiety. ${ }^{174,175}$ In a study done with patients with major depressive disorder (MDD), a single bout of treadmill running resulted in improved mood. ${ }^{176}$

\section{Thioredoxin System}

There are two main antioxidant systems in mammalian cells, the thioredoxin (Trx) system and the GPx system. ${ }^{177}$ The thioredoxin system is a pivotal component in the antioxidant defense system and is comprised of three components: NADPH, thioredoxin reductase (TrxR), and Trx. ${ }^{22,177,178,179}$ The Trx system defends against oxidative stress by the reduction of disulfide activity and regulating the dithiol/disulfide balance in cells. ${ }^{177,178,179} \operatorname{Trx} 1$ is found in the cytosol and nucleus, while Trx2 is located in the mitochondria. ${ }^{22,178,179}$ The Trx system plays a role in reversing oxidative modifications, like sulfenylation and nitrosylation. ${ }^{155}$ Trx1 becomes oxidized and inactivated after it reduces oxidized cysteine groups on intracellular proteins, and TrxR then can re-activate this oxidized Trx by reducing it through the use of NADPH. ${ }^{177,22,179} \operatorname{Trx} 2$ binds apoptosis-signaling kinase-1 (ASK-1) in the mitochondria and renders it dormant, allowing for the inhibition of ROS, inflammation, and apoptosis. ${ }^{155,180,181,182}$ Trx plays a crucial role in many protective mechanisms, including limiting apoptosis, protective anti-oxidant mechanisms, like breaking down hydrogen peroxide into water, and DNA synthesis and repair. ${ }^{177,178,179}$ 


\section{Thioredoxin Interacting Protein}

Thioredoxin-interacting protein (TXNIP) has also been referred to as vitamin Dupregulated protein and thioredoxin-binding-protein-2. ${ }^{22}$ This protein has structural characteristics that fit the $\alpha$-arrestin family, and has distinct binding sites for proteins like ASK-1 ubiquitin ligase, and others. ${ }^{183}$ TXNIP acts to inhibit the antioxidant capabilities of the Trx system. ${ }^{22,24,184,185,23}$ TXNIP is a proapoptotic factor that has been thought to be a key player in the glucotoxic $\beta$-cell death that is associated with insulin resistance and diabetes. ${ }^{24,185}$ TXNIP is localized to the nucleus in pancreatic $\beta$-cells, but "shuttles" to the cytoplasm and/or mitochondria of the pancreatic $\beta$-cells (Figure 3). ${ }^{22,23,25}$ Oxidative stress induced by hydrogen peroxide $\left(\mathrm{H}_{2} \mathrm{O}_{2}\right)$ has been shown to lead to shuttling of TXNIP into the mitochondria by TXNIP binding to importin- $\alpha .^{23}$ Within the mitochondria, TXNIP competes with ASK-1 for the binding site on Trx2, causing ASK-1 to be released and phosphorylated; this can further lead to mitochondrial dysfunction and apoptosis (Figure 3). ${ }^{22,23,25,186}$ It was shown with Trx2 knockdown in INS-1 $\beta$ cells that phosphorylation and activation of ASK-1 and activation of mitochondrial death pathways were increased. This mitochondrial death pathway was assessed via increases in activated caspase-3. It was also shown that increasing mitochondrial TXNIP resulted in increased Trz2 oxidation, decreased Trx2-ASK-1 binding, and increased phosphorylation and activation of ASK-1. ${ }^{23}$ Within the cytosol, TXNIP binds to reduced Trx1, inhibiting the ability of the antioxidant system to reverse protein cysteine oxidative modifications. ${ }^{22,27,155,178}$ 


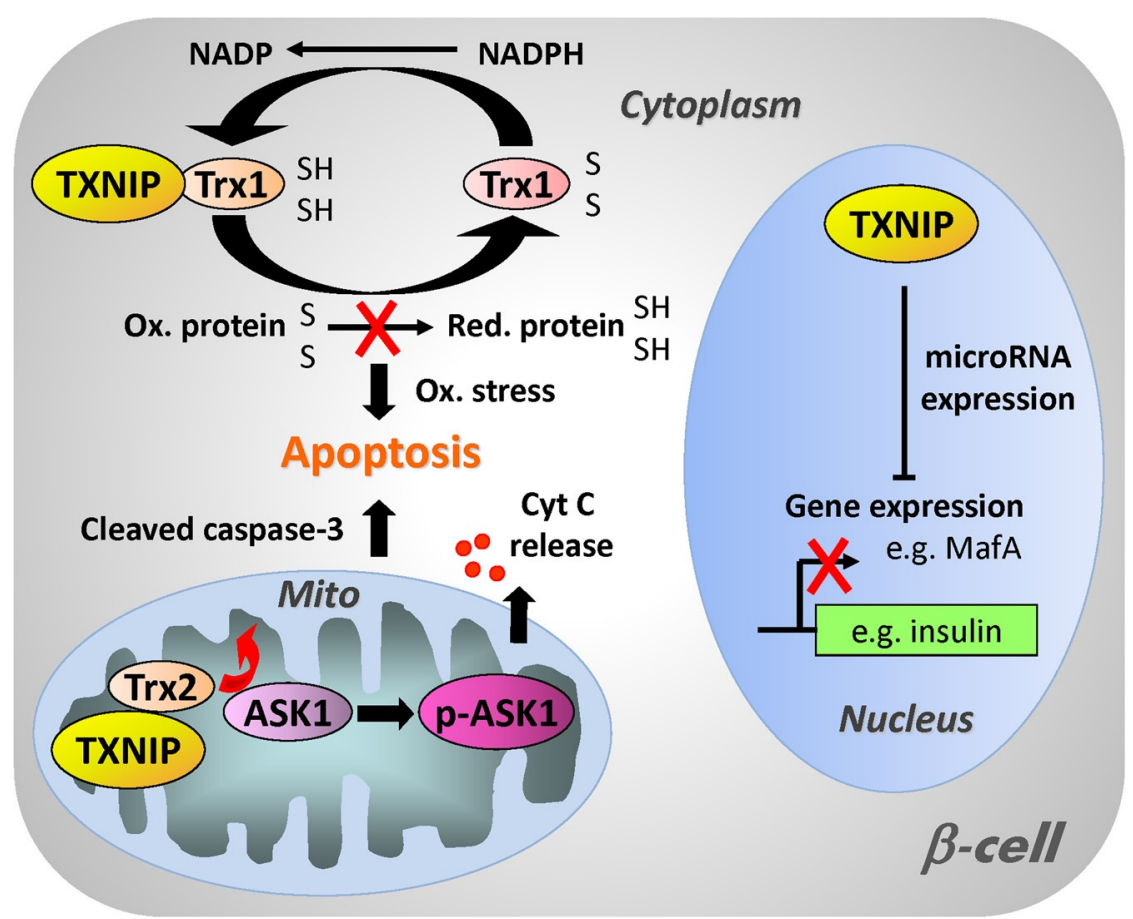

Figure 3 depicts the processes by which TXNIP interferes with the thioredoxin system in the pancreatic $\beta$-cell cytoplasm, mitochondria, and nucleus. ${ }^{25}$

TXNIP has been suggested to be the link between glucose toxicity and pancreatic $\beta$-cell apoptosis, such as that seen in diabetes. ${ }^{24,184,185}$ In both obese and non-obese diabetic mice, TXNIP expression is shown to be elevated in pancreatic $\beta$-cells. ${ }^{184,185}$ Incubation of human pancreatic islets in high glucose concentrations for 24 hours resulted in a five-fold increase in TXNIP expression when compared to islets incubated in low glucose concentrations. ${ }^{24,184}$ INS-1 $\beta$-cells incubated in high glucose concentrations resulted in increased TXNIP levels 18 -fold along with a 12 -fold increase in cleaved caspase-3. ${ }^{184,185}$ Overexpression of TXNIP resulted in increases in cellular levels of ROS and free radical-mediated stress to $\beta$-cells by $\mathrm{H}_{2} \mathrm{O}_{2}$, while overexpression of Trx inhibited the ROS increase. ${ }^{24,185}$ TXNIP knockout gene shows reduced hyperglycemic-induced increase in oxidative stress. ${ }^{24}$ Glucose-induced TXNIP increases also showed apoptosis in pancreatic islets of INS-1 cells, including increases in the Bax (proapoptotic) to Bcl-1 (antiapoptotic) ratio, increases in cleaved caspase-3, and TUNEL positive 
$\beta$-cells. ${ }^{184,185}$ Glucose is shown to induce TXNIP transcription via a carbohydrate response element (ChoRE). ${ }^{184}$

\section{TXNIP and Chronic Stress}

A study with INS1 $\beta$-cells and human and mouse pancreatic islets demonstrated that treatment with glucocorticosteroids led to increases in TXNIP expression, and that expression was even more pronounced than in hyperglycemic conditions. Over time, these increases in TXNIP were accompanied by the induction of pancreatic $\beta$-cell death. ${ }^{187}$ Chronic stress associations with increased TXNIP expression have been reported in other organs as well. In a study by Zhou and colleagues, rodents that experienced chronic stress had significantly elevated TXNIP expression in the hypothalamus and frontal cortex when compared to control mice. In addition to increases in TXNIP, increases in protein sulfenylation and nitrosylation and increases in phosphorylated ASK-1 in the hypothalamus and frontal cortex were also observed. It is proposed that increases in corticosterone due to stress lead to these increases in TXNIP and its downstream regulators. ${ }^{155}$ Bharti and colleagues ${ }^{188}$ showed that treatment of neuronal cells with human cortisol resulted in increased expression of TXNIP in the nucleus and cytoplasm, and that GR inhibition lead to blockage of the cortisol-induced TXNIP expression. Whether chronic stress also causes an increase in TXNIP within the pancreas remains to be determined.

\section{NLRP3 Inflammasome}

The nod-like receptor protein 3 (NLRP3) inflammasome is a major producer of IL-1 $\beta$, a

proinflammatory cytokine associated with insulin resistance (Figure 4). 22,27,189,190 This contribution to the proinflammatory environment can also promote increases in proapoptotic 
proteins, cleaved caspase-3 and cleaved PARP-1, which activate the apoptotic pathway P38 MAPK-JNK. ${ }^{22}$ TXNIP has been suggested to activate the NLPR3 inflammasome, triggering the production of IL-1 $\beta .^{22,27,189}$ TXNIP binds to the leucine rich repeat (LRR) region of the inflammasome, and the activation is dependent on the generation of ROS, as all NLRP3 activators are known to generate ROS..$^{27,191}$ This is furthered supported by the induction of NLRP3 inflammasome activity and IL-1 $\beta$ secretion by addition of $\mathrm{H}_{2} \mathrm{O}_{2}$ in THP-1 human macrophages. ${ }^{27,191}$ When TXNIP expression was suppressed, $\mathrm{H}_{2} \mathrm{O}_{2}$-driven inflammasome activation was blunted, as shown by suppression of IL- $1 \beta$ and caspase- $1 .{ }^{27}$

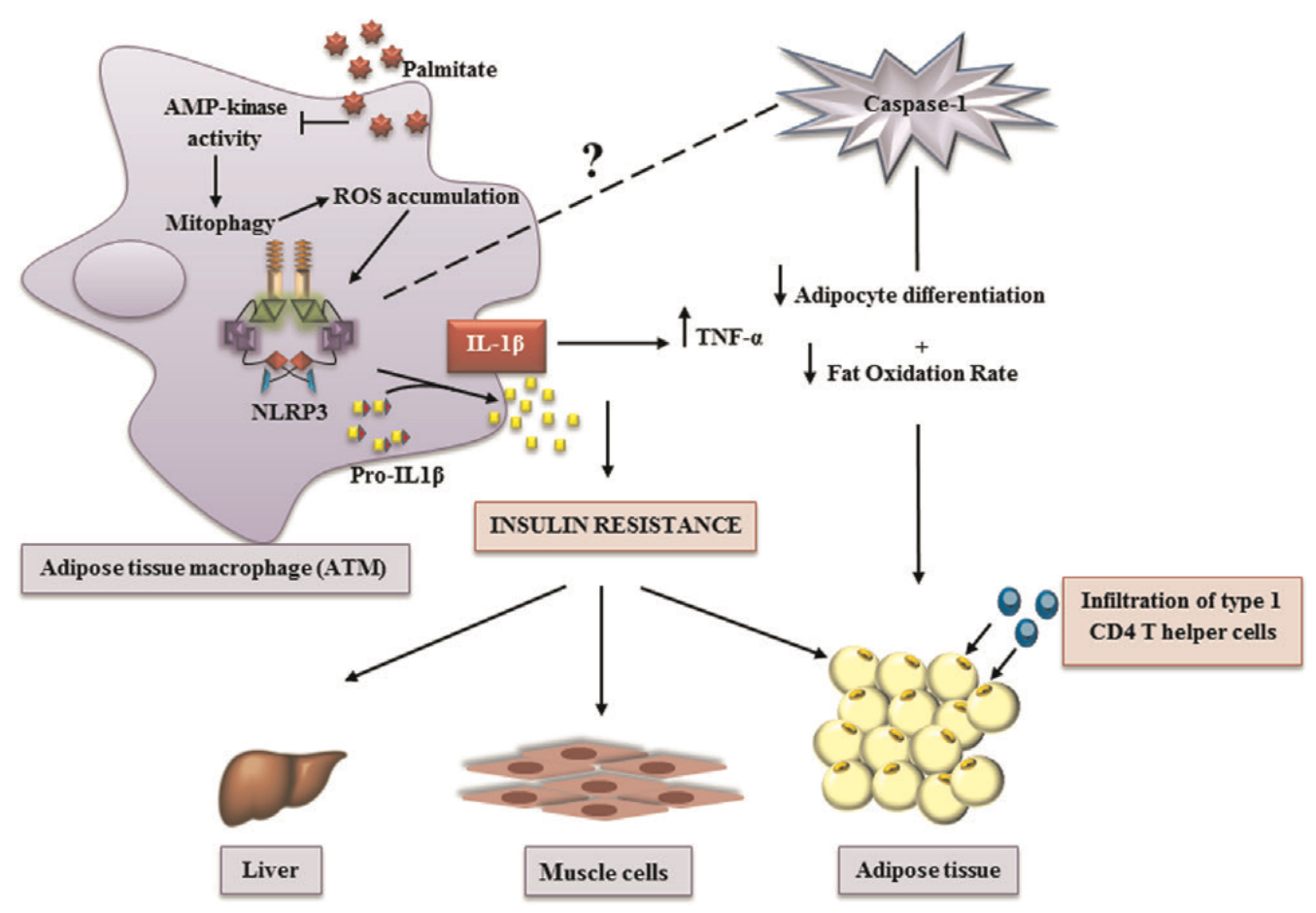

Figure 4 explains the role of adipose tissue NLPR3 inflammasome activity and its effects on other organs. The secretion of mature IL-1 $\beta$ by the adipose tissue is associated with insulin resistance. ${ }^{190}$

A HFD is accompanied by significant increases in the interaction of TXNIP with the NLRP3 inflammasome, along with significant increases in cleaved IL-1 $\beta$ and cleaved caspase-1 
and expression of TXNIP and mature IL-1 $\beta$. Mohamed et al incubated human retinal endothelial cells in palmitate-BSA to mimic HFD and found that the interaction of TXNIP and the inflammasome was increased, resulting in the activation of caspase- 1 and IL-1 $\beta$. To further confirm these results, TXNIP was silenced and resulted in the abolishment of the palmitate-BSA increase of cleaved IL-1 $\beta$ and decreases in cell death, as shown by decreases in proapoptotic cleaved caspase-3 and larger proportion of live cells to dead cells. ${ }^{189}$ 


\section{CHAPTER 3: METHODS AND MATERIALS}

\section{Animals}

32 male OZRs and 32 male LZRs, ages 7-8 weeks, were obtained from Harlan. All rats were acclimatize to their environment for one week in the West Virginia University Health Sciences Animal Facility then placed on a reverse 12 hour light-dark cycle. LZRs and OZRs were then randomly assigned to four groups: 1$)$ sedentary controls $(\mathrm{C}: \mathrm{n}=8) ; 2)$ unpredictable chronic mild stress (S: $n=8) ; 3$ ) exercise (EX: $n=8)$; and 4) a combination of UCMS and Ex (EXS: $\mathrm{n}=8$ ). All rats received standard chow and tap water ad libitum, and protocols received approval from the WVUHSC Animal Care and Use Committee prior to the start.

\section{UCMS Protocol}

The UCMS protocol was developed to produce depression-like behaviors in rodents. ${ }^{112,146,148}$ This approach is the most appropriate model for clinical depression in rodents and mimics human-like depression behaviors, including anhedonia and learned helplessness. ${ }^{192}$ During the UCMS protocol, rats were singly housed, and randomly exposed to the following mild environmental stressors for 8 hours each day, 5 days per week, over the 8 week course:

1. Damp bedding - 10 oz. of water was added to each standard cage

2. Bath - all bedding was removed and $\sim 0.5$ inches of water was added to the empty cage. Water temperature was at room temperature, $\sim 24^{\circ} \mathrm{C}$

3. Cage tilt - cage was tilted to 45 degrees without bedding

4. Social stress - each rat was switched into a cage of a neighboring rat

5. No bedding - all bedding was removed from the cage 
6. Alignment of light/dark cycles - turning the lights off/on in random increments for a scheduled period

The protocol was altered each day to prevent rats from habituating to the stress. ${ }^{192}$

\section{Exercise Training Protocol}

EX and EXS groups underwent 8 weeks of treadmill running, 5 days per week on multilane motor driven treadmills set at a 5\% grade. The animals were acclimatized during the first week by running for 20 minutes then increasing by 10 minutes per day until a sustainable duration of 60 minutes daily was achieved. A maximum speed test was conducted on each rat to determine a target-running speed of $60-70 \%$ of the determined maximum. Once acclimatized, rats exercise for 60 minute per day. During the first 15 minute, the treadmill speed was gradually increased until the targeted-running speed was reached. At that point, the rats continued running at the targeted-running speed for the remaining 45 minutes. To discourage rats from stopping, a mild electrical stimulus $(\leq 0.3 \mathrm{~mA})$ was used at the rear of the treadmill. At the end of the 8 -week exercise protocol, there was a 48-hour wash out period between the last bout of Ex and the terminal surgery.

\section{UCMS and Exercise Combination Protocol}

LZRs and OZRs assigned to the EXS group preformed the treadmill running first thing in the morning (8-9am) and then were immediately subjected to the UCMS protocol, as described previously. ${ }^{192}$ 


\section{Stress Marker Analysis}

Coat Score

Throughout the 8-week protocol, coat scores were recorded every week for all rodents, with 0 being clean and 1 being dirty, for eight different body parts (i.e. head, neck, forelimbs, stomach, hindlimbs, tail, genitals). A total cumulative coat score was determined across all parts, and weight was recorded each week along with grooming habits.

\section{Circulating Cortisol}

A commercially available ELISA Kit (Cayman Chemical, Item \#501320) was used to examine corticosterone levels in duplicate accordingly to the manufacture's instruction. Blood samples were collected at the time of the terminal surgery and plasma was used for the ELISA Kit.

\section{Pancreas Health Analysis}

\section{Immunohistochemistry (IHC) Protocol}

Pancreatic tissue was sectioned by cryo-stating (Leica CM3050S cryostat) three tissue samples per slide and 5 slides per animal. The cryo-stat was kept as close to $-23^{\circ} \mathrm{C}$ as possible throughout the procedure, and the thickness was set to $8 \mu \mathrm{m}$. These slides were then stored in a freezer at $-18^{\circ} \mathrm{C}$.

Sectioned slides with pancreatic tissue were air-dried for 5-10 minutes before the IHC process occurred. Once the slides were dried, the pap-pen was used to draw thin but solid lines around each tissue section, and the slides were then rehydrated in 1X PBS 10 minutes. The slides were fixed in room temperature, 4\% paraformaldehyde for 20 minutes. Three, five-minute 
washes were done in $1 \mathrm{X}$ PBS before the slides were permeabilized using $0.2 \%$ Triton X-100 at $4^{\circ} \mathrm{C}$. After 10 minutes, the slides were again washed in $1 \mathrm{X}$ PBS for three, 5 -minute rounds. After the third wash, the pap pen lines were carefully dried with Kimwipes and blocked with $150 \mu \mathrm{L}$ horse serum and 10mL 1X PBS for 60 minutes. The pap pen lines were re-dried after the 60 minute blocking period, and the primary Insulin (C27C9) Rabbit mAb \#3014 antibody and primary Glucagon (10988) Mouse mAb solution was incubated on slides in a damp box at $4^{\circ} \mathrm{C}$ overnight.

On the second day of the IHC protocol, the slides were washed three times in 1X PBS. After the final wash, the lights were turned off and remained off for the remainder of the protocol due to the use of photosensitive antibodies. Alexafluor $546 \mathrm{IgG}$ anti-rabbit secondary (for insulin) and Alexafluor $488 \mathrm{IgG}$, IgM anti-mouse (for glucagon) was incubated on the slides for 45 minutes. The slides were then washed in PBS three times for 10 minutes each round. Using Kimwipes, the slides were dried as much as possible without disturbing the sections and were mounted with DAPI hard set/DAPI prolonged stain and a cover. The slides were stored in the dark at room temperature overnight. The slides were imaged using SPOT5.2 Advanced program, and the images were analyzed using ImageJ.

\section{Protein Analysis}

\section{Protein Quantification}

Homogenates were made up by combining $200 \mu \mathrm{L}$ of RIPA buffer (with added dissolved protease-inhibitor tablet) for every $1 \mathrm{~mL}$ of pancreatic tissue into a tube with ceramic beads, and using the BeadMill system, the tubes were homogenized for 30 seconds at a speed of $4 \mathrm{~m} / \mathrm{s}$. Homogenates were centrifuged for 10 minutes at $4^{\circ} \mathrm{C}$ at a speed of 10rpm, and the supernatant 
was pipetted into fresh tubes and saved, while the rest was discarded. Standards were prepared for the DC assay (Bio-Rad, Hercules, California). Homogenates were diluted with doubledistilled water at a 1:20 ratio, and samples and standards were pipetted, in duplicate fashion, into a 96 -well plate. A mixture of $20 \mu \mathrm{L}$ of reagent S per every $1 \mathrm{~mL}$ of reagent $\mathrm{A}$ was made, and $25 \mu \mathrm{L}$ of this mixture was pipetted into each well except the blanks in wells $\mathrm{H} 1-\mathrm{H} 2.200 \mu \mathrm{L}$ of reagent $\mathrm{B}$ was added to each well, except the blanks in wells $\mathrm{H} 1-\mathrm{H} 2$, and the plate was gently shaken for 30 seconds and incubated for 15 minutes before begin read at $750 \mathrm{~nm}$.

\section{TXNIP Analysis}

To prepare the Simple Western System Wes plate (Protein Simple ${ }^{\text {, }}$, San Jose, California), DDT powder was mixed with $40 \mu \mathrm{L}$ of DIY water, and Master Mix tube powder was mixed with $20 \mu \mathrm{L}$ DDT mix and $20 \mu \mathrm{L} 10 \mathrm{X}$ Sample Buffer. The Biotinylated ladder was made by adding $20 \mu \mathrm{L}$ of double-distilled water to the ladder powder. Samples were diluted with $0.1 \mathrm{X}$ sample buffer to equate $3 \mu \mathrm{L}$ of protein per sample. After these were made, $4 \mu \mathrm{L}$ of diluted lysate and $1 \mu \mathrm{L}$ of Master Mix were mixed in fresh tubes. After all the samples were made up in Master Mix, they were heat denatured at $95^{\circ} \mathrm{C}$ for 5 minutes. The samples were added after they had been allowed to cool to room temperature. The primary TXNIP (TG2596699, Invitrogen $®$ ) Rabbit IgG mAb and TXNIP (188865, abcam $\left.{ }^{\circledR}\right)$ Rabbit IgG mAb were diluted to a 1:50 ratio. The secondary conjugate (anti-Rabbit, (Protein Simple ${ }^{\circledR}$, San Jose, California) was diluted 10fold, and $200 \mu \mathrm{L}$ of Luminal-S was added to $200 \mu \mathrm{L}$ of Peroxide to yield the Luminol-Peroxide mix added to the fifth row of the plate.

The plate was centrifuged for 5 minutes at room temperature at $1000 \mathrm{~g}$ or $2500 \mathrm{rpm}$. The Wash Buffer was added to the top three rows. The bottom foil was then removed after centrifuge, 
and any bubbles that had formed in the plate were popped using pipette tips or the foil before the plate was run.

Before running the Wes plate, a Self-Test was run on the Wes System. The plate and capillaries were then loaded, and the assay tab was set to the correct setting for the plate size being ran. The stacking time was changed to 18 minutes, the separation time to 31 minutes, and the antibody times all to 30 minutes, after which the plate was run.

\section{Cytokine Analysis}

RayBiotech $^{\circledR}$ (Peachtree Corners, GA) kits were used for all ELISAs (IL-4, IL-6, IL-10, IL-1 $\beta$, and TNF- $\alpha$ ). A DC assay was done before the ELISA kits were started to get the protein concentrations. Wash Buffer (20X) was diluted to a 1X Wash Buffer, the Sample Diluent Buffer and the Assay Diluent Buffer were diluted 5-fold. Standards were made according to each different cytokine ELISA based on the manufacturer's instructions.

$100 \mu \mathrm{L}$ of the standards and samples were added in duplicate to the wells. The plate was covered and incubated for 2.5 hours at room temperature with gentle shaking. The plate was washed four times by filling the wells with $300 \mu \mathrm{L} 1 \mathrm{X}$ Wash Buffer. The wells were completely dried by carefully vacuuming out all the remaining liquid. The biotinylated ladder was made by adding $100 \mu \mathrm{L}$ of Assay Diluent Buffer to the Detection Antibody, and the detection antibody concentrate was then diluted 80 -fold. $100 \mu \mathrm{L}$ of the $1 \mathrm{X}$ biotinylated ladder was added to every well and incubated, covered for 1 hour at room temperature with gentle shaking. The washing step was then repeated, and all remaining liquid was removed from all the wells. HPR-

Streptavidin concentrate was made for each ELISA as follows:

○ IL-4: 600-fold dilution with 1X Assay Diluent Buffer 
○ IL-6: 400-fold dilution with 1X Assay Diluent Buffer

- IL-10: 140-fold dilution with 1X Assay Diluent Buffer

○ IL-13: 200-fold dilution with 1X Assay Diluent Buffer

○ TNF- $\alpha$ : 200-fold dilution with Assay Diluent Buffer

Each HPR-Streptavidin concentrate was made into $10 \mathrm{~mL}$ stocks, and $100 \mu \mathrm{L}$ was pipetted into each well and incubated, covered at room temperature with gentle shaking for 45 minutes. The wash step was repeated, and all the liquid was vacuumed out of the wells. With the lights dimmed $100 \mu \mathrm{L}$ of the One-Step Substrate Reagent was added to each well, and the plate was covered and incubated in the dark at room temperature with gentle shaking for 30 minutes. $50 \mu \mathrm{L}$ of Stop Solution was added to the wells, and the plate was read immediately at $450 \mathrm{~nm}$.

\section{Cell Death Analysis}

TUNEL staining was performed using a Cell Death Detection ELISA ${ }^{\text {PLUS }}$ (Roche ${ }^{\circledR}$ Indianapolis, IN). Slides were sectioned with $8 \mu \mathrm{m}$ thick pancreas tissue and stored in $-20^{\circ} \mathrm{C}$ freezer. After air-drying for 10-15 minutes, sections were tightly traced with the pap-pen. Slides were fixed in $4 \%$ paraformaldehyde for 10 minutes, after which three, five-minute washes were done with $1 \mathrm{X}$ PBS. Slides were dried and permeabilized in $0.1 \mathrm{X}$ Triton-X-100 for two minutes. Slides were washed twice for ten minutes in $1 \mathrm{X}$ PBS. Slides were dried, and TUNEL solution was made using an In Situ Cell Death Detection Kit, Fluorescein. $450 \mu \mathrm{L}$ of labeling solution was added to $50 \mu \mathrm{L}$ of enzyme solution. $50 \mu \mathrm{L}$ of this mixture was added to ten sections, and $50 \mu \mathrm{L}$ of labeling solution alone was added to two sections for negative controls. Slides were incubated again and placed in a humidifier at $37^{\circ} \mathrm{C}$, or body temperature, for 60 minutes. A final tenminute wash was done after the TUNEL incubation in 1X PBS. The dried slides were mounted 
with DAPI hard set/DAPI prolonged stain and a cover slip. The slides were stored in the dark at room temperature overnight.

Pancreatic lysate homogenates were used in the Pierce ${ }^{\mathrm{TM}}$ BCA Protein Assay Kit (ThermoFisher Scientific, Waltham, MA) to obtain protein concentration values for all samples. Samples were diluted to a 1:20 ratio with double-distilled water, and $10 \mu \mathrm{L}$ of standard and $10 \mu \mathrm{L}$ of sample were added to each well in two 96-well plates in a duplicate fashion. Working reagent was made by thoroughly mixing 50 parts of BCA Reagent A with 1 part BCA Reagent B, and $200 \mu \mathrm{L}$ of the working reagent was added to each well, expect the duplicate blank wells. The plate was shaken for 30 seconds and left to incubate for 30 minutes in $37^{\circ} \mathrm{C}$. After the plate was cooled to room temperature, the absorbance was measured at $562 \mathrm{~nm}$ on a plate reader.

The same homogenates were used from the BCA Protein Assay for the Cell Death ELISA $^{\text {PLUS }}$ kit (Roche ${ }^{\circledR}$ Indianapolis, IN). $20 \mu \mathrm{L}$ of samples were randomly plated in duplicate in a pre-coated 96-well Cell Death ELISA plate, along with a positive control provided by the Cell Death kit and one blank well. All samples were carefully pipetted into the center of the plate. To each well, $80 \mu \mathrm{L}$ of the Immunoreagent was added. The Microplate (MP) was covered in an adhesive cover and incubated for 2 hours, shaking at $300 \mathrm{rpm}$ at $25^{\circ} \mathrm{C}$. The MP was washed three times by filling and emptying the wells with $250-300 \mu \mathrm{L}$ of incubation buffer. The wells were dried completely, and $100 \mu \mathrm{L}$ of ABTS solution was added. The plate incubated for approximately 15 minutes with shaking at $250 \mathrm{rpm} .100 \mu \mathrm{L}$ of Stop Solution was pipetted into the wells, and the absorbance was measured at $405 \mathrm{~nm}$ in a plate reader. 


\section{Oxidative Stress Analysis}

Hydrogen Peroxide Analysis

Pancreatic lysate homogenates were used for a DC Assay prior to the Amplex ${ }^{\circledR}$ Red Kit (Invitrogen ${ }^{\circledR}$ ), as described above. $10 \mathrm{mM} \mathrm{Amplex}{ }^{\circledR}$ Red reagent stock solution was made dissolving Amplex ${ }^{\circledR}$ Red reagent vial contents in $60 \mu \mathrm{L}$ of DMSO, and 1X Reaction Buffer was made by adding $4 \mathrm{~mL}$ of $5 \mathrm{X}$ Reaction Buffer to $16 \mathrm{~mL}$ of deionized water. $10 \mathrm{U} / \mathrm{mL}$ of Horseradish Peroxidase (HRP) was made by dissolving the contents of the HRP vial in $1.0 \mathrm{~mL}$ of 1X Reaction Buffer. 20mM Hydrogen Peroxidase $\left(\mathrm{H}_{2} \mathrm{O}_{2}\right)$ working solution was made by diluting $22.7 \mu \mathrm{L}$ of $\sim 3 \% \mathrm{H}_{2} \mathrm{O}_{2}$ into $977 \mu \mathrm{L}$ of $1 \mathrm{X}$ Reaction Buffer. Standards were prepared in a serial dilution from $2.5 \mu \mathrm{M}$ to $0.02 \mu \mathrm{M}$ using the $20 \mathrm{mM} \mathrm{H}_{2} \mathrm{O}_{2}$ working solution.

$50 \mu \mathrm{L}$ of the standards were pipetted in duplicate into the first two columns of wells, and $50 \mu \mathrm{L}$ of sample were pipetted in duplicate in random order in the rest of the wells. This was done over two plates, with five samples from plate one being added to five single wells on plate two for cross-plate comparisons. An Amplex ${ }^{\circledR}$ Red reagent/HRP working solution was made by combining $50 \mu \mathrm{L}$ of $10 \mathrm{mM}$ Amplex ${ }^{\circledR}$ Red reagent stock solution, $100 \mu \mathrm{L}$ of $10 \mathrm{U} / \mathrm{mL}$ HRP stock solution, and $4.85 \mathrm{~mL}$ of $1 \mathrm{X}$ Reaction Buffer. $50 \mu \mathrm{L}$ of this Amplex ${ }^{\circledR}$ Red reagent/HRP working solution was added to each well, and the plate was incubated at room temperature for 30 minutes, protected from the light. A microplate reader equipped for excitation in the range of 530-560nm was used to read the plate after incubation.

Nitrate/Nitrite Analysis

The Sievers Nitric Oxide Analyzer (NOA 280) was used for Nitrate Analysis. Samples approximately $50 \mu \mathrm{g}$ in size were homogenized using RIPA buffer with protease inhibitors to 
give volumes of approximately $100 \mu \mathrm{g}$. Standards were made using 1/10 dilutions starting with $100 \mathrm{mM} \mathrm{NO}_{3}{ }^{-}$of stock solution sodium nitrate $\left(0.425 \mathrm{~g} \mathrm{NaNO}_{3}^{-} / 50 \mathrm{~mL} \mathrm{H}_{2} 0\right)$. The standards were made as follows: $10 \mathrm{mM}, 1 \mathrm{mM}, 100 \mu \mathrm{M}, 10 \mu \mathrm{M}, 1 \mu \mathrm{M}$, and $0.1 \mu \mathrm{M}$. Figure 5 shows the set up for the NOA 208.

$50 \mu \mathrm{L}$ injections were done for standards and samples. After samples were taken up in the syringe, the needle was wiped with a kimwipe and then injected into the needle valve. After injections, the syringe was cleaned with distilled water two to three times, and the needle was wiped with a kimwipe. The standards and samples were injected after baseline was attained after each injection. Samples were tested in a triplicate manner, and standards were retested throughout the experiment to make sure no changes were occurring in the NOA 208 environment. 


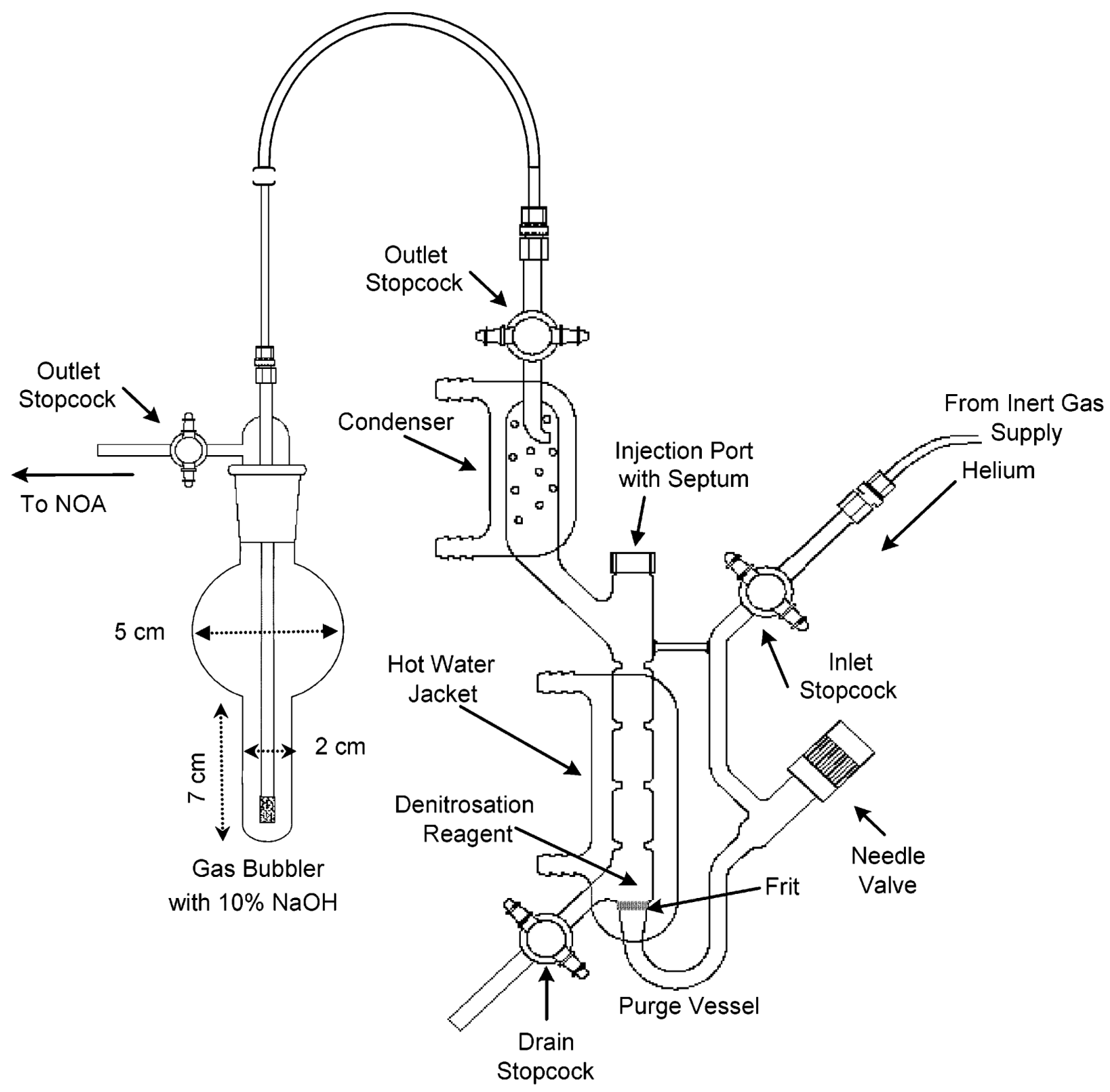

Figure 5 shows the set-up of the Sievers Nitric Oxide Analyzer (NOA 280) was used for Nitrate Analysis. ${ }^{193}$

Superoxide/Uric Acid Analysis

Homogenates from above DC Protein Assays were used. Stock solutions were prepared and the concentrations of the standards was determined using the spectrophotometer. These 
concentrations were used to determine the dilutions of the stock solutions. The water bath was set to $37^{\circ} \mathrm{C}$, and three tubes were labeled for each sample, with duplicates for each tube (i.e. six total tubes for each sample).

The samples were columned through G-25 columns. One tube collected the volume liquid that eludes from the column before the Blue-Dextran colored solution (pre-column). A second tube collected the blue stained solution (post-column). The meniscus were marked on each of these tubes to use as a reference to other samples collected in fresh tubes. BCA protein assays were ran before and after columning to obtain protein concentrations for a ratio pre-column to post-column to determine the dilution factor due to columning.

After Xanthine was added to the samples, the tubes were vortexed and incubated in a $37^{\circ} \mathrm{C}$ water bath for 60 minutes. During the incubation, $150 \mu \mathrm{L}$ solution of Allopurinol in Acetonitrile $(\mathrm{ACN})$ was made. At the 55 minute mark of the incubation, the tubes were placed in the same order as the addition of Xanthine, and at the 60 minute mark, $1 \mathrm{~mL}$ of ice cold ACN/Allopurinol solution was added in the same order as Xanthine addition. The samples were vortexed and centrifuged at $4^{\circ} \mathrm{C}$ at $12,600 \mathrm{rpm}$ for 15 minutes. The supernatant was transferred to the second set of pre-labeled tubes and store at $-80^{\circ} \mathrm{C}$ until time of analysis.

At the time of analysis by HPLC-EC, the samples were speed-dried and resolubilized in $300 \mu \mathrm{L}$ of mobile phase. The uric acid standards were prepared and both standards and samples were ran as prepared.

\section{Statistical Analysis}

All data are expressed as means and \pm standard errors. A multifactorial (analysis of variance (ANOVA) with an interaction term was performed to determine differences between 
groups using SPSS program. Tukey's post hoc analysis was performed to compare between groups. Independent T-tests were used to compare differences between two groups when appropriate. Statistical significance was set to $\mathrm{P} \leq 0.05$. 


\section{CHAPTER 4: RESULTS}

Treadmill running for eight weeks significantly decreased body mass in both genotypes (LZR and OZR). In addition, UCMS alone significantly decreased body mass in both LZR and OZR. UCMS significantly increased glucose, corticosterone, and coat scores levels in LZR and OZR, which demonstrated that the UCMS protocol was successful in producing a stress response in the rats (Table 1). EX rodents had significantly lower glucose levels when compared to $\mathrm{C}$ and EXS animals. Insulin plasma levels were significantly lower with training and increased with UCMS in LZR. This data is shown in Table 1.

Table $1 * \mathrm{P}<0.05$ vs. control group within same strain, $\$ \mathrm{P}<0.05$ vs. UCMS group within strain, $\S \mathrm{P}<0.05$ vs. Training group.

\begin{tabular}{|c|c|c|c|c|c|c|c|c|}
\hline & LZR-C & $\begin{array}{c}\text { LZR- } \\
\text { EX }\end{array}$ & LZR-S & $\begin{array}{l}\text { LZR- } \\
\text { EXS }\end{array}$ & $\begin{array}{c}\text { OZR- } \\
\text { C }\end{array}$ & $\begin{array}{c}\text { OZR- } \\
\text { EX }\end{array}$ & OZR-S & $\begin{array}{l}\text { OZR- } \\
\text { EXS }\end{array}$ \\
\hline $\begin{array}{c}\text { Age } \\
\text { (weeks) }\end{array}$ & 18 & 18 & 18 & 18 & 18 & 18 & 18 & 18 \\
\hline $\begin{array}{c}\text { Body Mass } \\
(\mathrm{g})\end{array}$ & $\begin{array}{c}400 \pm \\
20\end{array}$ & $\begin{array}{c}358 \pm \\
15^{*}\end{array}$ & $\begin{array}{c}361 \pm \\
12^{*}\end{array}$ & $\begin{array}{c}343 \pm \\
12^{*}\end{array}$ & $\begin{array}{c}641 \pm \\
29\end{array}$ & $\begin{array}{c}599 \pm \\
27^{*}\end{array}$ & $\begin{array}{c}585 \pm \\
20^{*}\end{array}$ & $\begin{array}{c}567 \pm \\
25\end{array}$ \\
\hline $\begin{array}{l}\text { Glucose } \\
\text { (mg dl-1) }\end{array}$ & $98 \pm 15$ & $\begin{array}{c}101 \pm \\
20 \ddagger\end{array}$ & $\begin{array}{c}124 \pm \\
17^{*}\end{array}$ & $\begin{array}{c}115 \pm \\
15\end{array}$ & $\begin{array}{c}184 \pm \\
29\end{array}$ & $\begin{array}{l}154 \pm \\
29 *+\end{array}$ & $\begin{array}{c}230 \pm \\
34^{*}\end{array}$ & $\begin{array}{l}219 \pm \\
37 * \S\end{array}$ \\
\hline $\begin{array}{c}\text { Insulin } \\
\text { (ng ml-1) }\end{array}$ & $\begin{array}{c}1.2 \pm \\
0.5\end{array}$ & $1.4 \pm 0.7$ & $\begin{array}{c}2.1 \pm \\
1.0\end{array}$ & $\begin{array}{c}1.8 \pm \\
1.0\end{array}$ & $\begin{array}{c}6.6 \pm \\
2.7\end{array}$ & $\begin{array}{l}4.6 \pm \\
2.4^{*}\end{array}$ & $\begin{array}{l}7.8 \pm \\
3.7^{*}\end{array}$ & $\begin{array}{c}6.2 \pm \\
2.4\end{array}$ \\
\hline Corticosterone & $\begin{array}{c}6.97 \pm \\
0.4\end{array}$ & $\begin{array}{c}9.44 \pm \\
2.6\end{array}$ & $\begin{array}{c}8.78 \pm \\
1.3^{*}\end{array}$ & $\begin{array}{c}10.67 \pm \\
3.6^{*}\end{array}$ & $\begin{array}{c}13.82 \pm \\
1.4\end{array}$ & $\begin{array}{c}10.6 \pm \\
2.4^{*}\end{array}$ & $\begin{array}{c}17.3 \pm \\
3.6^{*}\end{array}$ & $\begin{array}{c}15.78 \pm \\
3.6 \S\end{array}$ \\
\hline
\end{tabular}

\section{The effects of obesity on pancreatic morphology}

Pancreatic $\beta$-cell numbers $(\mathrm{p}=0.03), \alpha$-cell numbers $(\mathrm{p}=0.00)$, and islet area $(\mathrm{p}=0.01)$ were significantly higher in OZR-C versus LZR-C (Figure 6A, C, and E), while $\beta$-cell to $\alpha$-cell ratio ( $p=0.07)$ was trending higher in LZR-C versus OZR-C (Figure 6F). $\beta$-cell density was 
decreased $(p=0.02)$, while $\alpha$-cell density was increased $(p=0.05)$ in OZR-C compared to LZR-C (Figure $6 \mathrm{~B}$ and D).

A
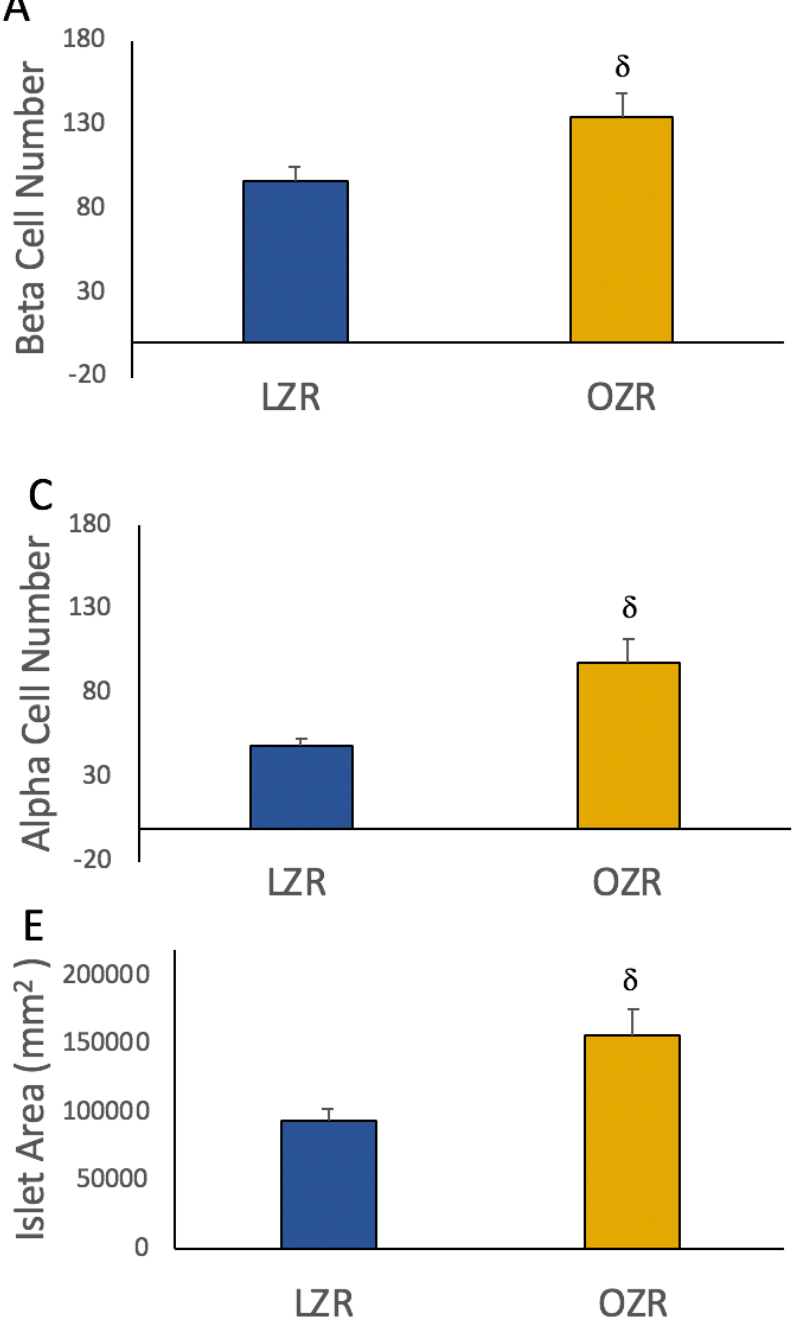

B

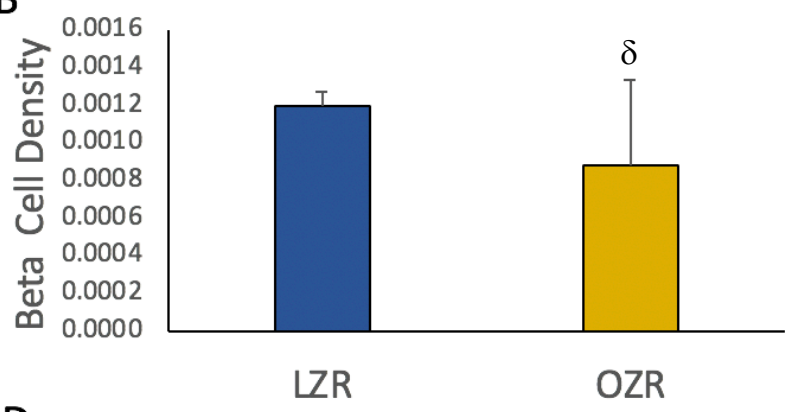

D
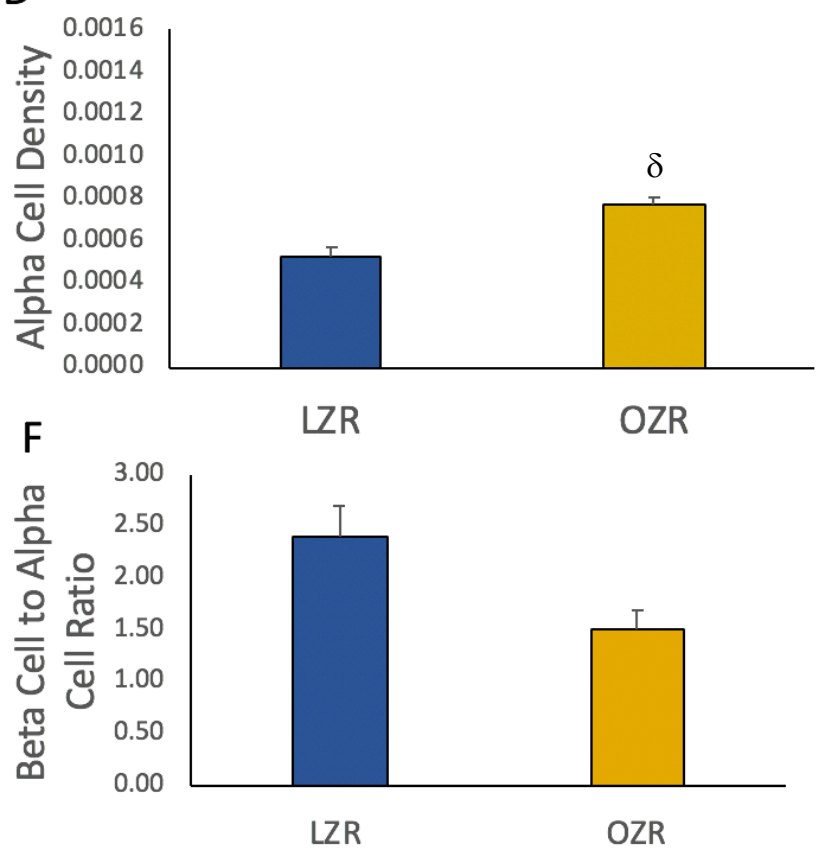

Figure 6 LZR-C vs. OZR-C mean $\beta$-cell number (A), $\beta$-cell density (B), $\alpha$-cell number (C), $\alpha$ cell density (D), islet area (E), and $\beta$-cell to $\alpha$-cell ratio (F). $\delta p<0.05$ vs LZR-C.

The effects of stress alone and in combination with obesity on pancreatic morphology

There were no significant differences in $\beta$-cell numbers, $\alpha$-cell numbers, islet area, or $\beta$ cell to $\alpha$-cell ratio in LZR-S versus LZR-C (Figure 7A, C, and E). Although $\beta$-cell density was 
not significantly changed, $\alpha$-cell density was increased $(p=0.01)$ in LZR-S compared to LZR-C

(Figure 7B and D). OZR-S had a significantly lower number of $\alpha$-cells $(p=0.00)$ compared to OZR-C (Figure 8C), but there were no significant differences in $\beta$-cell numbers, islet area, or $\beta$ cell to $\alpha$-cell ratio in OZR-S versus OZR-C (Figure 8A, C, and E). $\beta$-cell and $\alpha$-cell densities were not different in OZR-S versus OZR-C (Figure 8B and D).

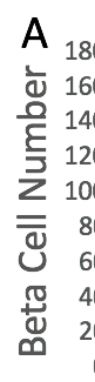

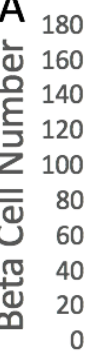

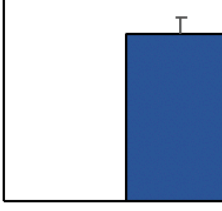

LZR

C

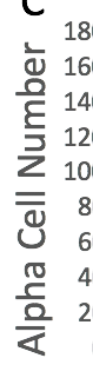

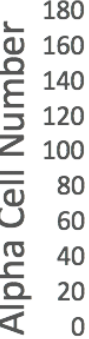
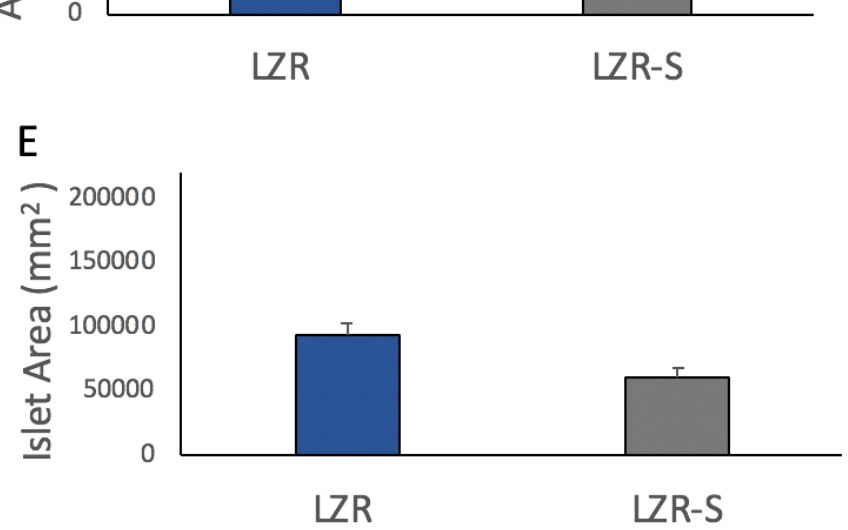

B

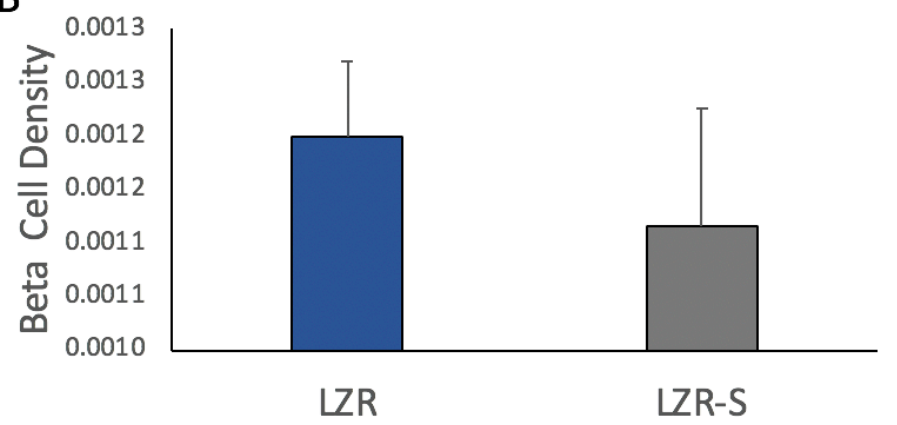

D

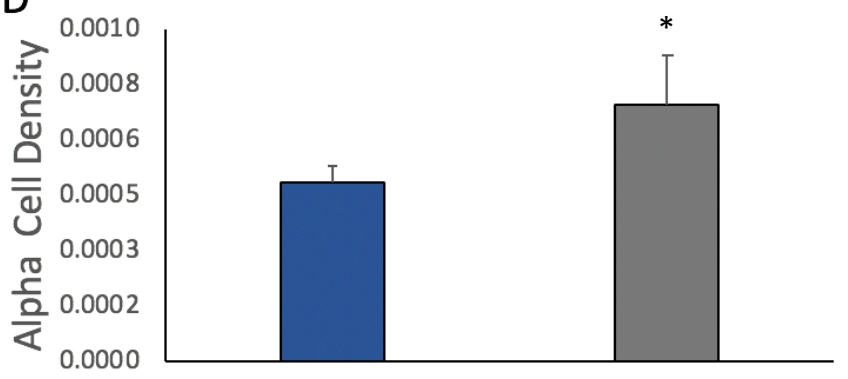

$\mathrm{F}$

LZR

LZR-S

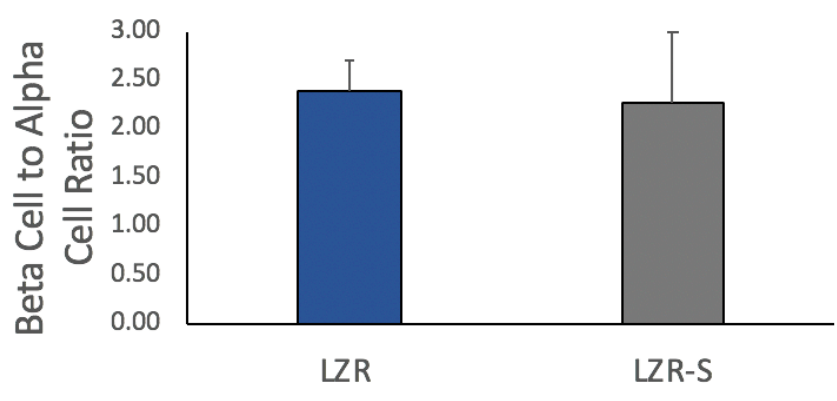

Figure 7 LZR-C vs. OZR-S mean $\beta$-cell number (A), density (B), $\alpha$-cell number (C), $\alpha$-cell density (D), islet area (E), and $\beta$-cell to $\alpha$-cell ratio (F). ${ }^{*} \mathrm{p}<0.05$ vs. control group within same strain. 

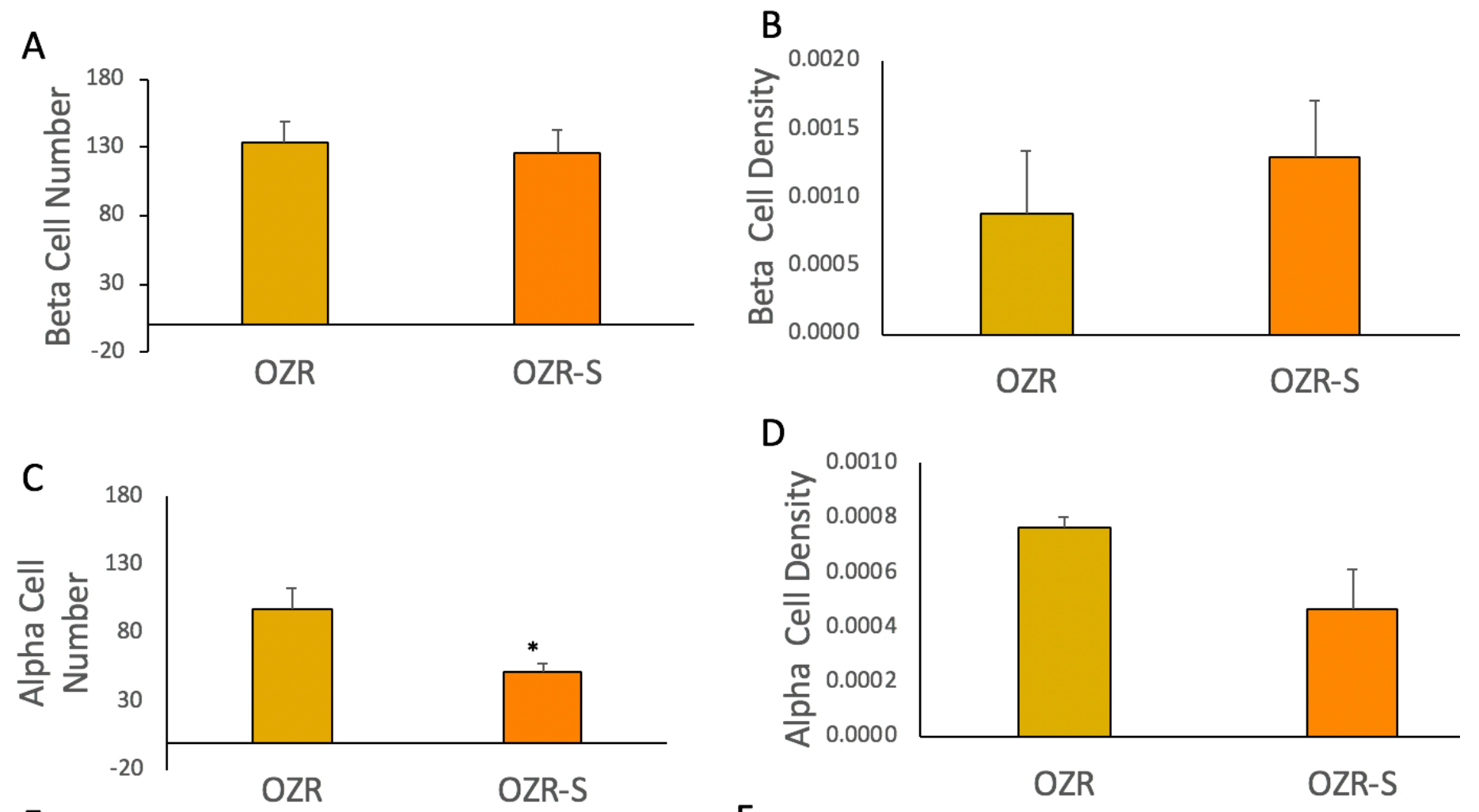

\section{D}
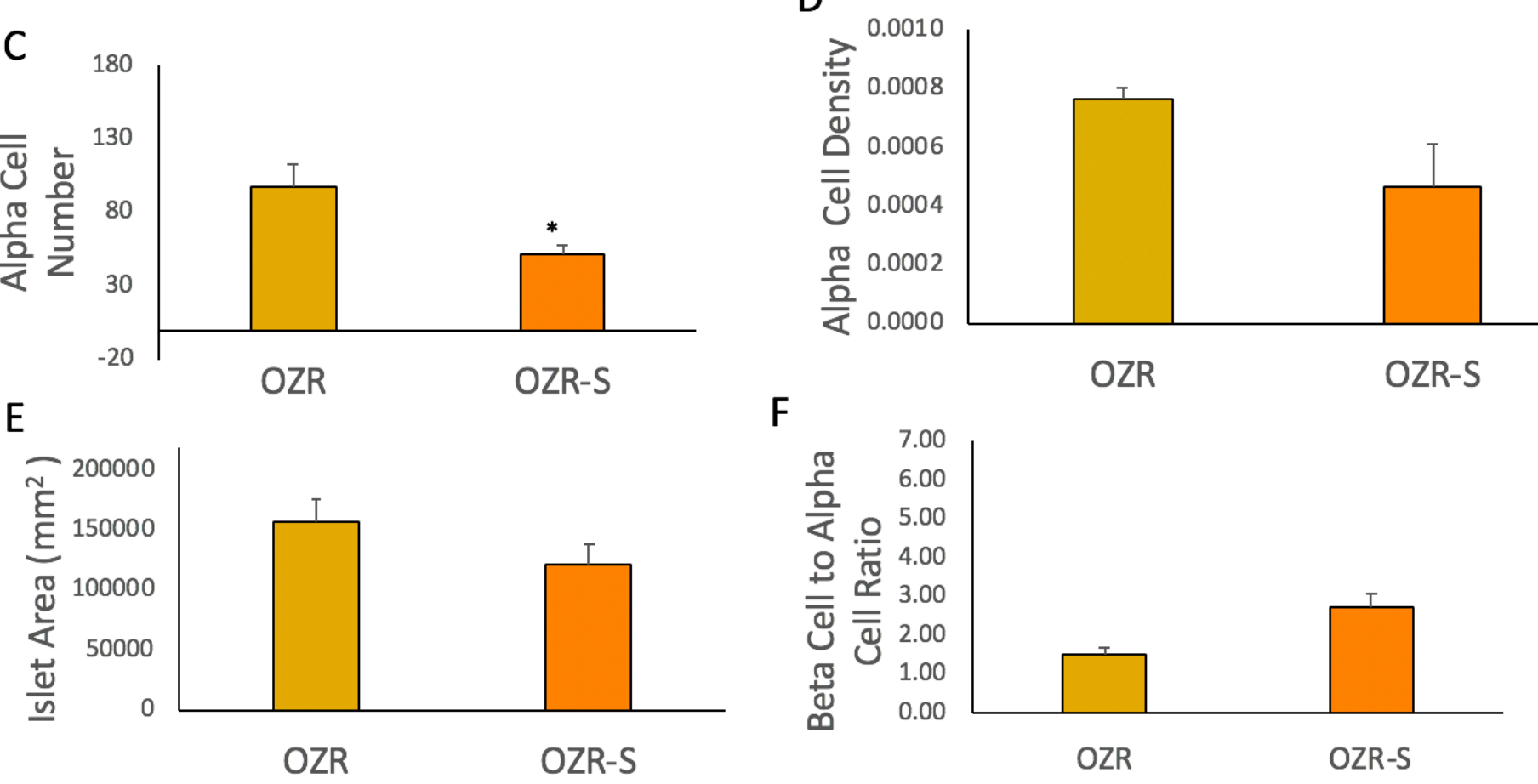

Figure 8 OZR-C vs. OZR-S mean $\beta$-cell number (A), $\beta$-cell density (B), $\alpha$-cell number (C), $\alpha$ cell density (D), islet area (E), and $\beta$-cell to $\alpha$-cell ratio (F). ${ }^{*} p<0.05$ vs. control group within same strain.

\section{The effects of exercise training on obesity and stress related changes to pancreatic}

\section{morphology}

There was no significant difference in pancreatic $\beta$-cell number, but $\beta$-cell density was trending to increase $(\mathrm{p}=0.10)$ between OZR-EX and OZR-C (Figure 9A-B). The $\alpha$-cell number $(\mathrm{p}=0.00)$ was lower and the islet area $(\mathrm{p}=0.02)$ was smaller in OZR-EX compared to OZR-C 
(Figure 9C and E). The $\alpha$-cell density did not significantly change between these groups (Figure

9D). In addition, the $\beta$-cell to $\alpha$-cell ratio was significantly higher $(\mathrm{p}=0.04)$ in OZR-EX versus

OZR-C (Figure 9F).

$\mathrm{P}=0$.

A

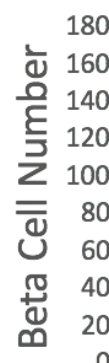

C

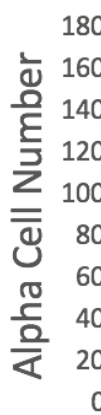

E

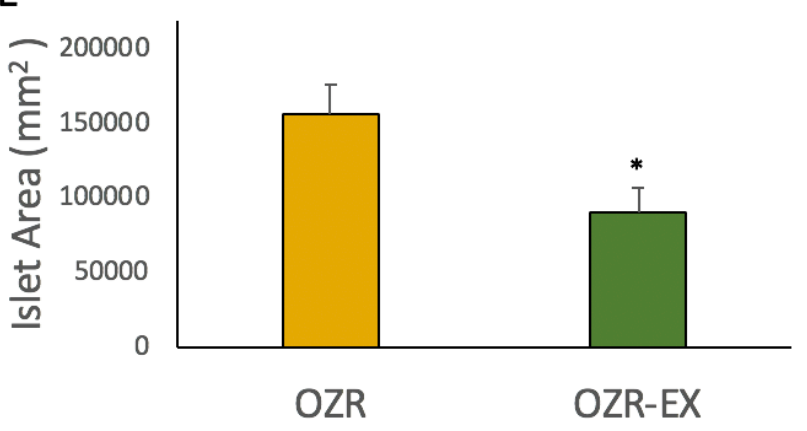

OZR-EX
B
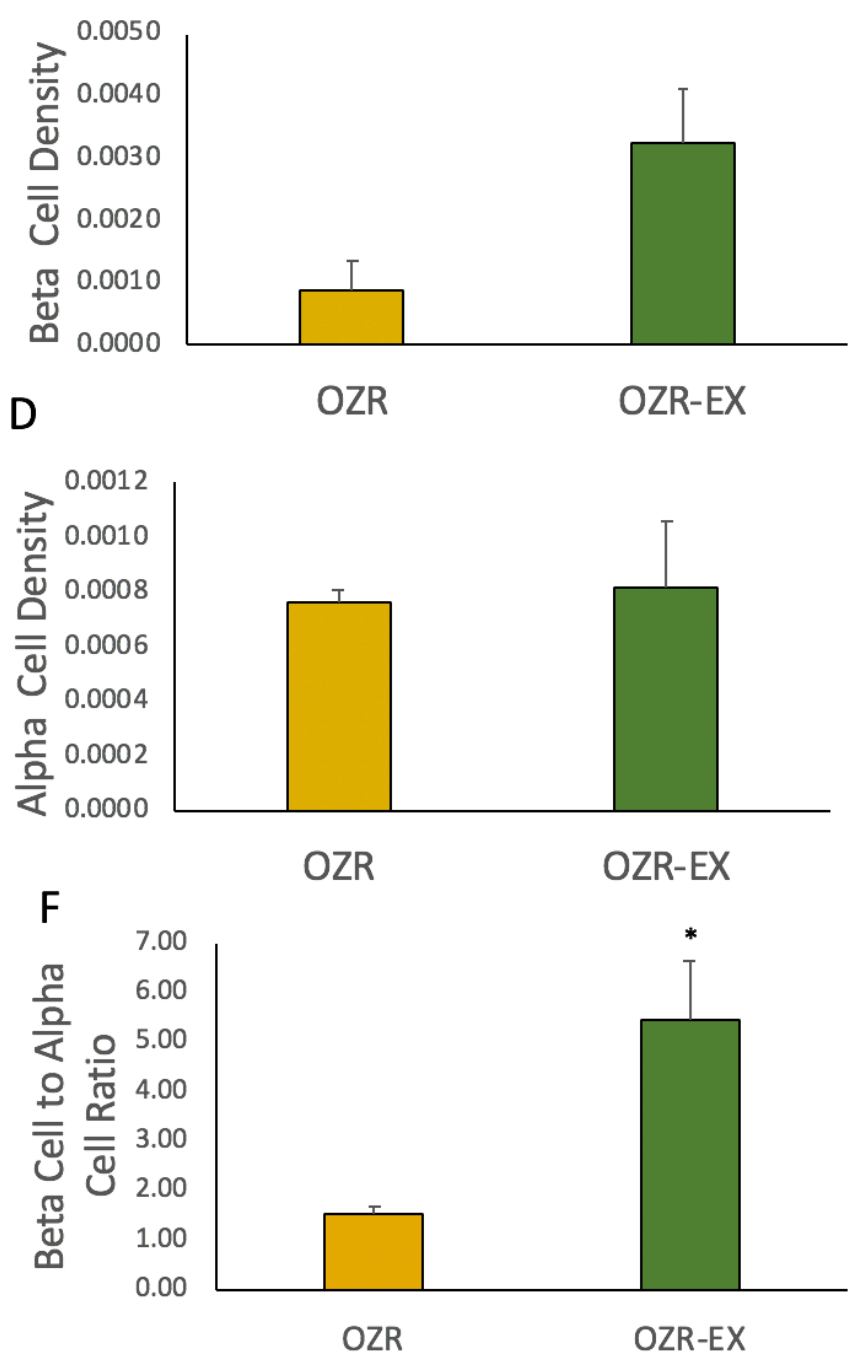

Figure 9 OZR-C vs. OZR-EX mean $\beta$-cell number (A), $\beta$-cell density (B), $\alpha$-cell number (C), $\alpha$-cell density (D), islet area (E), and $\beta$-cell to $\alpha$-cell ratio $(F) .{ }^{*} p<0.05$ vs. control group within same strain.

In the UCMS model, $\beta$-cell number $(\mathrm{p}=0.00), \alpha$-cell number $(\mathrm{p}=0.00)$, and islet area $(\mathrm{p}=0.00)$ were significantly higher in LZR-EXS compared to LZR-S, but there were no significant changes in $\beta$-cell or $\alpha$-cell density or $\beta$-cell to $\alpha$-cell ratio (Figure10A-F). 
A

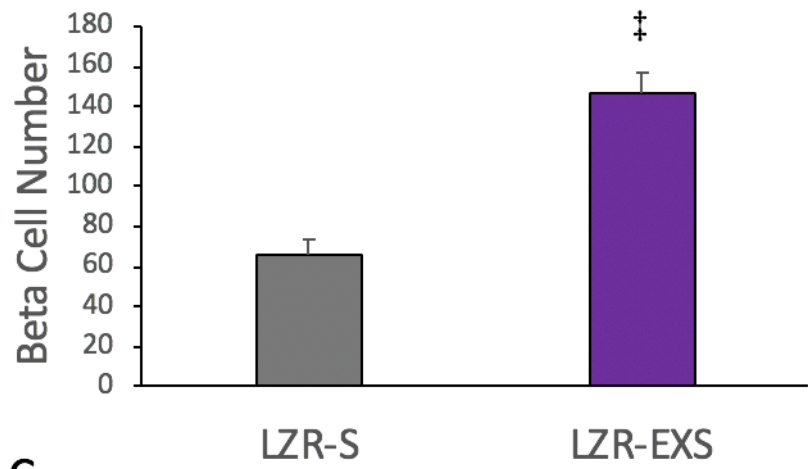

C

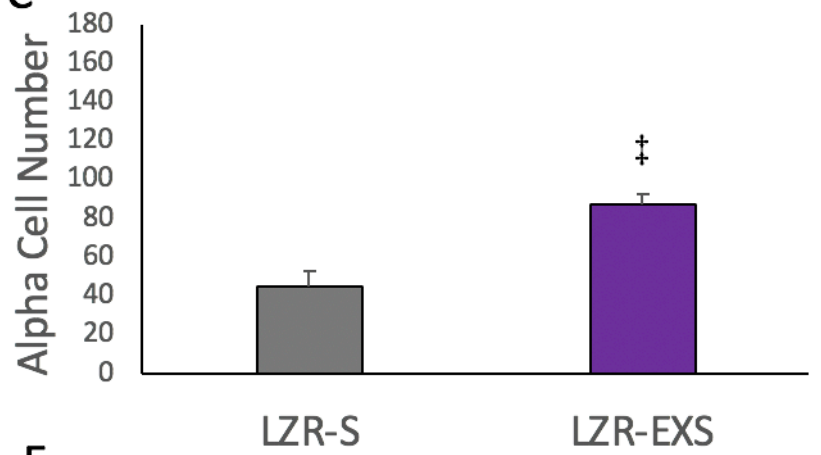

$\mathrm{E}$

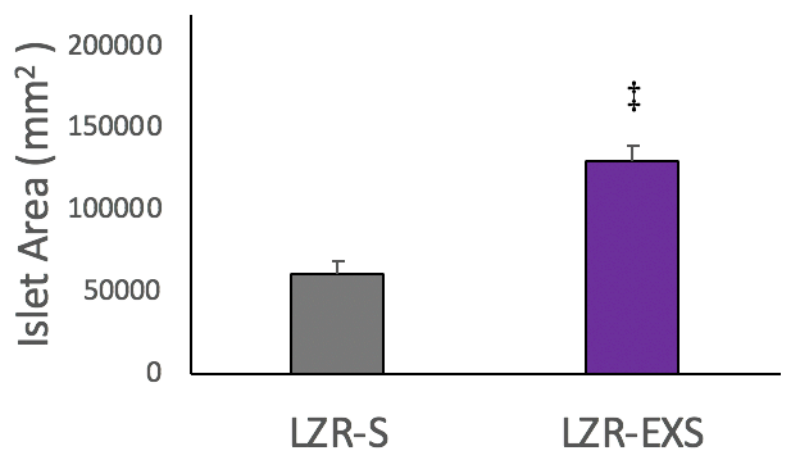

B
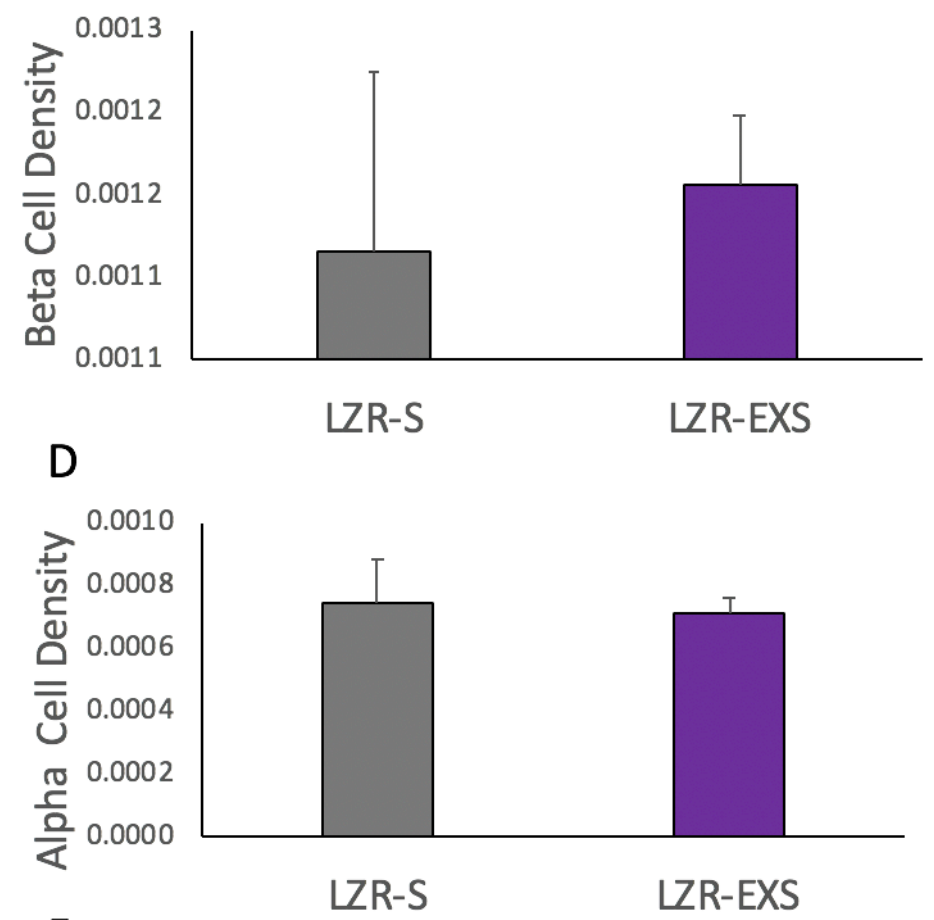

$\mathrm{F}$

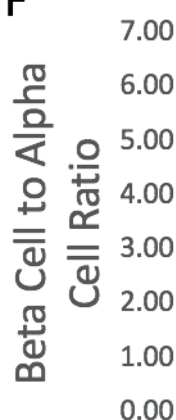

LZR-EXS

\begin{tabular}{l|}
7.00 \\
6.00 \\
.00 \\
4.00 \\
.00 \\
2.00 \\
.00 \\
.00
\end{tabular}

Figure 10 LZR-S vs. LZR-EXS mean $\beta$-cell number (A), $\beta$-cell density (B), $\alpha$-cell number (C), $\alpha$-cell density (D), islet area (E), and $\beta$-cell to $\alpha$-cell ratio (F). $₫ \mathrm{p}<0.05$ vs. UCMS group within strain.

Pancreatic $\beta$-cell number and density, $\alpha$-cell number and density, islet area, and $\beta$-cell to $\alpha$-cell ratio did not show significant differences in OZR-EXS versus OZR-S (Figure 11A-F). All of the data from the above results on pancreatic $\beta$-cell number, $\alpha$-cell number, islet area, and $\beta$-cell to $\alpha$-cell ratio is also shown in Table 2. 
A

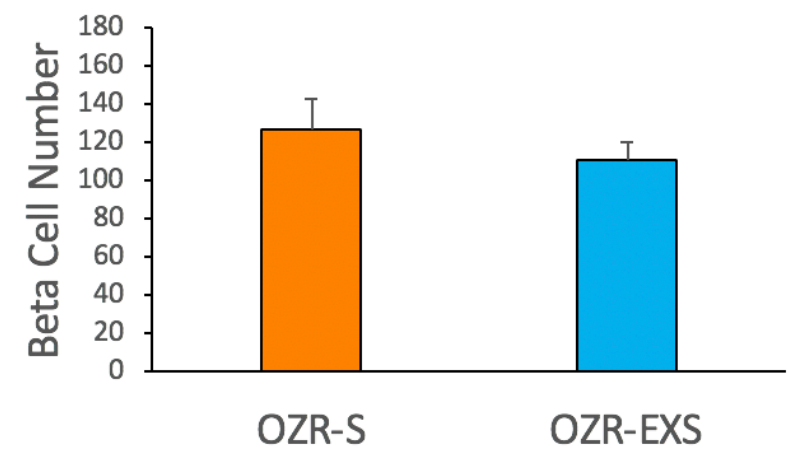

C

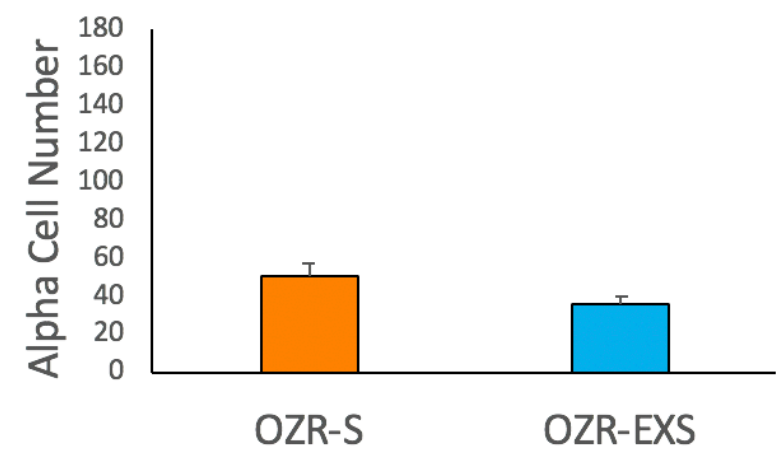

$\mathrm{E}$

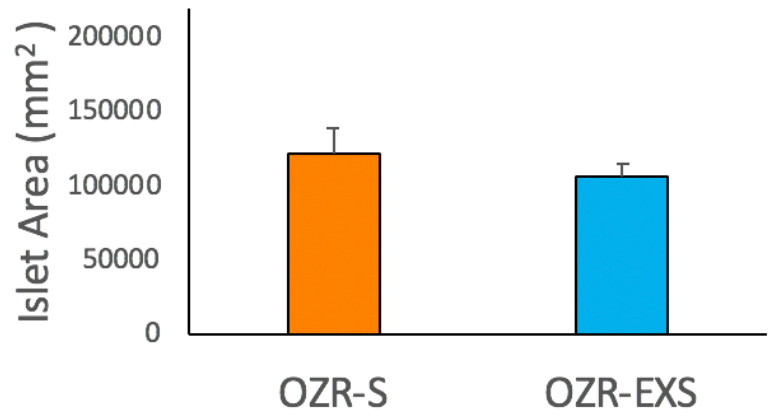

B

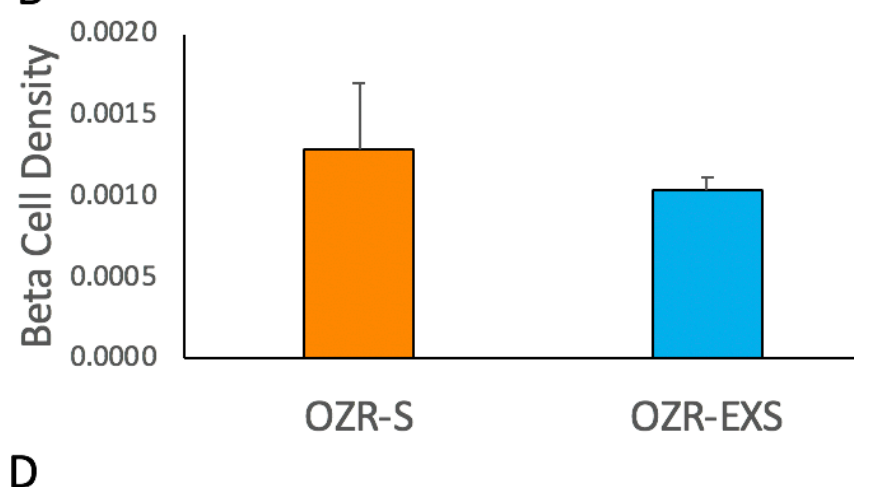

D

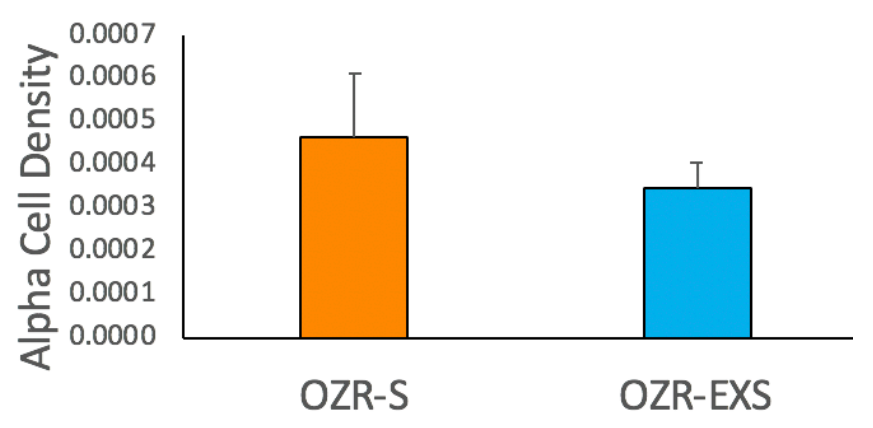

$\mathrm{F}$

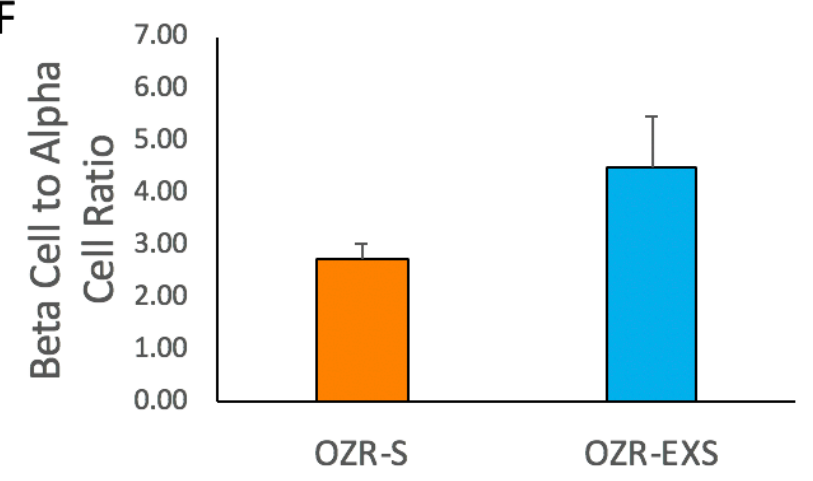

Figure 11 OZR-S vs. OZR-EXS mean $\beta$-cell number (A), $\beta$-cell density (B), $\alpha$-cell number (C), $\alpha$-cell density (D), islet area (E), and $\beta$-cell to $\alpha$-cell ratio (F). $\$ p<0.05$ vs. UCMS group within strain. 
Table $2 * \mathrm{P}<0.05$ vs. control group within same strain, $t \mathrm{P}<0.05$ vs. UCMS group within strain

\begin{tabular}{|c|c|c|c|c|c|c|c|c|}
\hline & $\underset{\mathbf{C}}{\mathbf{L R R}-}$ & $\begin{array}{c}\text { LZR- } \\
\text { Ex }\end{array}$ & $\begin{array}{l}\text { LZR- } \\
\quad \mathbf{S}\end{array}$ & $\begin{array}{c}\text { LZR- } \\
\text { ExS }\end{array}$ & $\begin{array}{c}\text { OZR- } \\
\mathrm{C}\end{array}$ & $\begin{array}{c}\text { OZR- } \\
\text { Ex }\end{array}$ & $\begin{array}{c}\text { OZR- } \\
\mathbf{S}\end{array}$ & $\begin{array}{c}\text { OZR- } \\
\text { ExS }\end{array}$ \\
\hline$\beta$-Cell & $96 \pm 9$ & $\begin{array}{c}123 \pm \\
10^{*}\end{array}$ & $66 \pm 9$ & $\begin{array}{c}147 \pm \\
11 \ddagger\end{array}$ & $134 \pm 15$ & $146 \pm 22$ & $\begin{array}{c}127 \pm \\
16\end{array}$ & $\begin{array}{c}111 \pm \\
9\end{array}$ \\
\hline$\alpha-$ Cell & $49 \pm 4$ & $55 \pm 4$ & $45 \pm 7$ & $88 \pm 6$ & $98 \pm 15$ & $35 \pm 5$ & $51 \pm 6$ & $36 \pm 5$ \\
\hline $\begin{array}{c}\beta \text {-Cell to } \\
\alpha \text {-Cell } \\
\text { Ratio } \\
\end{array}$ & $\begin{array}{c}2.4 \pm \\
0.31 \\
\end{array}$ & $\begin{array}{c}2.3 \pm \\
0.14\end{array}$ & $\begin{array}{c}2.3 \pm \\
0.72 \\
\end{array}$ & $\begin{array}{l}1.8 \pm \\
0.11\end{array}$ & $\begin{array}{c}1.5 \pm \\
0.16\end{array}$ & $\begin{array}{c}5.4 \pm \\
1.2\end{array}$ & $\begin{array}{c}2.7 \pm \\
0.33 \\
\end{array}$ & $\begin{array}{c}4.5 \pm \\
0.96\end{array}$ \\
\hline $\begin{array}{c}\text { Islet } \\
\text { Area }\end{array}$ & $\begin{array}{r}94167 \\
\pm 8708\end{array}$ & $\begin{array}{l}106783 \\
\pm 9479\end{array}$ & $\begin{array}{r}61746 \\
\pm 7409\end{array}$ & $\begin{array}{r}129770 \\
\pm 10463\end{array}$ & $\begin{array}{c}157002 \\
\pm 19128\end{array}$ & $\begin{array}{c}91687 \pm \\
15615\end{array}$ & $\begin{array}{r}121704 \\
\pm 17613\end{array}$ & $\begin{array}{l}106769 \\
\pm 9240\end{array}$ \\
\hline
\end{tabular}

The effects of obesity on the pancreatic pro-inflammatory environment and level of apoptosis

TXNIP was trending higher $(\mathrm{p}=0.10)$ in pancreatic tissue of the OZR-C compared to the LZR-C (Figure 12A). As expected, TNF- $\alpha$ concentration was higher $(p=0.03)$ in OZR-C versus LZR-C (Figure 12B), however, although IL-1 $\beta$ appeared greater in OZR-C compared to LZR-C, the difference was not significant (Figure 12C). IL-4 concentration was higher $(\mathrm{p}=0.01)$ in OZRC versus LZR-C, but IL-10 and IL-6 showed no significant differences between groups, although IL-10 $(p=0.08)$ did show a trending increase (Figure 12D-F). Hydrogen peroxide was shown to decrease in OZR-C compared to LZR-C $(\mathrm{p}=0.00)$, but other markers of oxidative stress were not significantly different (Figure 13A-C). No differences were noted in the level of apoptosis between groups. 
A

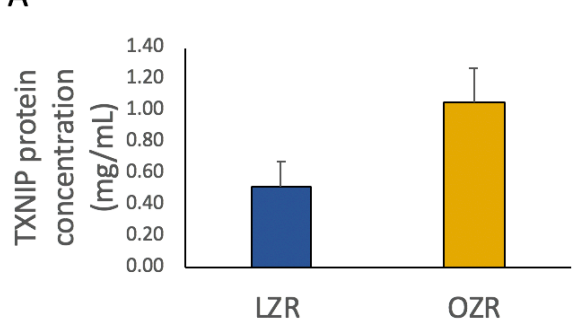

D

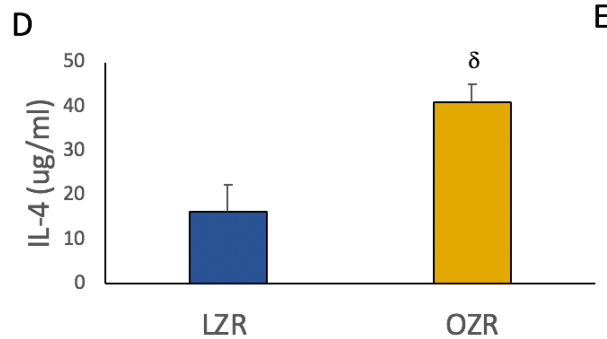

B

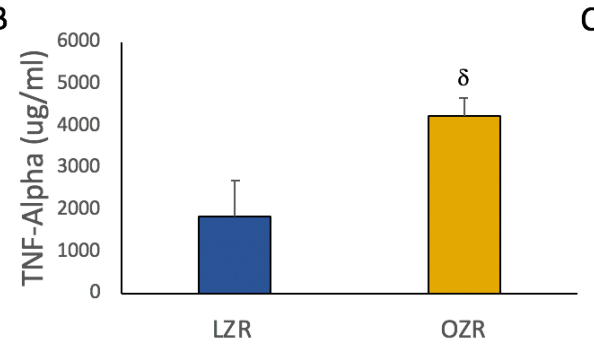

$\mathrm{E}$

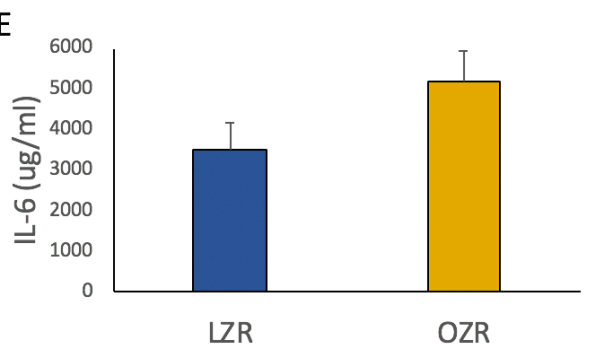

C

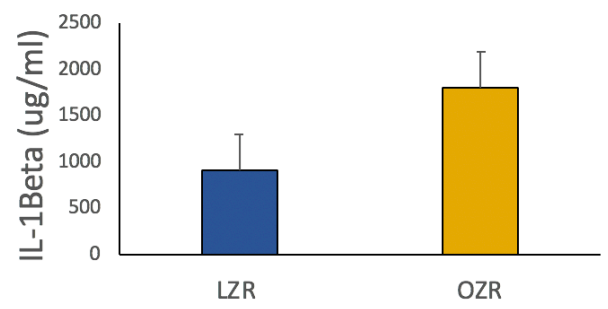

$\mathrm{F}$

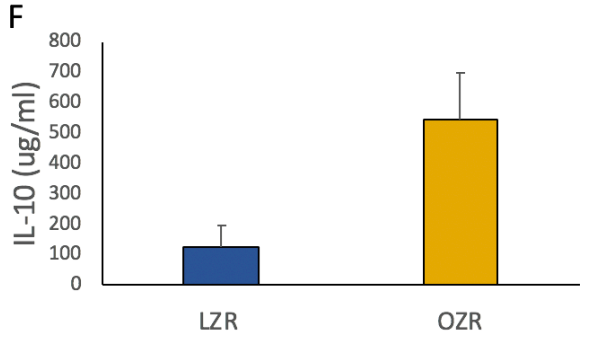

Figure 12 LZR-C vs. OZR-C mean TXNIP (A), TNF- $\alpha$ (B), IL-1 $\beta$ (C), IL-4 (D), IL-6 (E), IL10 (F) concentration. $\delta \mathrm{p}<0.05$ vs LZR-C.

A

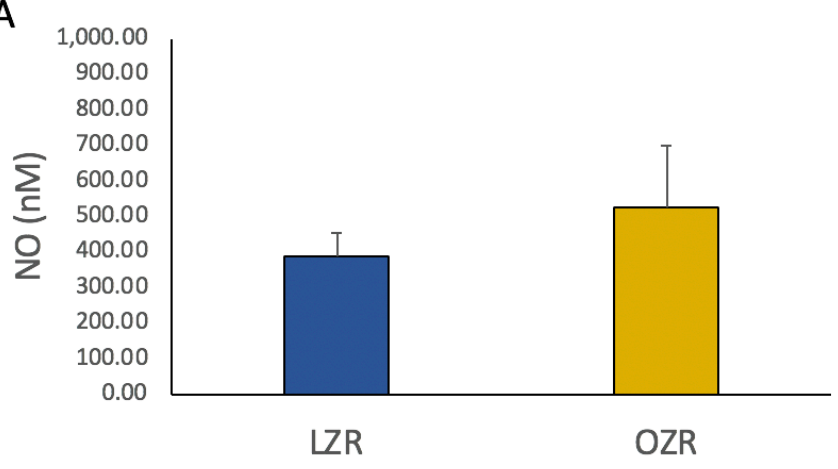

C

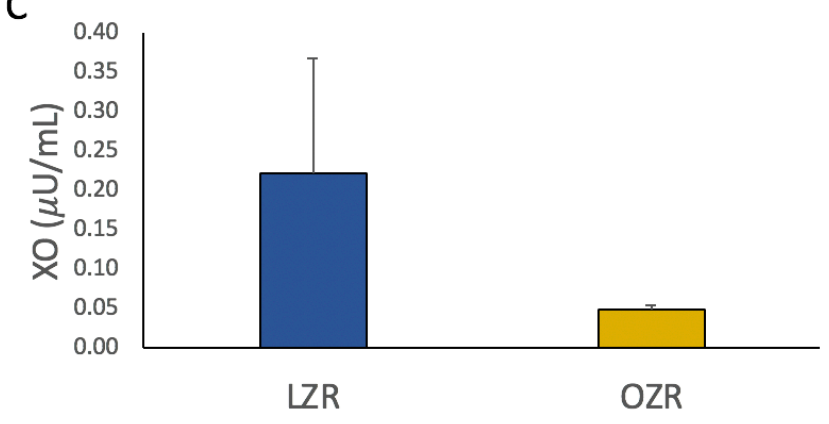

B

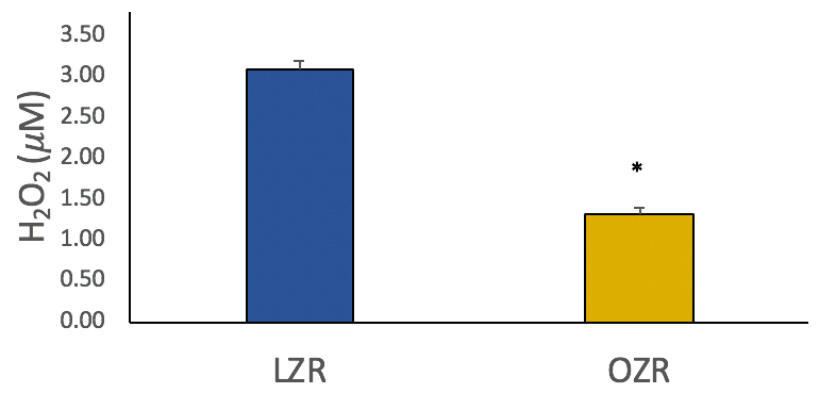

Figure 13 LZR-C vs. OZR-C Nitrate/nitrite, $\mathrm{NO}$ (A), hydrogen peroxide, $\mathrm{H}_{2} \mathrm{O}_{2}$ (B), and superoxide, $\mathrm{XO}(\mathrm{C}) .{ }^{*} \mathrm{p}<0.05$ 
The effects of stress alone and in combination with obesity on the pancreatic proinflammatory environment and level of apoptosis

Stress, alone (LZR-S) and in combination with obesity (OZR-S), did not cause a significant increase in TXNIP when compared with matched controls (Figure 14A and 16A). No cytokines, including TNF- $\alpha$, IL-1 $\beta$, IL-4, IL-5, and IL10, were significantly different in LZR-S compared to LZR-C (Figure 14B-F). In OZR-S, TNF $\alpha$ ( $\mathrm{p}=0.03$ ), IL-4 ( $\mathrm{p}=0.02)$, and IL-6 $(\mathrm{p}=0.01)$ concentrations were lower when compared to OZR-C (Figure 16B, D, and F). IL-1 $\beta$ and IL-10 concentrations were not different in OZR-S compared to OZR-C (Figure 16C and E). Hydrogen peroxide was decreased in LZR-S and OZR-S when compared to their respective controls $(\mathrm{p}=0.00)$, although no other markers of oxidative stress were not significantly different between these groups. (Figure 15 and 17A-C). No changes in apoptosis were seen between any of these groups.
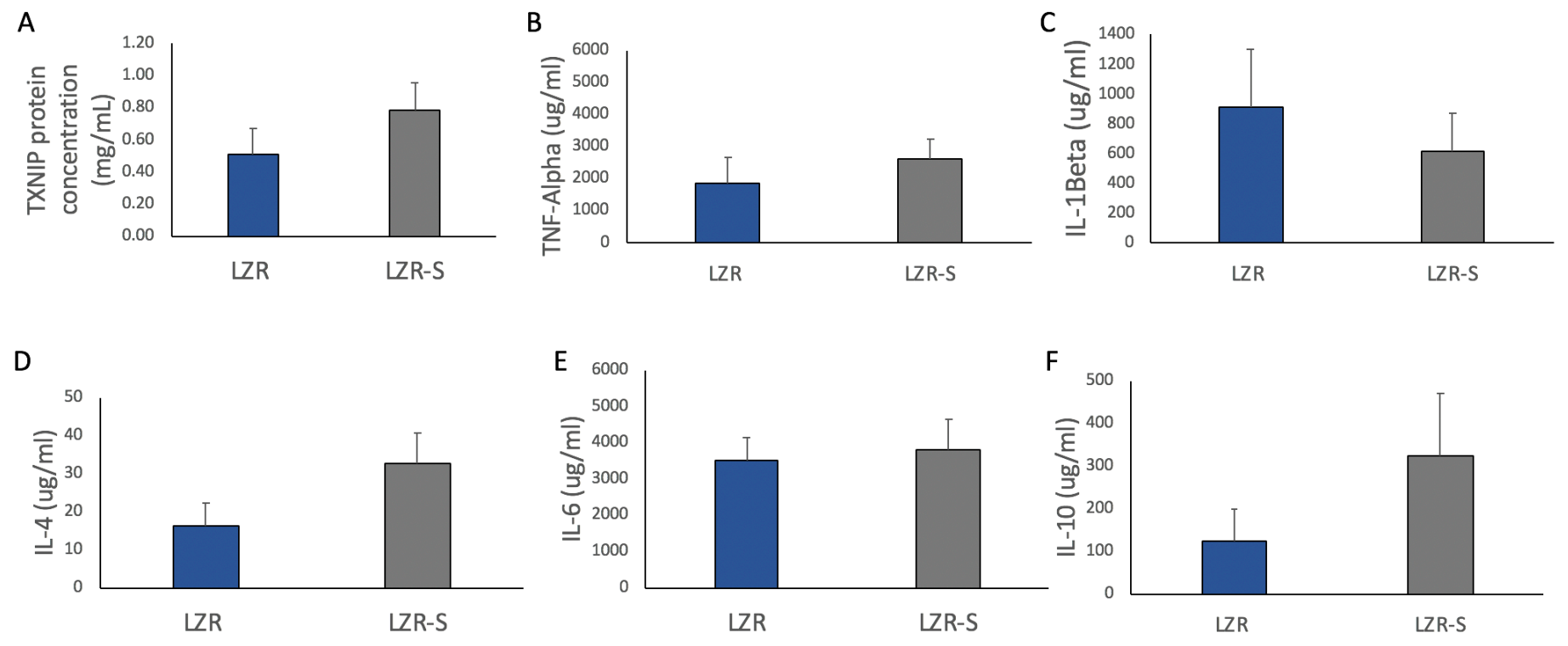

Figure 14 LZR-C vs. LZR-S mean TXNIP (A), TNF- $\alpha$ (B), IL-1 $\beta$ (C), IL-4 (D), IL-6 (E), IL$10(\mathrm{~F})$ concentration. ${ }^{*} \mathrm{p}<0.05$ vs control group within same strain. 


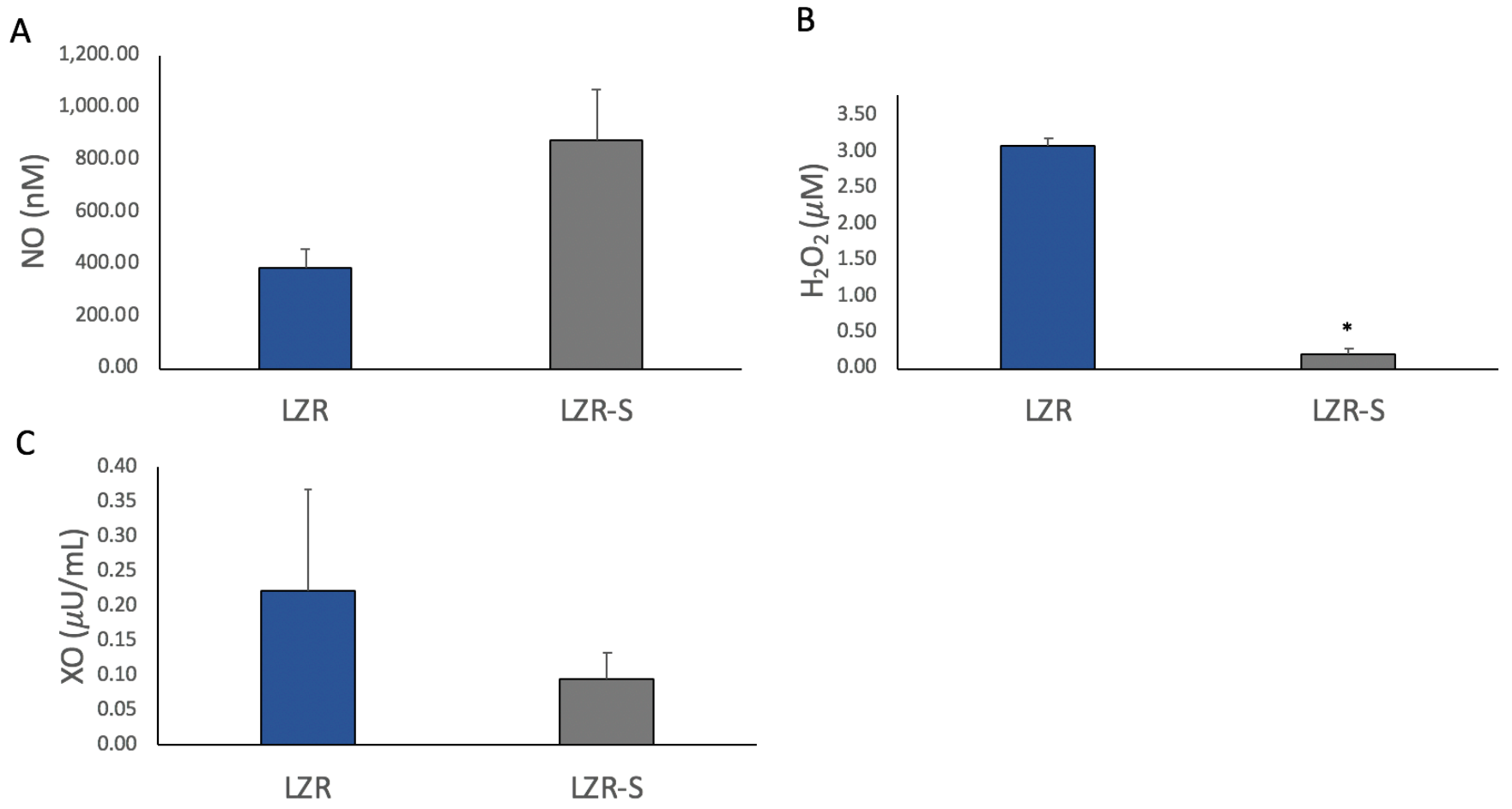

Figure 15 LZR-C vs. LZR-S Nitrate/nitrite, $\mathrm{NO}$ (A), hydrogen peroxide, $\mathrm{H}_{2} \mathrm{O}_{2}$ (B), and superoxide, $\mathrm{XO}(\mathrm{C}) .{ }^{*} \mathrm{p}<0.05$
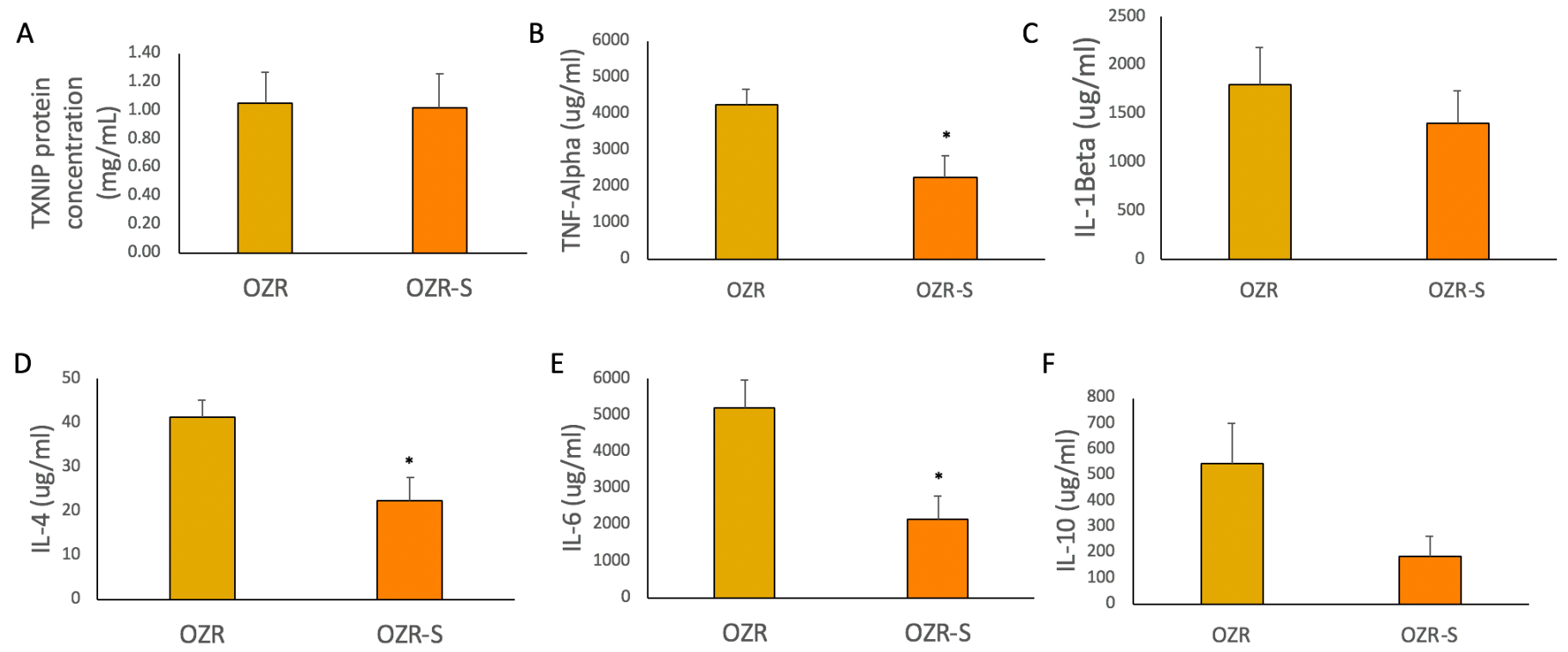

Figure 16 OZR-C vs. OZR-S mean TXNIP (A), TNF- $\alpha$ (B), IL-1 $\beta$ (C), IL-4 (D), IL-6 (E), IL10 (F) concentration. ${ }^{*} \mathrm{p}<0.05$ vs control group within same strain. 
A

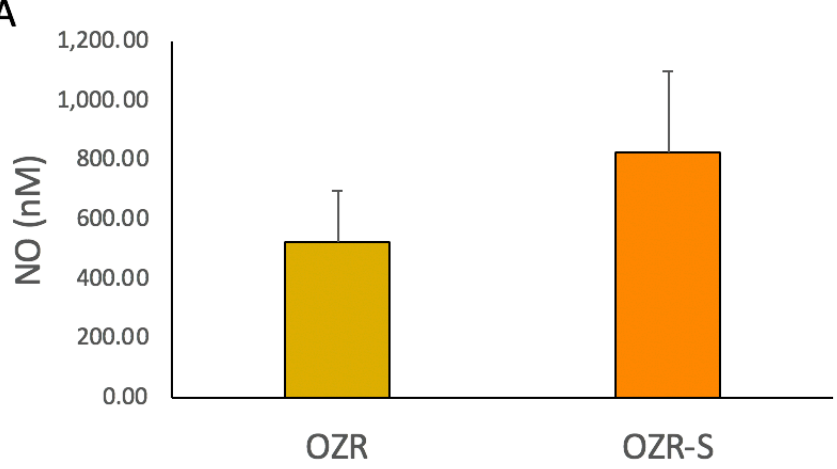

C

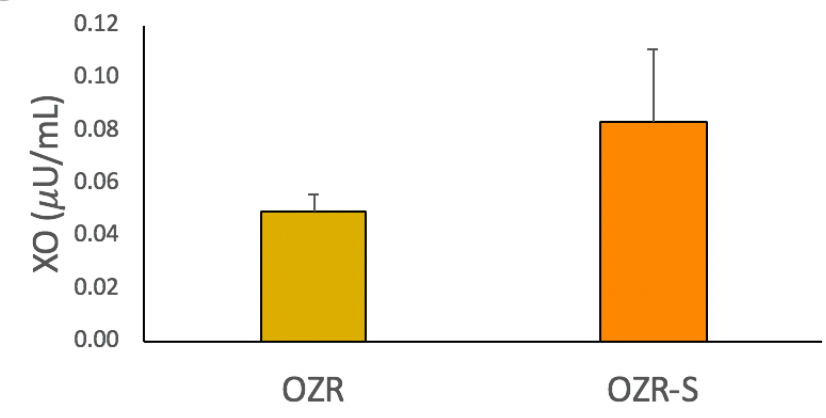

B

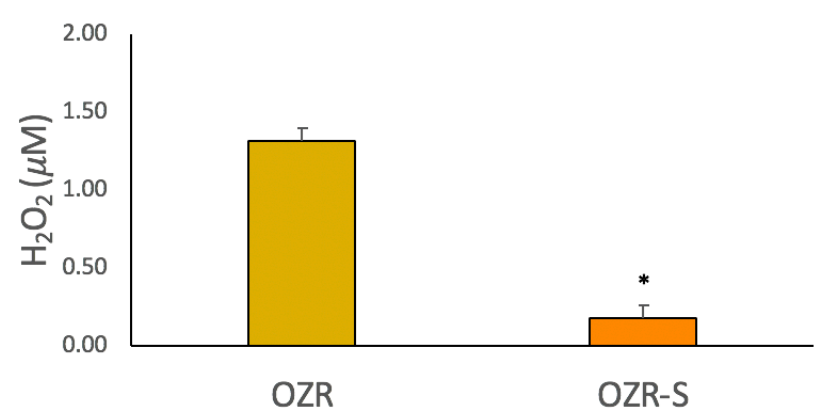

Figure 17 OZR-C vs. OZR-S Nitrate/nitrite, $\mathrm{NO}$ (A), hydrogen peroxide, $\mathrm{H}_{2} \mathrm{O}_{2}$ (B), and superoxide, $\mathrm{XO}(\mathrm{C}) .{ }^{*} \mathrm{p}<0.05$

The effects of exercise training on the obesity and stress related changes to the pancreatic proinflammatory environment and level of apoptosis

TXNIP was not significantly different in OZR-EX versus OZR-C (Figure 18A). IL-4 $(p=0.03)$ and IL-6 $(p=0.03)$ were significantly lower (Figure 18D and F), while IL-10 $(p=0.06)$ and TNF- $\alpha(\mathrm{p}=0.07)$ were trending lower in OZR-EX compared to OZR-C (Figure 18B and E). IL-1 $\beta$ concentration was not significantly different between these two groups (Figure 18C). Although hydrogen peroxide was shown to be lower in OZR-EX versus OZR-C ( $p=0.00)$, no other markers of oxidative stress were different (Figure 19A-C). 
A

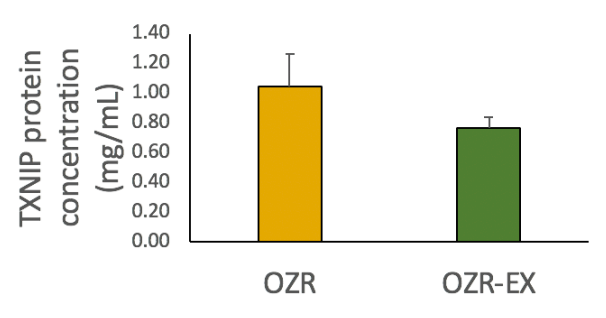

D

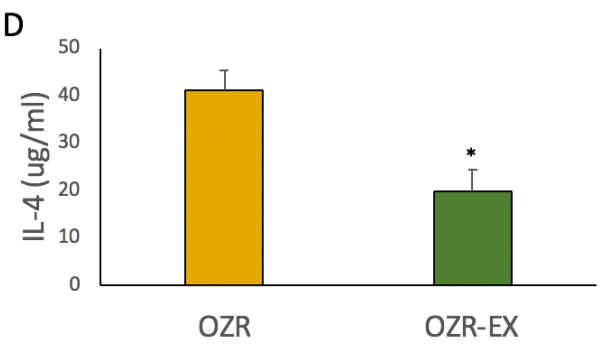

B

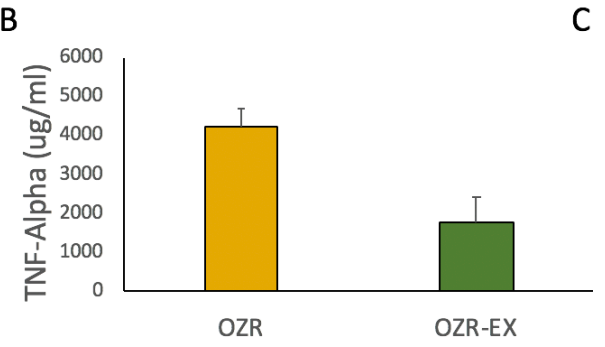

C

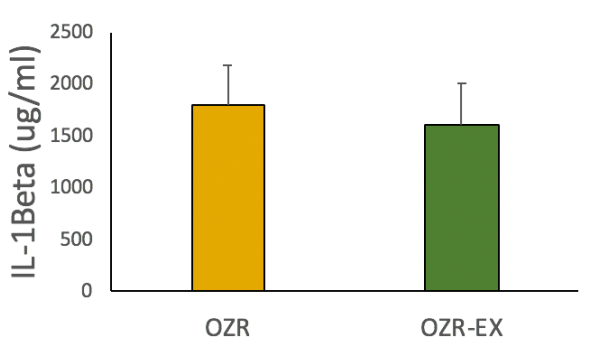

E
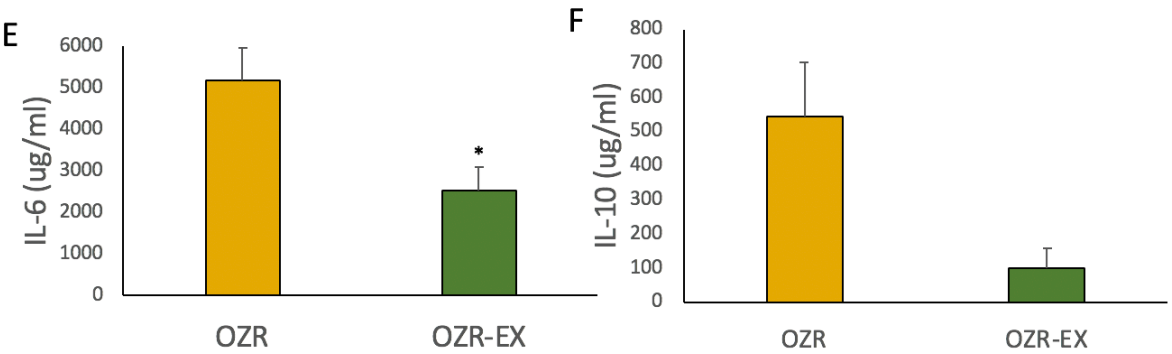

Figure 18 OZR-C vs. OZR-EX mean TXNIP (A), TNF- $\alpha$ (B), IL-1 $\beta$ (C), IL-4 (D), IL-6 (E), IL-10 (F) concentration. ${ }^{*} \mathrm{p}<0.05$ vs control group within same strain.
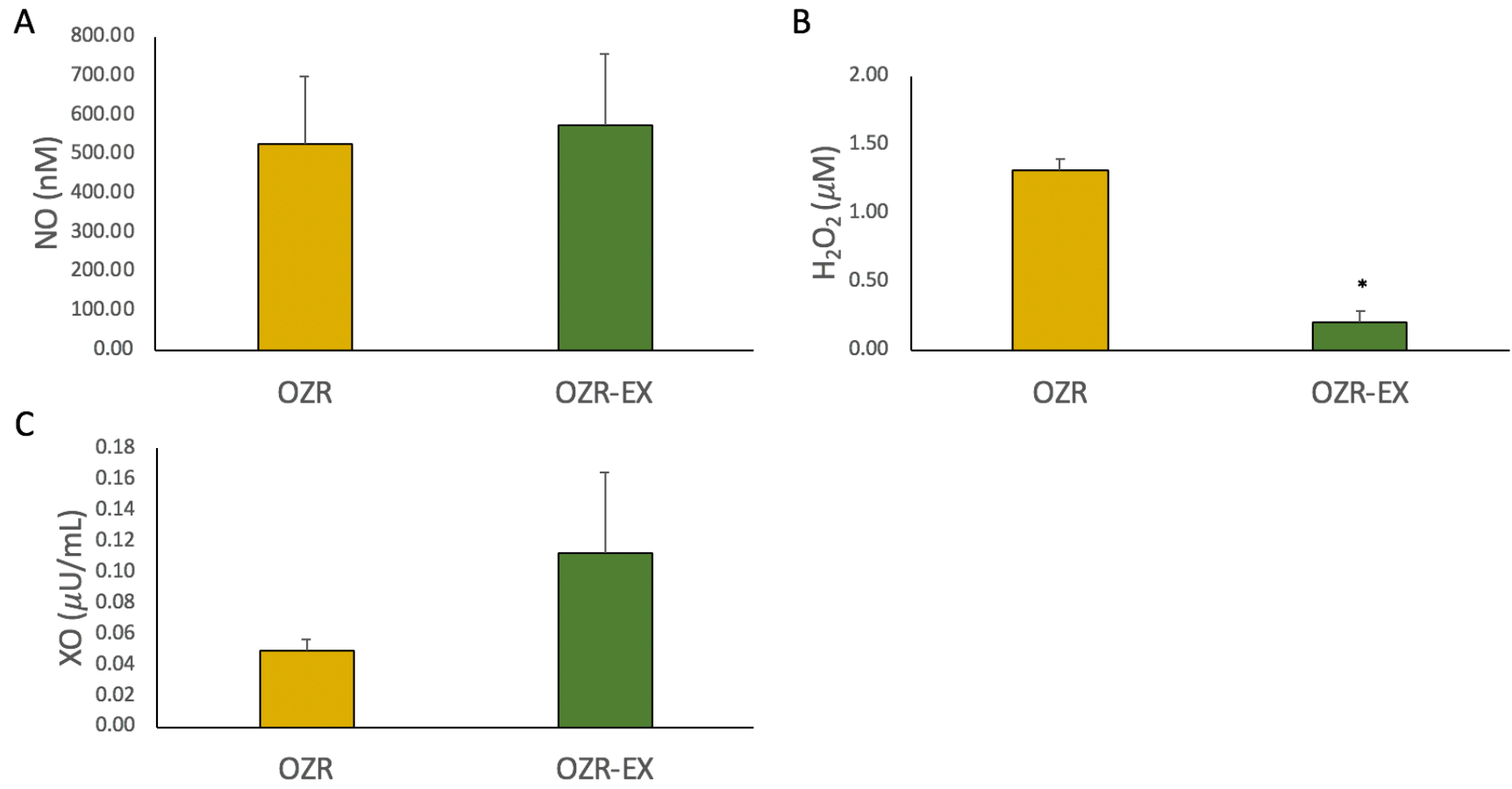

Figure 19 LZR-C vs. LZR-S Nitrate/nitrite, $\mathrm{NO}$ (A), hydrogen peroxide, $\mathrm{H}_{2} \mathrm{O}_{2}(\mathrm{~B})$, and superoxide, $\mathrm{XO}(\mathrm{C}) .{ }^{*} \mathrm{p}<0.05$ 
TXNIP ( $\mathrm{p}=0.01$ ) was significantly lower in LZR-EXS compared to LZR-S (Figure 20A), but no significant differences were seen in the proinflammatory cytokines TNF- $\alpha$, IL-1 $\beta$, IL-4, IL-6, or IL-10 concentrations between LZR-EXS and LZR-S (Figure 20B-F). Nitrate/nitrite activity was lower, and hydrogen peroxide was higher in LZR-EXS compared to LZR-S ( $\mathrm{p}=0.02)$, while superoxide was not different (Figure 21A-C).The mean TXNIP in OZR-EXS tended to be lower $(\mathrm{p}=0.10)$ compared with OZR-S (Figure 22A). TNF- $\alpha$, IL-1 $\beta$, IL-4, IL-6, and IL-10 concentrations were not significantly different in OZR-EXS versus OZR-S (Figure 22B-F). Nitrate/Nitrite activity was lower in OZR-EXS versus OZR-S ( $\mathrm{p}=0.02$ ), although no other oxidative stress measures saw significant differences (Figure 23A-C). No apoptosis was see with any exercise groups.

A
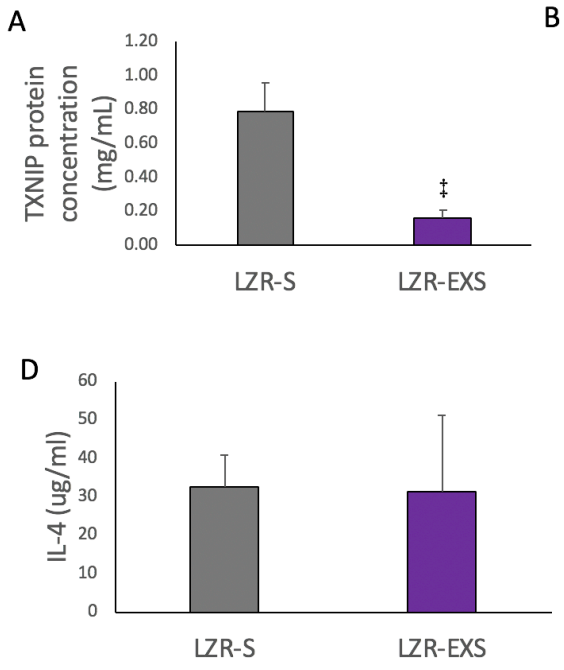

B
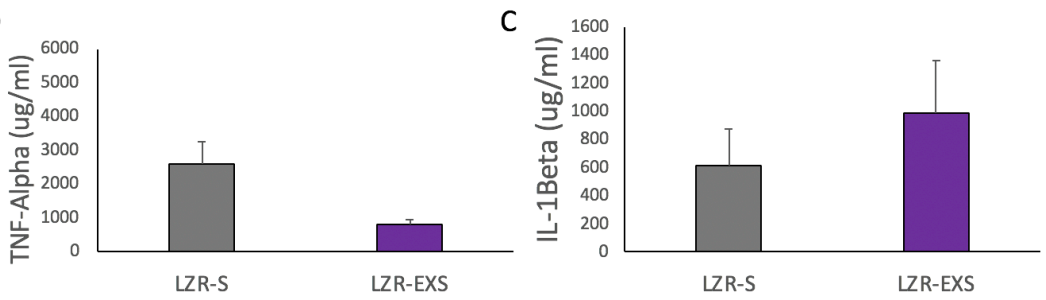

$E$

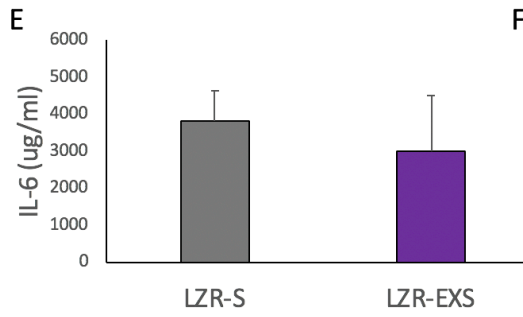

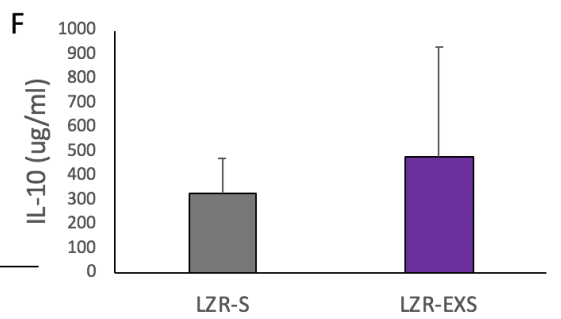

Figure 20 LZR-S vs. LZR-EXS mean TXNIP (A), TNF- $\alpha$ (B), IL-1 $\beta$ (C), IL-4 (D), IL-6 (E), IL-10 (F) concentration. $\$ \mathrm{p}<0.05$ vs. UCMS group within strain. 
A

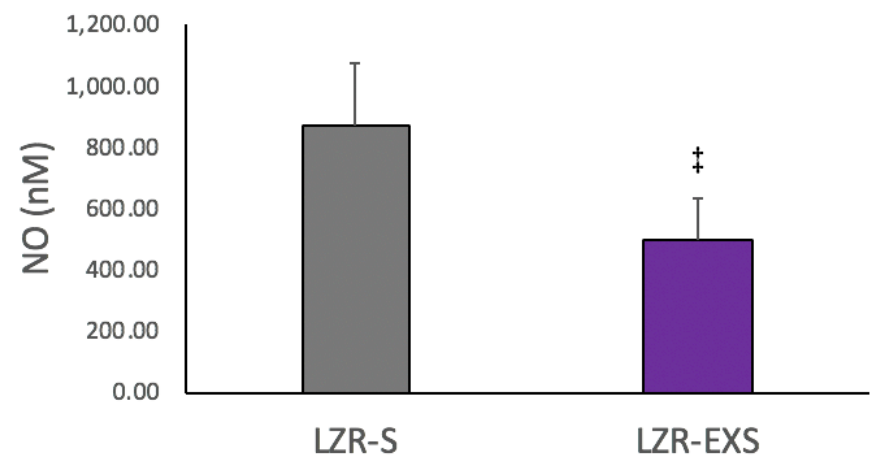

C

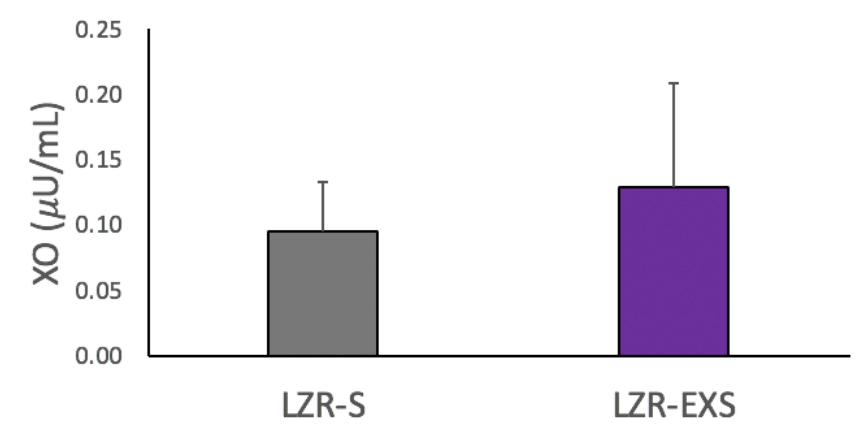

B

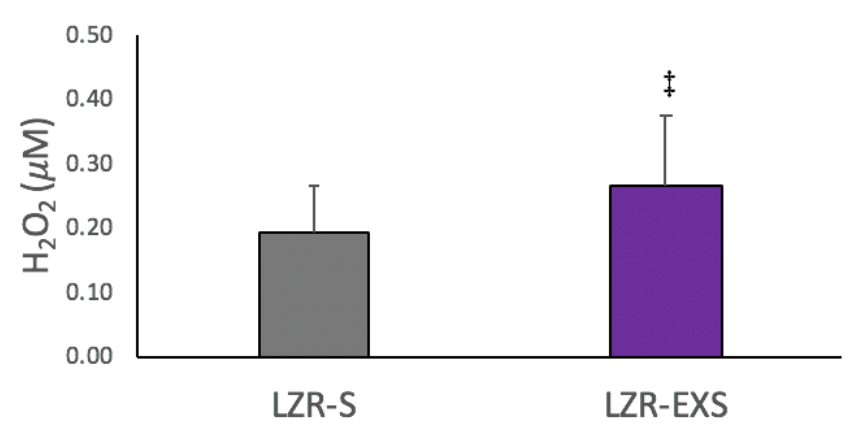

Figure 21 LZR-C vs. LZR-S Nitrate/nitrite, $\mathrm{NO}$ (A), hydrogen peroxide, $\mathrm{H}_{2} \mathrm{O}_{2}$ (B), and superoxide, $\mathrm{XO}(\mathrm{C}) . \$ \mathrm{p}<0.05$
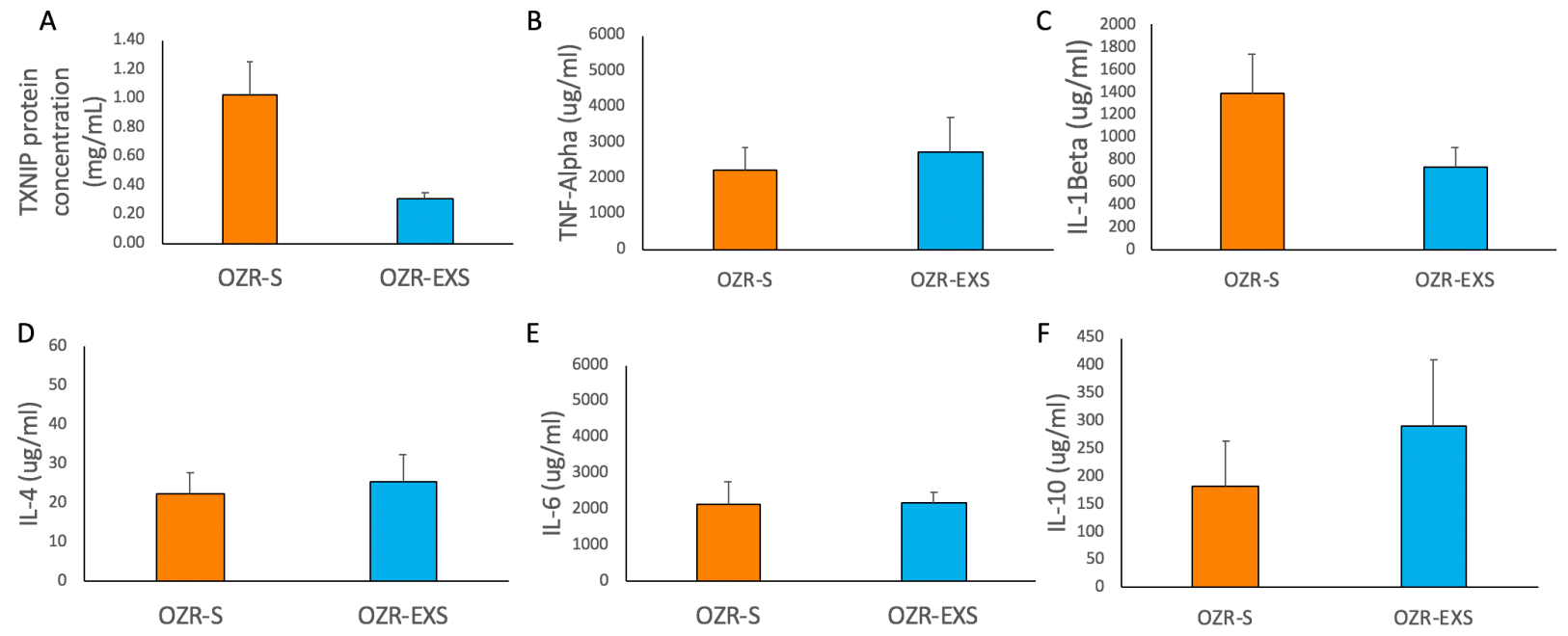

Figure 22 OZR-S vs. OZR-EXS mean TXNIP (A), TNF- $\alpha$ (B), IL-1 $\beta$ (C), IL-4 (D), IL-6 (E), IL-10 (F) concentration. $\$ \mathrm{p}<0.05$ vs. UCMS group within strain. 
A

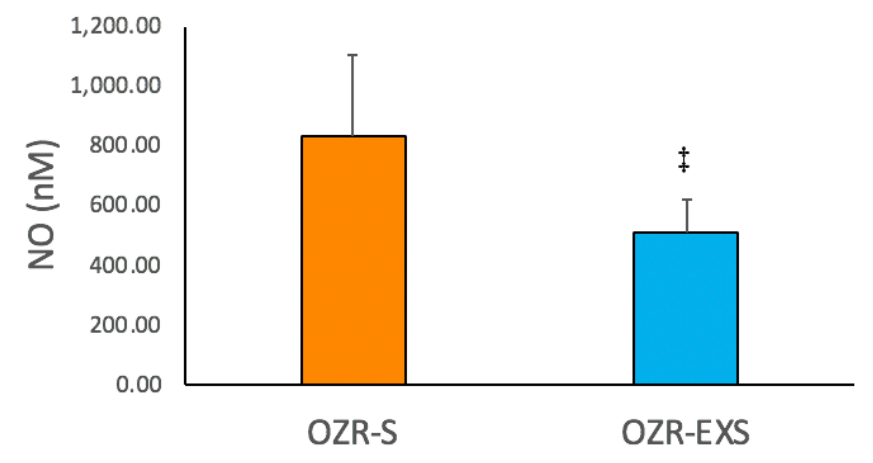

C

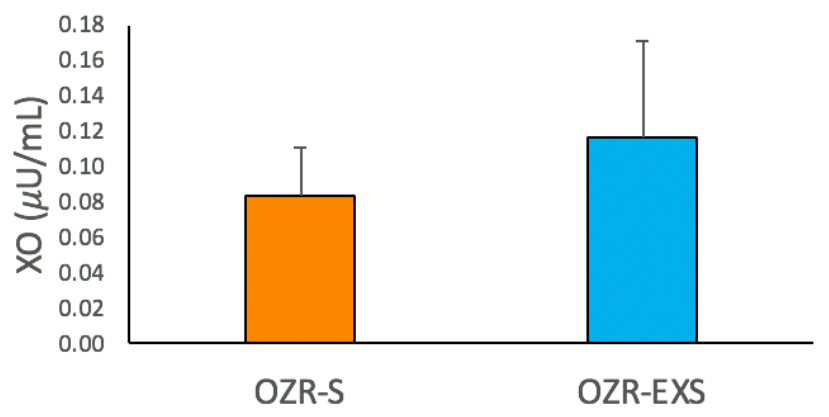

B

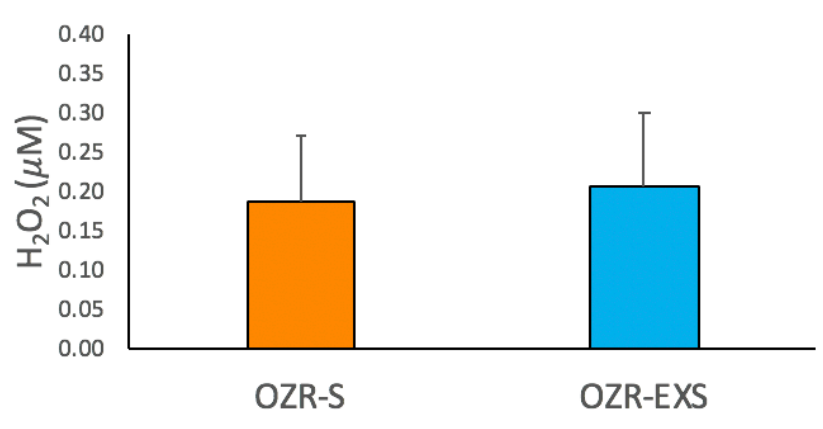

Figure 23 LZR-C vs. LZR-S Nitrate/nitrite, $\mathrm{NO}$ (A), hydrogen peroxide, $\mathrm{H}_{2} \mathrm{O}_{2}$ (B), and superoxide, $\mathrm{XO}(\mathrm{C}) . \$ \mathrm{p}<0.05$ 


\section{CHAPTER 5: DISCUSSION}

The primary purpose of this study was to determine the effects of obesity, chronic stress and exercise training on pancreatic morphology and health. We hypothesized that obesity would decrease the number of pancreatic $\beta$-cells, the $\beta$-cell to $\alpha$-cell ratio, and islet area. A primary finding of this study was that obesity did not result in an decrease in $\beta$-cell number but instead was associated with increases in $\beta$-cell number, $\alpha$-cell number, and islet area. With pancreatic $\beta$ cell and $\alpha$-cell numbers increasing, this lead to no change in the $\beta$-cell to $\alpha$-cell ratio. Islet area may have increased to compensate for increases in both $\beta$-cell and $\alpha$-cell numbers, and did so at a greater magnitude as indicated by the lower $\beta$-cell density in the obese animals. Previous research has shown that there are five stages to developing insulin resistance: compensation, stable adaptation, unstable early decompensation, stable decompensation, and severe decompensation. ${ }^{42}$ Given that pancreatic $\beta$-cell numbers were higher with obesity in this study, it can be suggested that the obese animals were in an early compensation stage of insulin resistance. This is further supported by the fact that plasma insulin was higher in the obese animals. The insulin producing pancreatic $\beta$-cells may have been undergoing hyperplasia to control for the higher levels of glucose also seen in the obese animals. Although the glucose measurement, $184 \mathrm{mg} \mathrm{dl}^{-1}$ could suggest that the rats were further along than the compensation phase, this was not a fasted measurement and was only taken at the time of the termination surgery. In order to compensate for increases in $\beta$ - and $\alpha$-cell numbers, islet area also increased in the obese animals. Previous research has suggested that obesity leads to a reduced $\beta$-cell to $\alpha$ cell ratio due to $\beta$-cell apoptosis with no real change to $\alpha$-cell numbers. ${ }^{40}$ However, this would most likely occur during later phases of decomposition, when the pancreatic $\beta$-cells begin experiencing elevated apoptosis and greater sustained fasted glucose levels than observed in the 
present study. ${ }^{40,42}$ Our results showed very little apoptosis in the obese animals and no differences compared with controls again indicating an earlier stage of decompensation. Although these results differ from those of Shimabukuro et al ${ }^{89}$ who reported that apoptosis occurred during the early stages of diabetes development in obese homozygous $(f a / f a)$ male ZDF, they are consistent with those found that in human pancreas from obese individuals during autopsies. ${ }^{93}$ In the latter study, $\beta$-cell mass was actually increased with obesity. ${ }^{93}$

We also hypothesized that chronic stress would negatively alter the morphology of the pancreas. However, no significant differences were observed between stress and controlled rats in the number of $\beta$ - and $\alpha$-cells, islet area, or the $\beta$-cell to $\alpha$-cell ratio. The $\alpha$-cell density did increase in the lean stress environment, which can be a result of the small decrease seen in islet area, though that decrease was not significant. We further hypothesized that stress in combination with obesity would have a combined deleterious effect on the pancreatic $\beta$-cell and $\alpha$-cell numbers, islet area, and $\beta$-cell to $\alpha$-cell ratio. However, the combined effect only had a deleterious effect on the $\alpha$-cell numbers. The fact that obesity and chronic stress had little negative effects on pancreatic morphology was further confirmed by the absence of pancreatic apoptosis in each of these conditions. Plasma insulin levels at the time of surgery were higher in the stressed, obese animals, again suggesting that $\beta$-cells were still able to compensate for the elevated glucose plasma levels that were seen in the stressed, obese animals. Altogether this can suggest that these animals were in the early compensation phase of the pathway to insulin resistance. $^{42}$

Chronic stress which leads to elevated levels of GCs can result in damage to the pancreas that can lead to insulin resistance, hyperinsulinemia, and hyperglycemia. ${ }^{5,9,98,109}$ Humans subjected to chronic GC treatment ( $>14$ days) showed decreases in insulin secretion when 
subjected to a glucose challenge. This impairment in insulin action could suggest an indirect loss in pancreatic $\beta$-cell function or suppression of the release of insulin by pancreatic $\beta$-cells. ${ }^{110,111}$ Rats exposed to eight weeks of UCSM did in fact, have significantly elevated corticosteroid and glucose levels. However, the UCMS protocol used in the current study produced very few morphological changes to the pancreas and was not associated with a loss of $\beta$-cells. These results go against the belief that GCs cause metabolic and morphological attenuations to the pancreatic $\beta$-cells. ${ }^{20,112}$ It is possible that the level of stress used in the current study was too low to produce the morphological changes to the pancreas often seen in other models. The stress method used by Zhou et $a l^{155}$ that resulted in increases in TXNIP within the hippocampus and frontal cortex with stress, utilized a much more intense protocol, including foot shock, tail clamp, and cold water swimming. Give that our UCMS model was a mild stress model, this may suggest that a longer duration is required to see these negative effects at the level of the pancreas.

Chronic exercise has been shown to improve physical attributes of health, including reduced blood pressure, enhanced cardiovascular fitness, increased insulin sensitivity, reduced abdominal adiposity, and prevention of chronic diseases, such as obesity. ${ }^{157,158}$ We hypothesized that the addition of eight weeks of treadmill running would attenuate obesity-related changes in $\beta$-cell numbers, the $\beta$-cell to $\alpha$-cell ratio, and islet area. Exercise training in the obese animals was associated with decreases in $\alpha$-cell numbers and islet area, but increases in $\beta$-cell to $\alpha$-cell ratio. Eight weeks of treadmill running was associated with lower body weights in both obese and lean animals compared with controls. This was associated with slightly lower glucose and corticosterone levels, both of which are known to stimulate $\beta$-cell proliferation and islet growth. It is possible that many of the deleterious physiological effects associated with obesity were 
blunted in the trained rats, which provided less stress on the pancreas leading to reduced cell and islet proliferation.

It was also hypothesized that eight weeks of treadmill running would attenuate the stressrelated morphological changes to the pancreas. The UCSM protocol used in this study, shown to be effective by increased coat scores in the stress animals, produced only a few measured morphological changes to pancreas even when combined with obesity. However, when combined with exercise, stressed animals had greater numbers of $\beta$ - and $\alpha$-cells and a larger islet area when compared with the stressed only rats. This effect may represent either a reversal of the minor stress-induced decreases to the pancreas (e.g., smaller islet area) or more likely, a greater stimulation for pancreatic growth. Although exercise training has been shown to reduce stress, the model used in the current study required animals to be stimulated to run. ${ }^{169,172,173}$ Animals, which simultaneously underwent the UCMS protocol, may have been conditioned to perceive the treadmill running as an additional stressor. The UCSM protocol induces stress that presents similar behaviors to that of depression in rodents, presenting itself such that rodents show anhedonia-like behavior and other behaviors that suggest depression is present. ${ }^{112,146,148}$ Although HPA-axis activity decreased in rats exposed to low-intensity stressors with six-weeks of intermittent, voluntary wheel running, forced treadmill running when combined with the UCMS may have caused greater levels of corticosteroid release and a greater stimulation of pancreatic growth. ${ }^{170,171}$ Interesting, corticosteroid was slightly higher in the LZR-EXS compared with the LZR-EX rats, supporting this idea.

Obesity and chronic stress have been shown to result in a proinflammatory environment within the host. ${ }^{7}, 17,99,117,130,131$ TXNIP is a proapoptotic protein associated with increased oxidative stress and apoptosis, specifically $\beta$-cell apoptosis within the pancreas. ${ }^{24,25,185}$ 
According to previous research, obesity and chronic stress are associated with increases in TXNIP throughout different parts of the body. ${ }^{155,184,185,187,188,189}$ Based on this research, we hypothesized that TXNIP would increase with obesity in the pancreas, and our findings indicated that TXNIP was elevated, although not significantly, in the obese versus lean rats. We also hypothesized that obesity would be associated with an increased proinflammatory environment. Our results showed that the proinflammatory cytokine TNF- $\alpha$ was significantly elevated in the obese animals, although IL-1 $\beta$ was not. Previous research has suggested that both TNF- $\alpha$ and IL$1 \beta$ increase in conjunction with obesity. ${ }^{7,10,22,27,28}$ IL-1 $\beta$ did appear to be somewhat elevated with obesity in the present study, but this elevation did not reach significance compared with controls. IL-1 $\beta$ is a proinflammatory cytokine, primarily produced by the NLPR3 inflammasome and triggered by TXNIP. ${ }^{22,27,189,190}$ Since we did not see a significant increase in TXNIP, it can be suggested that IL-1 $\beta$ would also not be significantly increased. IL-4, a cytokine that can act acutely as an anti-inflammatory cytokine and chronically as a proinflammatory cytokine, was increased with obesity; IL-4 works to increase macrophage activation to combat foreign substances, but IL-4 can chronically stimulate inflammation. ${ }^{194}$ IL6, a cytokine acting as either anti-inflammatory or proinflammatory depending on the tissue of origin, was not effected by obesity. ${ }^{13,67,68,69}$ Finally, IL-10 concentrations, an anti-inflammatory cytokine, had an increasing trend in the obese animals. ${ }^{13,70}$ These results may suggest that there was an increase in the proinflammatory environment of the obese animals, and that an antiinflammatory response was reacting to reduce this inflammation. Obesity has been shown to induce a phenotypic change in macrophage polarization, from $\mathrm{M}_{2}$ to $\mathrm{M}_{1} \cdot{ }^{13,65}$ During this shift, it would be reasonable to see both proinflammatory and anti-inflammatory cytokines upregulated as the environment is shifting from $\mathrm{M}_{1}$ to $\mathrm{M}_{2}$. 
We hypothesized that eight weeks of UCMS alone and in combination with obesity would increase pancreatic TXNIP, proinflammatory cytokines, and apoptosis and decrease antiinflammatory cytokines. TXNIP was not shown to be increased in the pancreas by either chronic stress alone, or in combination with obesity. The fact that we did not see a difference in TXNIP between the LZR-S and LZR-C indicates that the UCMS protocol alone was either not stressful enough or too short to produce an effect within the pancreas. Previous research has reported that rodents that experienced chronic stress had significantly elevated TXNIP expression in the hypothalamus and frontal cortex when compared to control mice. It was proposed that increases in corticosterone due to stress lead to these increases in TXNIP and its downstream regulators. ${ }^{155}$ A study done with INS1 $\beta$-cells and human and mouse pancreatic islets demonstrated that treatment with glucocorticosteroids led to increases in TXNIP expression, and that expression was even more pronounced than in hyperglycemic conditions. ${ }^{187}$ Although circulating corticosteroid and glucose were higher in the LZR-S versus LZR-C animals, these values may not have reached the level necessary to cause an elevation in pancreatic TXNIP in the stressed animals. Furthermore, no cytokines, including TNF- $\alpha$, IL-1 $\beta$, IL-4, IL-6, and IL10, were changed with chronic stress alone. These results were further confirmed when comparing OZR-S to OZR-C. In combination with obesity, TNF- $\alpha$, IL-4, and IL-6 were actually decreased in the obese stressed rats, while IL-10 and IL-1 $\beta$ were not changed. These results were highly surprising and seem to indicate a unique interaction between the two treatments. It must be noted that the cytokines were measured within the pancreas lysates. Future research should examine the level of stress necessary to see changes to the proinflammatory environment within the pancreas independent of other conditions. 
Although we hypothesized that eight weeks of treadmill running would decrease TXNIP, proinflammatory cytokines concentrations, and indices of apoptosis in combination with obesity, our results showed that TXNIP and IL-1 $\beta$ was not different between OZR-EX and OZR-C. However, obese animals which underwent eight weeks of treadmill running did have lower TNF$\alpha$, IL-4 and IL-6, cytokines that can be proinflammatory, and lowering trends in IL-10, an antiinflammatory cytokine. ${ }^{13,56,70}$ When combined with the fact that treadmill running was associated with reduced $\alpha$-cell numbers and smaller islet, this seems to indicate that our exercise training was sufficient to limit some of the deleterious effects of obesity. Brunn et al showed that 15 weeks of hypocaloric diet and daily exercise resulted in decreases in circulating proinflammatory cytokines and decreases in adipose tissue expression of inflammatory markers, like IL-6 and TNF- $\alpha .{ }^{163}$ Given our exercise protocol was only eight weeks, it is promising to see that there are already lowering cytokine levels.

Treadmill running in combination with chronic stress was hypothesized to attenuate the stress-induced increases in TXNIP, proinflammatory cytokines, and apoptosis. However, as previously mentioned, stress alone produced very few negative effects within the pancreas. When combined with treadmill running, only TXNIP was lower in LZR-EXS compared with LZR-S animals. No differences were seen with any cytokine concentrations, including TNF- $\alpha$, IL-1 $\beta$, IL-4, IL-6, or IL-10. It is interesting that no differences were observed in the proinflammatory environment between those animals who underwent eight weeks of UCMC and treadmill running verses UCMS alone. These results do seem to go along with our findings that the combined treatment caused enhanced pancreatic growth. We speculate that the latter was caused by a combination of the stimulatory effects of enhanced circulating glucocorticoids and possibly glucose, and a pancreatic environment conducive to growth. Associated with this idea 
was the fact that TXNIP was lowered in the combined group. This would have led to a reduced environment for apoptosis, possibly allowing $\beta$ cells to proliferate and islets to grow. The fact that the oxidative stress marker $\mathrm{H}_{2} \mathrm{O}_{2}$ was higher in LZR-EXS animals may indicate that the combined treatment was more stimulatory to the pancreas. However, these results must be taken with caution as oxidative stress was measured on frozen not fresh tissue.

We further hypothesized that eight weeks of treadmill running would attenuate the combined effects of obesity and UCMS on pancreatic increases in TXNIP, proinflammatory cytokines, and apoptosis and decreases in anti-inflammatory cytokines. TXNIP concentration did show a decreasing trend with exercise, although there were no differences in any of the cytokines, including TNF- $\alpha$, IL-1 $\beta$, IL-4, IL-6, and IL-10. This would again indicate that the UCSM protocol used in the present student may have been ineffective in causing negative changes within the pancreas.

The stress-induced increases in TXNIP in the hippocampus and frontal cortex in mice, was associated with increases in corticosterone, a key regulator of TXNIP. ${ }^{155}$ Corticosterone followed the TXNIP pattern in the current study, increasing with obesity and decreasing with exercise training. UCMS also increased corticosterone significantly in both genotypes although TXNIP was not significantly increased with chronic stress. This again would indicate that obesity, more so than the UCMS used in the current study, was able to alter specific hormones and proteins know to have an effect on pancreatic morphology and health.

Although TXNIP, a proapoptotic protein, was increased in some incidences in this study, there were no signs of apoptosis, as confirmed through multiple methods. This could suggest that downstream markers of this proapoptotic pathway, such as p-ASK-1, were not yet activated in the cascade to cell death. 


\section{CONCLUSION}

In conclusion, in a model of obesity and metabolic syndrome, the pancreas appeared to be stimulated to grow as indicated by greater numbers of $\beta$ - and $\alpha$-cells and larger islets even in the presence of slightly higher pancreatic TXNIP and TNF- $\alpha$. Since apoptosis was not observed, it can be suggested that the proapoptotic-TXNIP pathway in the pancreas may take more time than we allotted to reach a true proapoptotic phase. Eight weeks of treadmill exercise training was shown to attenuate some of the obesity-induced morphological and proinflammatory changes within the pancreas. It did not however appear to reduce TXNIP. Eight weeks of UCMS alone produced no morphological changes in the pancreas, no alterations in TXNIP, and no changes in the measured proinflammatory cytokines compared with controls. When combined with obesity, we also very few deleterious effects within the pancreas. Exercise training did appear to lower TXNIP in both lean and obese stressed mice. It would appear from this study that a greater stress load or a longer period of stress is necessary to show detrimental effects within the pancreas.

\section{LIMITATIONS AND FUTURE RESEARCH}

A limitation to this study is that data was collected at s a single time-point in the progression of the chronic stress and obesity protocol. When forming a hypothesis, it is impossible to know at what point in the progression of pancreatic health decline the animals may be. Future research should examine the longitudinal effects of both obesity and stress. Another limitation to this study is that pancreatic lysates were made of the whole pancreas tissue homogenates. Although we had desired to isolate the $\beta$-cells and mitochondria of the $\beta$-cells, these procedures could not be done on previously frozen tissue. Results for many of the measured oxidative stress markers were quite surprising and opposite to what has been reported 
in the literature. A major limitation to this data was the fact that these measures were made on frozen not fresh tissue, the preferred method for this analysis. Unfortunately, fresh tissue was unavailable and having only samples from a previous study limits experiments that require fresh tissue. Lastly, it would benefit this study to have more animals, as some of the groups only had 3 or 4 pancreases available.

Future research can be done to evaluate the training relationship with TXNIP and the thioredoxin system. A longevity study can be done to assess at what point pancreatic health (along with other organs) begins to decline and $\beta$-cell numbers begin to change and the role that TXNIP and its downstream agonists play in the development of insulin resistance with this model. Using a model, such as Zucker Fatty Diabetic (ZDF) rat, would be better to assess the effects of TXNIP, given that this model is known to develop pancreatic $\beta$-cell dysfunction and apoptosis. Using the ZDF model in a longevity study, could provide a better understanding of TXNIP's relationship with $\beta$-cell apoptosis and how high feeding, chronic stress fat, and exercise influence outcomes. A TXNIP knockout or overexpressed mouse could be used to better understand the role of TXNIP in apoptosis in the pancreas and other organs and how chronic stress and training influence these effects, though this would be more useful after studies were done with the ZDF rats. These proteins and relationships can also be studied on other organs. Skeletal muscle expression of TXNIP levels and other downstream markers of the TXNIP pathway can be measured to assess if training is changing the periphery environment in a model of metabolic syndrome and chronic stress. 


\section{REFERNECES}

1. (ADA) ADA. Statistics About Diabetes.

2. Pedroza-Tobias A, Trejo-Valdivia B, Sanchez-Romero LM, Barquera S. Classification of metabolic syndrome according to lipid alterations: Analysis from the Mexican National Health and Nutrition Survey 2006. BMC Public Health. 2014. doi:10.1186/1471-2458-141056

3. Moore JX, Chaudhary N, Akinyemiju T. Metabolic Syndrome Prevalence by Race/ Ethnicity and Sex in the United States, National Health and Nutrition Examination Survey, 1988-2012 PEER REVIEWED. Natl Heal Nutr Exam Surv. 1988;14:160287. doi: $10.5888 / \mathrm{pcd} 14.160287$

4. Christensen CS, Christensen DP, Lundh M, et al. Skeletal muscle to pancreatic $\beta$-cell cross-talk: The effect of humoral mediators liberated by muscle contraction and acute exercise on $\beta$-cell apoptosis. J Clin Endocrinol Metab. 2015;100(10):E1289-E1298. doi: $10.1210 /$ jc. $2014-4506$

5. Beaudry JL, D’souza AM, Teich T, Tsushima R, Riddell MC. Exogenous glucocorticoids and a high-fat diet cause severe hyperglycemia and hyperinsulinemia and limit islet glucose responsiveness in young male Sprague-Dawley rats. Endocrinology. 2013;154(9):3197-3208. doi:10.1210/en.2012-2114

6. Prevention C for DC and. Adult Obesity Facts.

7. Jung U, Choi M-S. Obesity and Its Metabolic Complications: The Role of Adipokines and the Relationship between Obesity, Inflammation, Insulin Resistance, Dyslipidemia and Nonalcoholic Fatty Liver Disease. Int J Mol Sci. 2014;15(4):6184-6223. doi:10.3390/ijms15046184

8. Dandona P, Aljada A, Bandyopadhyay A. Inflammation: the link between insulin resistance, obesity and diabetes. Trends Immunol. 2004. doi:10.1016/j.it.2003.10.013

9. Beaudry JL, D'souza AM, Teich T, Tsushima R, Riddell MC. Exogenous glucocorticoids and a high-fat diet cause severe hyperglycemia and hyperinsulinemia and limit islet glucose responsiveness in young male Sprague-Dawley rats. Endocrinology. 2013. doi:10.1210/en.2012-2114

10. Wensveen FM, Jelenčić V, Valentić S, et al. NK cells link obesity-induced adipose stress to inflammation and insulin resistance. Nat Immunol. 2015;16(4):376-385.

doi: $10.1038 /$ ni. 3120

11. Pickup JC. Inflammation and activated innate immunity in the pathogenesis of type 2 diabetes. Diabetes Care. 2004. doi:10.2337/diacare.27.3.813

12. Romacho T, Elsen M, R??hrborn D, Eckel J. Adipose tissue and its role in organ crosstalk. Acta Physiol. 2014;210(4):733-753. doi:10.1111/apha.12246

13. Lauterbach MAR, Wunderlich FT. Macrophage function in obesity-induced inflammation and insulin resistance. Pflügers Arch - Eur J Physiol. 2017;469(3-4):385-396. doi:10.1007/s00424-017-1955-5

14. Chrousos $\mathrm{G}$. The role of stress and the hypothalamic \pm pituitary \pm adrenal axis in the pathogenesis of the metabolic syndrome : neuro-endocrine and target tissue-related causes. Int J Obes. 2000;6:50-55.

15. Mezuk B, Eaton WW, Albrecht S, Golden SH. Depression and type 2 diabetes over the lifespan: A meta-analysis. Diabetes Care. 2008;31(12):2383-2390. doi:10.2337/dc080985

16. Tian R, Hou G, Li D, Yuan TF. A possible change process of inflammatory cytokines in 
the prolonged chronic stress and its ultimate implications for health. Sci World J. 2014. doi: $10.1155 / 2014 / 780616$

17. Cohen S, Janicki-Deverts D, Doyle WJ, et al. Chronic stress, glucocorticoid receptor resistance, inflammation, and disease risk. Proc Natl Acad Sci. 2012;109(16):5995-5999. doi:10.1073/pnas.1118355109

18. Obesity S of. National Obesity Rates and Trends.

19. Dubé JJ, Allison KF, Rousson V, Goodpaster BH, Amati F. Exercise dose and insulin sensitivity: Relevance for diabetes prevention. Med Sci Sports Exerc. 2012;44(5):793-799. doi:10.1249/MSS.0b013e31823f679f

20. Jacqueline L. Beaudry MCR. Effects of glucocorticoids and exercise on pancreatic b-cell function and diabetes development. Diabetes Metab Res Rev. 2012;28:560-573. doi:10.1002/dmrr

21. Beaudry JL, Dunford EC, Leclair E, et al. Voluntary exercise improves metabolic profile in high-fat fed glucocorticoid-treated rats. J Appl Physiol. 2015;118(11):1331-1343. doi:10.1152/japplphysiol.00467.2014

22. Chong CR, Chan WP in. A, Nguyen TH, et al. Thioredoxin-interacting protein: pathophysiology and emerging pharmacotherapeutics in cardiovascular disease and diabetes. Cardiovasc Drugs Ther. 2014;28(4):347-360. doi:10.1007/s10557-014-6538-5

23. Saxena G, Chen J, Shalev A. Intracellular shuttling and mitochondrial function of thioredoxin- interacting protein. J Biol Chem. 2010;285(6):3997-4005. doi:10.1074/jbc.M109.034421

24. Schulze PC, Yoshioka J, Takahashi T, He Z, King GL, Lee RT. Hyperglycemia promotes oxidative stress through inhibition of thioredoxin function by thioredoxin-interacting protein. J Biol Chem. 2004;279(29):30369-30374. doi:10.1074/jbc.M400549200

25. Shalev A. Minireview: Thioredoxin-Interacting Protein: Regulation and Function in the Pancreatic $\beta$-Cell. Mol Endocrinol. 2014;28(8):1211-1220. doi:10.1210/me.2014-1095

26. Szpigel A, Hainault I, Carlier A, et al. Lipid environment induces ER stress, TXNIP expression and inflammation in immune cells of individuals with type 2 diabetes. Diabetologia. 2018. doi:10.1007/s00125-017-4462-5

27. Zhou R, Tardivel A, Thorens B, Choi I, Tschopp J. Thioredoxin-interacting protein links oxidative stress to inflammasome activation. Nat Immunol. 2010;11(2):136-140. doi:10.1038/ni.1831

28. Oslowski CM, Hara T, O’Sullivan-Murphy B, et al. Thioredoxin-interacting protein mediates ER stress-induced $\beta$ cell death through initiation of the inflammasome. Cell Metab. 2012;16(2):265-273. doi:10.1016/j.cmet.2012.07.005

29. Bensellam M, Laybutt DR, Jonas JC. The molecular mechanisms of pancreatic $\beta$-cell glucotoxicity: Recent findings and future research directions. Mol Cell Endocrinol. 2012;364(1-2):1-27. doi:10.1016/j.mce.2012.08.003

30. Ye L, Robertson MA, Hesselson D, Stainier DYR, Anderson RM. Glucagon Is Essential for Alpha Cell Transdifferentiation and Beta Cell Neogenesis. Development. 2015;142(8):1407-1417. doi:10.1242/dev.117911

31. Grompe M, Zaret KS. Generation and Regeneration of Cells of the Liver and Pancreas. Science (80- ). 2008;322(5907):1490-1494. doi:10.1126/science.1161431

32. Pandol S. The Exocrine Pancreas. In: The Exocrine Pancreas. San Rafael (CA): MOrgan \& Claypool Life Sciences; 2010.

33. The Endocrine Pancreas. ER Services Anatomy and Physiology II. 
https://courses.lumenlearning.com/suny-ap2/chapter/the-endocrine-pancreas/.

34. Garofano A, Czernichow P, Bréant B. In utero undernutrition impairs rat beta-cell development. Diabetologia. 1997;40(10):1231-1234. doi:10.1007/s001250050812

35. Henquin JC, Ravier MA, Nenquin M, Jonas JC, Gilon P. Hierarchy of the $\beta$-cell signals controlling insulin secretion. Eur J Clin Invest. 2003;33(9):742-750. doi:10.1046/j.13652362.2003.01207.x

36. la Vega-Monroy M-LL de, Fernandez-Meji C. Beta-Cell Function and Failure in Type 1 Diabetes. Type 1 Diabetes - Pathog Genet Immunother. 2011;(November). doi: $10.5772 / 22089$

37. Scaglia L, Cahill CJ, Finegood DT, Bonner-Weir S. Apoptosis participates in the remodeling of the endocrine pancreas in the neonatal rat. Endocrinology. 1997;138(4):1736-1741. doi:10.1210/endo.138.4.5069

38. Wang RN, Bouwens L, Klöppel G. Beta-cell proliferation in normal and streptozotocintreated newborn rats: site, dynamics and capacity. Diabetologia. 1994;37(11):1088-1096. http://www.ncbi.nlm.nih.gov/pubmed/7867880.

39. Habener JF, Stanojevic V. $\alpha$-cell role in $\beta$-cell generation and regeneration (C) 2012 Landes Bioscience . Do not distribute. Islets. 2012;4(3):188-198.

40. Henquin JC, Rahier J. Pancreatic alpha cell mass in European subjects with type 2 diabetes. Diabetologia. 2011;54(7):1720-1725. doi:10.1007/s00125-011-2118-4

41. Disease NI of D and D and K. Insulin Resistance \& Prediabetes. https://www.niddk.nih.gov/health-information/diabetes/overview/what-isdiabetes/prediabetes-insulin-resistance.

42. Weir GC, Bonner-Weir S. Five of stages of evolving $\beta$-cell dysfunction during progression to diabetes. Diabetes. 2004;53(SUPPL. 3).

doi:10.2337/diabetes.53.suppl_3.S16

43. Polonsky KS, Polonsky KS, Given BD, et al. Quantitative Study of Insulin Secretion and Clearance in Normal and Obese Subjects. J Clin Invest. 1988;81(2):442-448. doi:10.1172/JCI113339

44. Reaven GM. Role of Insulin Resistance in Human Disease. Am Diabetes Assoc. 1988;37(12):1595-1607. http://diabetes.diabetesjournals.org/content/37/12/1595.short.

45. Yoon KH, Ko SH, Cho JH, et al. Selective $\beta$-cell loss and $\alpha$-cell expansion in patients with type 2 diabetes mellitus in Korea. J Clin Endocrinol Metab. 2003;88(5):2300-2308. doi:10.1210/jc.2002-020735

46. Bray G, Culbert I, Champagne $\mathrm{C}$, et al. Reduction in the incidence of type 2 diabetes with lifestyle intervention or metformin. N Engl J Med. 2002;346(6):393.

47. Rosch T, Lightdale C, Botet JF, et al. The New England Journal of Medicine Downloaded from nejm.org on May 19, 2014. For personal use only. No other uses without permission. Copyright (C) 1992 Massachusetts Medical Society. All rights reserved. N Engl J Med. 1992;326(26):1721-1726.

48. Yan Y-X, Xiao H-B, Wang S-S, et al. Investigation of the Relationship Between Chronic Stress and Insulin Resistance in a Chinese Population. J Epidemiol. 2016;26(7):355-360. doi:10.2188/jea.je20150183

49. Perry BI, Khandaker GM, Marwaha S, et al. Insulin resistance and obesity, and their association with depression in relatively young people: Findings from a large UK birth cohort. Psychol Med. 2019. doi:10.1017/S0033291719000308

50. Singh MK, Leslie SM, Packer MM, et al. Brain and behavioral correlates of insulin 
resistance in youth with depression and obesity. Horm Behav. 2019;108(March 2018):7383. doi:10.1016/j.yhbeh.2018.03.009

51. Bose M, Oliván B, Laferrére B. The effect of remote ischemic conditioning for kidney transplantation. Curr Opin Endocrinol Diabetes Obes. 2009;16(5):340-346. doi:10.1097/MED.0b013e32832fa137.Stress

52. McCollister KE, Clarke T, Christ SL, et al. Prevalence of the Metabolic Syndrome Among U.S. Workers. Diabetes Care. 2010;33(11):2390-2395. doi:10.2337/dc10-0681

53. Unger RH, Clark GO, Scherer PE, Orci L. Lipid homeostasis, lipotoxicity and the metabolic syndrome. Biochim Biophys Acta - Mol Cell Biol Lipids. 2010;1801(3):209214. doi:10.1016/j.bbalip.2009.10.006

54. Wells HF, Buzby JC. Dietary Assessment of Major Trends in U.S. Food Consumption, 1970-2005. Econ Inf Bull. 2008;33(33):27. http://www.ers.usda.gov/publications/eibeconomic-information-bulletin/eib33.aspx\#.Uvi017RBpDU.

55. Lanningham-Foster L, Nysse LJ, Levine JA. Labor saved, calories lost: The energetic impact of domestic labor-saving devices. Obes Res. 2003;11(10):1178-1181. doi:10.1038/oby.2003.162

56. Esser N, Legrand-Poels S, Piette J, Scheen AJ, Paquot N. Inflammation as a link between obesity, metabolic syndrome and type 2 diabetes. Diabetes Res Clin Pract. 2014;105(2):141-150. doi:10.1016/j.diabres.2014.04.006

57. Vozarova B, Weyer C, Lindsay RS, Pratley RE, Bogardus C, Antonio Tataranni P. High white blood cell count is associated with a worsening of insulin sensitivity and predicts the development of type 2 diabetes. Diabetes. 2002;51(2):455-461.

doi:10.2337/diabetes.51.2.455

58. Phillips CM, Perry IJ. Does inflammation determine metabolic health status in obese and nonobese adults? J Clin Endocrinol Metab. 2013;98(10):1610-1619. doi:10.1210/jc.20132038

59. Jung UJ, Choi MS. Obesity and its metabolic complications: the role of adipokines and the relationship between obesity, inflammation, insulin resistance, dyslipidemia and nonalcoholic fatty liver disease. Int J Mol Sci. 2014. doi:10.3390/ijms15046184

60. Unger RH, Orci L. Diseases of liporegulation : new perspective on obesity. FASEB J.

61. Dennis M, Benos DJ, Editor D, et al. Review Adiposity of the Heart *, Revisited. 2015.

62. Poitout V. Minireview: Secondary -Cell Failure in Type 2 Diabetes--A Convergence of Glucotoxicity and Lipotoxicity. Endocrinology. 2004;143(2):339-342. doi:10.1210/en.143.2.339

63. Shigetada Furukawa, Takuya Fujita, Michio Shimabukuro MI, Yukio Yamada, Yoshimitsu Nakajima, Osamu Nakayama, Makoto Makishima, Morihiro Matsuda and IS. Increased oxidative stress in obesity and its impact on metabolic syndrome Shigetada. $J$ Clin Invest. 2017;114(12):1752-1761. doi:10.1172/JCI200421625.1752

64. Ku BJ, Shong M, Kim JM, et al. The Roles of Adipokines, Proinflammatory Cytokines, and Adipose Tissue Macrophages in Obesity-Associated Insulin Resistance in Modest Obesity and Early Metabolic Dysfunction. PLoS One. 2016;11(4):e0154003. doi:10.1371/journal.pone.0154003

65. Weisberg SP, Leibel RL, Anthony W, et al. Obesity is associated with macrophage accumulation in adipose tissue Find the latest version : Obesity is associated with. J Clin Invest. 2003;112(12):1796-1808. doi:10.1172/JCI200319246.Introduction

66. Olefsky JM, Glass CK. Macrophages, Inflammation, and Insulin Resistance. Vol 72.; 
2010. doi:10.1146/annurev-physiol-021909-135846

67. Dinarello CA. Historical insights into cytokines. Eur J Immunol. 2007;37(SUPPL. 1):3445. doi:10.1002/eji.200737772

68. Mauer J, Denson JL, Brüning JC. Versatile functions for IL-6 in metabolism and cancer. Trends Immunol. 2015;36(2):92-101. doi:10.1016/j.it.2014.12.008

69. Hotamisligil GS. Inflammatory pathways and insulin action. Int J Obes. 2003;27:S53-S55. doi:10.1038/sj.ijo.0802502

70. LOCATI M, SICA A, ALLAVENA P, SOZZANI S, MANTOVANI A, VECCHI A. The chemokine system in diverse forms of macrophage activation and polarization. Trends Immunol. 2004;25(12):677-686. doi:10.1016/j.it.2004.09.015

71. Nieto-Vazquez I, Fernández-Veledo S, Krämer DK, Vila-Bedmar R, Garcia-Guerra L, Lorenzo M. Insulin resistance associated to obesity: The link TNF-alpha. Arch Physiol Biochem. 2008;114(3):183-194. doi:10.1080/13813450802181047

72. Hotamisligil GS, Murray DL, Choy LN, Spiegelman BM, Kirschner MW. Tumor necrosis factor a inhibits signaling from the insulin receptor (cy e/lnu non-Iul-dependent diabetes mdstus/glucose ranport/tyrine e receptor). 1994;91(May):4854-4858. doi:10.1002/9780470649848.ch16

73. Rosenvinge A, Krogh-Madsen R, Baslund B, Pedersen BK. Insulin resistance in patients with rheumatoid arthritis: Effect of anti-TNFa therapy. Scand J Rheumatol. 2007;36(2):91-96. doi:10.1080/03009740601179605

74. Ruan H, Pownall HJ, Lodish HF. Troglitazone antagonizes tumor necrosis factor- $\alpha-$ induced reprogramming of adipocyte gene expression by inhibiting the transcriptional regulatory functions of NF-кB. J Biol Chem. 2003;278(30):28181-28192. doi:10.1074/jbc.M303141200

75. Sharma AM, Chetty VT. Obesity, hypertension and insulin resistance. Acta Diabetol. 2005;42(SUPPL. 1):3-8. doi:10.1007/s00592-005-0175-1

76. Yudkin JS, Klein S, Katz DR, et al. Subcutaneous Adipose Tissue Releases Interleukin-6, But Not Tumor Necrosis Factor- $\alpha$, in Vivo 1 . J Clin Endocrinol Metab. 2014;82(12):4196-4200. doi:10.1210/jcem.82.12.4450

77. Jansson P-A, Sandqvist M, Sopasakis VR, et al. High Local Concentrations and Effects on Differentiation Implicate Interleukin-6 as a Paracrine Regulator. Obes Res. 2008;12(3):454-460. doi:10.1038/oby.2004.51

78. O'Rourke RW, White AE, Metcalf MD, et al. Systemic inflammation and insulin sensitivity in obese IFN- $\gamma$ knockout mice. Metabolism. 2012;61(8):1152-1161. doi:10.1016/j.metabol.2012.01.018

79. Bruckert E, Robert J-J, Maachi M, et al. Adipose Tissue IL-6 Content Correlates with Resistance to Insulin Activation of Glucose Uptake both in Vivo and in Vitro . J Clin Endocrinol Metab. 2014;87(5):2084-2089. doi:10.1210/jcem.87.5.8450

80. Pradhan AD, Manson JE, Buring JE, Ridker PM. C-Reactive Protein, Interleukin 6, and Risk of Developing Type 2 Diabetes Mellitus. 2015;286(3):327-334.

81. Calhau C, Santos A. Oxidative stress in the metabolic syndrome. Oxidative Stress Inflamm Angiogenes Metab Syndr. 2009:33-63. doi:10.1007/978-1-4020-9701-0_3

82. Stefanadis C, Panagiotakos DB, Economou M, et al. The implication of obesity on total antioxidant capacity in apparently healthy men and women: The ATTICA study. Nutr Metab Cardiovasc Dis. 2006;17(8):590-597. doi:10.1016/j.numecd.2006.05.007

83. Pihl E, Zilmer K, Kullisaar T, Kairane C, Mägi A, Zilmer M. Atherogenic inflammatory 
and oxidative stress markers in relation to overweight values in male former athletes. Int $J$ Obes. 2006;30(1):141-146. doi:10.1038/sj.ijo.0803068

84. Schulze-Osthoff K, Bakker AC, Vanhaesebroeck B, Beyaert R, Jacob WA, Fiers W. Cytotoxic activity of tumor necrosis factor is mediated by early damage of mitochondrial functions. Evidence for the involvement of mitochondrial radical generation. $J$ Biol Chem. 1992;267(8):5317-5323.

85. Chen X, Andresen1 BT, Hill M, Zhang J, Booth F, Zhang C. Role of Reactive Oxygen Species in Tumor Necrosis Factor-alpha Induced Endothelial Dysfunction. Curr Hypertens Rev. 2008;4(4):245-255.

http://www.ncbi.nlm.nih.gov/pubmed/20559453\%0Ahttp://www.pubmedcentral.nih.gov/a rticlerender.fcgi?artid=PMC2886300.

86. Schulze-Osthoff K, Beyaert R, Vandevoorde V, Haegeman G, Fiers W. Depletion of the mitochondrial electron transport abrogates the cytotoxic and gene-inductive effects of TNF. EMBO J. 1993;12(8):3095-3104. doi:10.1002/j.1460-2075.1993.tb05978.x

87. J. Diez J, Iglesias P. The Role of the Novel Adipocyte-Derived Protein Adiponectin in Human Disease: An Update. Mini-Reviews Med Chem. 2010;10(9):856-869. doi:10.2174/138955710791608325

88. De Ferranti S, Mozaffarian D. The perfect storm: Obesity, adipocyte dysfunction, and metabolic consequences. Clin Chem. 2008;54(6):945-955.

doi:10.1373/clinchem.2007.100156

89. Shimabukuro M, Zhou YT, Levi M, Unger RH. Fatty acid-induced beta cell apoptosis: a link between obesity and diabetes. Proc Natl Acad Sci U S A. 1998;95(5):2498-2502. http://www.ncbi.nlm.nih.gov/pubmed/9482914\%0Ahttp://www.pubmedcentral.nih.gov/art iclerender.fcgi?artid=PMC19389.

90. Lupi R, Dotta F, Marselli L, et al. Prolonged Exposure to Free Fatty Acids Has Cytostatic and Pro-Apoptotic Effects on Human Pancreatic Islets. Diabetes. 2002;51(5):1437-1442. doi:10.2337/diabetes.51.5.1437

91. Butler AE, Janson J, Soeller WC, Butler PC. Increased $\beta$-Cell Apoptosis Prevents Adaptive Increase in $\beta$-Cell Mass in Mouse Model of Type 2 Diabetes. Diabetes. 2003;52(9):2304-2314. doi:10.2337/diabetes.52.9.2304

92. Kaneto H, Nakatani Y, Kawamori D, et al. Role of oxidative stress, endoplasmic reticulum stress, and c-Jun N-terminal kinase in pancreatic $\beta$-cell dysfunction and insulin resistance. Int J Biochem Cell Biol. 2006;38(5-6):782-793.

doi:10.1016/j.biocel.2006.01.004

93. Saisho Y, Butler AE, Manesso E, Elashoff D, Rizza RA, Butler PC. $\beta$-Cell mass and turnover in humans: Effects of obesity and aging. Diabetes Care. 2013;36(1):111-117. doi:10.2337/dc12-0421

94. Matsuoka T, Kawamori R, Yamasaki Y. Glycation-dependent, reactive oxygen speciesmediated suppression of the insulin gene promoter activity in HIT cells . Find the latest version : 1997;99(1):144-150.

95. Rudich A, Tlrosh A, Potashnik R, Hemi R, Kanety H, Bashan N. Prolonged oxidative stress impairs insulin-induced GLUT4 translocation in 3T3-L1 adipocytes. Diabetes. 1998;47(10):1562-1569. doi:10.2337/diabetes.47.10.1562

96. Goldfine AL, Maddux BA, Lawrence JC, Evans JL, See W, Goldfine ID. Protection Against Oxidative Stress--Induced Insulin Resistance in Rat L6 Muscle Cells by Micromolar Concentrations of -Lipoic Acid. Diabetes. 2007;50(2):404-410. 
doi: $10.2337 /$ diabetes.50.2.404

97. Herman JP, Mcklveen JM, Ghosal S, et al. Regulation of the hypothalamic-pituitaryadrenocortical stress response. Compr Physiol. 2016;6(2):603-621.

doi:10.1002/cphy.c150015.Regulation

98. Peckett AJ, Wright DC, Riddell MC. The effects of glucocorticoids on adipose tissue lipid metabolism. Metabolism. 2011;60(11):1500-1510. doi:10.1016/j.metabol.2011.06.012

99. Webster Marketon JI, Glaser R. Stress hormones and immune function. Cell Immunol. 2008;252(1-2):16-26. doi:10.1016/j.cellimm.2007.09.006

100. Cruz-Topete D, Cidlowski JA. One hormone, two actions: Anti- And pro-inflammatory effects of glucocorticoids. Neuroimmunomodulation. 2014;22:20-32.

doi:10.1159/000362724

101. Kloet ERDE, Vreugdenhil E, Oitzl MS, Pharmacology M, Amsterdam L. Brain Corticosteroid Receptor Balance in Health and Disease. 2016;19(May):269-301.

102. Thompson AK, Fourman S, Packard AEB, Egan AE, Ryan KK, Ulrich-Lai YM. Metabolic consequences of chronic intermittent mild stress exposure. Physiol Behav. 2015;150:24-30. doi:10.1016/j.physbeh.2015.02.038

103. Oliver G, Wardle J, Gibson L. Stress and Food Choice: A Laboratory Study : Psychosomatic Medicine. Psychosom Med. 2000;62(6):853-865.

https://journals.lww.com/psychosomaticmedicine/pages/articleviewer.aspx?year=2000\&is sue $=11000 \&$ article $=00016 \&$ type $=$ abstract.

104. Dallman MF. Stress-induced obesity and the emotional nervous system. Trends Endocrinol Metab. 2009;21(3):159-165. doi:10.1016/j.tem.2009.10.004

105. Levine AS, Morley JE. Stress-induced eating in rats. Am J Physiol Integr Comp Physiol. 2017;241(1):R72-R76. doi:10.1152/ajpregu.1981.241.1.r72

106. Stress-Induced Hyperphagia and Obesity in Rats : A Possible Model for Understanding Human Obesity Author ( s ): Neil E . Rowland and Seymour M . Antelman Published by : American Association for the Advancement of Science Stable URL : https://www.jstor.org. 2019;191(4224):310-312.

107. Torres SJ, Nowson CA. Relationship between stress, eating behavior, and obesity. Nutrition. 2007;23(11-12):887-894. doi:10.1016/j.nut.2007.08.008

108. Van Raalte DH, Ouwens DM, Diamant M. Novel insights into glucocorticoid-mediated diabetogenic effects: Towards expansion of therapeutic options? Eur J Clin Invest. 2009;39(2):81-93. doi:10.1111/j.1365-2362.2008.02067.x

109. Bosqueiro JR, Carneiro EM, Abrantes JLF, et al. Glucocorticoids in Vivo Induce Both Insulin Hypersecretion and Enhanced Glucose Sensitivity of Stimulus-Secretion Coupling in Isolated Rat Islets . Endocrinology. 2009;151(1):85-95. doi:10.1210/en.2009-0704

110. Van Raalte DH, Brands M, Van Der Zij1 NJ, et al. Low-dose glucocorticoid treatment affects multiple aspects of intermediary metabolism in healthy humans: A randomised controlled trial. Diabetologia. 2011;54(8):2103-2112. doi:10.1007/s00125-011-2174-9

111. Hansen KB, Vilsbøll T, Bagger JI, Holst JJ, Knop FK. Reduced glucose tolerance and insulin resistance induced by steroid treatment, relative physical inactivity, and highcalorie diet impairs the incretin effect in healthy subjects. J Clin Endocrinol Metab. 2010;95(7):3309-3317. doi:10.1210/jc.2010-0119

112. López-López AL, Bonilla HJ, Escobar Villanueva M del C, Brianza MP, Vázquez GP, Alarcón FJA. Chronic unpredictable mild stress generates oxidative stress and systemic inflammation in rats. Physiol Behav. 2016;161(2016):15-23. 
doi:10.1016/j.physbeh.2016.03.017

113. Sorrells SF, Sapolsky RM. An inflammatory review of glucocorticoid actions in the CNS. Brain Behav Immun. 2007;21(3):259-272. doi:10.1016/j.bbi.2006.11.006

114. Bhattacharyya S, Brown DE, Brewer JA, Vogt SK, Muglia LJ. Macrophage glucocorticoid receptors regulate Toll-like receptor 4-mediated inflammatory responses by selective inhibition of p38 MAP kinase. Blood. 2007;109(10):4313-4319. doi:10.1182/blood-2006-10-048215

115. NEUROENDOCRINE REGULATION OF IMMUNITY.pdf.

116. Schmidt M, Pauels HG, Lügering N, Lügering A, Domschke W, Kucharzik T. Glucocorticoids induce apoptosis in human monocytes: potential role of IL-1 beta. $J$ Immunol. 1999;163(6):3484-3490. http://www.ncbi.nlm.nih.gov/pubmed/10477621.

117. Miller GE, Chen E, Sze J, et al. A Functional Genomic Fingerprint of Chronic Stress in

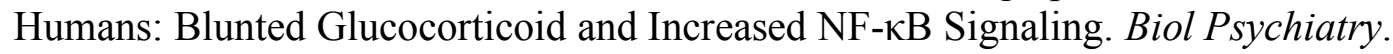
2008;64(4):266-272. doi:10.1016/j.biopsych.2008.03.017

118. Elenkov IJ, Chrousos GP. Stress Hormones, Elenkov. 1999;10(9). doi:10.1016/S10432760(99)00188-5

119. Auchus RJ. Addison's Disease. Encycl Neurol Sci. 2014;41(9):55-57. doi:10.1016/B9780-12-385157-4.01204-5

120. Rhen T, Cidlowski JA. Antiinflammatory Action of Glucocorticoids - New Mechanisms for Old Drugs. N Engl J Med. 2005;353(16):1711-1723. doi:10.1056/nejmra050541

121. Miller GE, Cohen S, Ritchey AK. Chronic psychological stress and the regulation of proinflammatory cytokines: A glucocorticoid-resistance model. Heal Psychol. 2002;21(6):531-541. doi:10.1037/0278-6133.21.6.531

122. Kiecolt-Glaser JK, Glaser R, Strain EC, et al. Modulation of cellular immunity in medical students. J Behav Med. 1986;9(1):5-21.

123. Glacer R, Kiecolt-Glacer JK, Stout JC, Tarr KL, Speicher CE, Holliday JE. Stress-related impairments in cellular immunity. Psychiatry Res. 1985;16(3):233-239. doi:10.1016/0165-1781(85)90111-8

124. Kiecolt-glaser JK, Kennedy S. Psychosom Med 1988 Kiecolt-Glaser. 2005;229:1-17. papers2://publication/uuid/967DBB7B-3AB9-4C20-B4BA-50629FBAE76B.

125. Sgoutas-Emch, Sandra A., Cacioppo JT, Uchino BN, Malarkey W, Pearl D, KiecoltGlaser JK, Glaser R. The effects of an acute psychological stressor on cardiovascular, endocrine, and cellular immune response: A prospective study of individuals high and low in heart rate reactivity. Psychophysiology. 1994;31(3):264-271. doi:10.1111/j.14698986.1994.tb02215.x

126. Glaser R, Pearson GR, Bonneau RH, Esterling BA, Atkinson C, Kiecolt-Glaser JK. Stress and the Memory T-Cell Response to the Epstein-Barr Virus in Healthy Medical Students. Heal Psychol. 1993;12(6):435-442. doi:10.1037/0278-6133.12.6.435

127. Glaser R, Kiecolt-Glaser JK. Chronic stress modulates the virus-specific immune response to latent herpes simplex virus type 1. Ann Behav Med. 1997;19(2):78-82. doi:10.1007/BF02883323

128. Kiecolt-Glaser JK, Garner W, Speicher C, Penn GM, Holliday J, Glaser R. Psychosocial modifiers of immunocompetence in medical students. Psychosom Med. 1984;46(1):7-14. doi:10.1097/00006842-198401000-00003

129. Kusnecov A V., Grota LJ, Schmidt SG, et al. Decreased herpes simplex viral immunity and enhanced pathogenesis following stressor administration in mice. J Neuroimmunol. 
1992;38(1-2):129-137. doi:10.1016/0165-5728(92)90097-5

130. Stark JL, Avitsur R, Padgett DA, Campbell KA, Beck FM, Sheridan JF. Social stress induces glucocorticoid resistance in macrophages. Am J Physiol Integr Comp Physiol. 2017;280(6):R1799-R1805. doi:10.1152/ajpregu.2001.280.6.r1799

131. Miller GE, Chen E. Life stress and diminished expression of genes encoding glucocorticoid receptor and beta2-adrenergic receptor in children with asthma. Proc Natl Acad Sci. 2006;103(14):5496-5501. doi:10.1073/pnas.0506312103

132. Busillo JM, Azzams KM, Cidlowski JA. Glucocorticoids sensitize the innate immune system through regulation of the NLRP3 inflammasome. J Biol Chem. 2011;286(44):38703-38713. doi:10.1074/jbc.M111.275370

133. Schwartzman RA. Apoptosis: the biochemistry and molecular biology of programmed cell death. Endocr Rev. 2004;14(2):133-151. doi:10.1210/er.14.2.133

134. Kannan K, Jain SK. Oxidative stress and apoptosis. Pathophysiology. 2000;7(3):153-163. http://www.ncbi.nlm.nih.gov/pubmed/10996508.

135. Zamzami N, Marchetti P, Castedo M, et al. Sequential reduction of mitochondrial transmembrane potential and generation of reactive oxygen species in early programmed cell death. J Exp Med. 1995;182(2):367-377.

http://www.ncbi.nlm.nih.gov/pubmed/7629499\%0Ahttp://www.pubmedcentral.nih.gov/art iclerender.fcgi?artid=PMC2192111.

136. Kroemer G. Mitochondrial control of apoptosis: an overview. Biochem Soc Symp. 2015;66:1-15. doi:10.1042/bss0660001

137. Ola MS, Berkich DA, $\mathrm{Xu} \mathrm{Y}$, et al. Analysis of glucose metabolism in diabetic rat retinas. Am J Physiol Metab. 2005;290(6):E1057-E1067. doi:10.1152/ajpendo.00323.2005

138. Rosca MG, Chen Q, Kerner J, Vazquez EJ, Hoppel CL, Kern TS. Oxidation of Fatty Acids Is the Source of Increased Mitochondrial Reactive Oxygen Species Production in Kidney Cortical Tubules in Early Diabetes. Diabetes. 2012;61(8):2074-2083. doi: $10.2337 / \mathrm{db} 11-1437$

139. Rebolledo OR, Dato SMA. Characteristics, Evaluation and Effects of Postprandial Hyperglycemia. 2005;(Figure 1):191-208.

140. Reyes A, Cárdenas ML. All hexokinase isoenzymes coexist in rat hepatocytes. Biochem J. 2015;221(2):303-309. doi:10.1042/bj2210303

141. Hirst J. Mitochondrial Complex I. Annu Rev Biochem. 2013;82(1):551-575. doi:10.1146/annurev-biochem-070511-103700

142. Pryde KR, Hirst J. Superoxide Is Produced by the Reduced Flavin in Mitochondrial Complex I. J Biol Chem. 2011;286(20):18056-18065. doi:10.1074/jbc.M110.186841

143. Kim JA, Wei Y, Sowers JR. Role of mitochondrial dysfunction in insulin resistance. Circ Res. 2008;102(4):401-414. doi:10.1161/CIRCRESAHA.107.165472

144. Yan L-J. Protein Redox Modification as a Cellular Defense Mechanism against Tissue Ischemic Injury. Oxid Med Cell Longev. 2014;2014:1-12. doi:10.1155/2014/343154

145. Antonio C. Postprandial Hyperglycemia and Diabetes Complications: Is It Time to Treat. Diabetes. 2005;54:1-7.

146. Wang $\mathrm{C}, \mathrm{Wu} \mathrm{HM}$, Jing XR, et al. Oxidative parameters in the rat brain of chronic mild stress model for depression: Relation to anhedonia-like responses. $J$ Membr Biol. 2012;245(11):675-681. doi:10.1007/s00232-012-9436-4

147. Priya Palta, PhD, MHS, Laura J. Samuel, PhD, MSN, Edgar R. Miller III, PhD, MD, and Sarah L. Szanton, PhD C. Depression and Oxidative Stress: Results From a Meta-Analysis 
of Observational Studies. Psychosom Med. 76(1):12-19.

doi:10.1097/PSY.0000000000000009.Depression

148. Duda W, Curzytek K, Kubera M, et al. The Effect of Chronic Mild Stress and Imipramine on the Markers of Oxidative Stress and Antioxidant System in Rat Liver. Neurotox Res. 2016;30(2):173-184. doi:10.1007/s12640-016-9614-8

149. Moreno J, Gaspar E, López-Bello G, et al. Increase in nitric oxide levels and mitochondrial membrane potential in platelets of untreated patients with major depression. Psychiatry Res. 2013;209(3):447-452. doi:10.1016/j.psychres.2012.12.024

150. Herken H, Gurel A, Selek S, et al. Adenosine Deaminase, Nitric Oxide, Superoxide Dismutase, and Xanthine Oxidase in Patients with Major Depression: Impact of Antidepressant Treatment. Arch Med Res. 2007;38(2):247-252. doi:10.1016/j.arcmed.2006.10.005

151. Dimopoulos N, Piperi C, Psarra V, Lea RW, Kalofoutis A. Increased plasma levels of 8iso-PGF2 $\alpha$ and IL-6 in an elderly population with depression. Psychiatry Res. 2008;161(1):59-66. doi:10.1016/j.psychres.2007.07.019

152. Black CN, Bot M, Scheffer PG, Cuijpers P, Penninx BWJH. Is depression associated with increased oxidative stress? A systematic review and meta-analysis. Psychoneuroendocrinology. 2015;51:164-175. doi:10.1016/j.psyneuen.2014.09.025

153. Che Y, Wang JF, Shao L, Young LT. Oxidative damage to RNA but not DNA in the hippocampus of patients with major mental illness. J Psychiatry Neurosci. 2010;35(5):296-302. doi:10.1503/jpn.090083

154. Gawryluk JW, Wang JF, Andreazza AC, Shao L, Young LT. Decreased levels of glutathione, the major brain antioxidant, in post-mortem prefrontal cortex from patients with psychiatric disorders. Int $J$ Neuropsychopharmacol. 2011;14(1):123-130. doi:10.1017/S1461145710000805

155. Zhou H, Tan H, Letourneau L, Wang JF. Increased thioredoxin-interacting protein in brain of mice exposed to chronic stress. Prog Neuro-Psychopharmacology Biol Psychiatry. 2019;88(March 2018):320-326. doi:10.1016/j.pnpbp.2018.08.013

156. Stojanovska L, Apostolopoulos V, Polman R, Borkoles E. To exercise, or, not to exercise, during menopause and beyond. Maturitas. 2014;77(4):318-323. doi:10.1016/j.maturitas.2014.01.006

157. Mikkelsen K, Stojanovska L, Polenakovic M, Bosevski M, Apostolopoulos V. Exercise and mental health. Maturitas. 2017;106(September 2017):48-56. doi:10.1016/j.maturitas.2017.09.003

158. Church T. Exercise in Obesity, Metabolic Syndrome, and Diabetes. Prog Cardiovasc Dis. 2011;53(6):412-418. doi:10.1016/j.pcad.2011.03.013

159. Seo D il, So WY, Ha S, et al. Effects of 12 weeks of combined exercise training on visfatin and metabolic syndrome factors in obese middle-aged women. J Sport Sci Med. 2011;10(1):222-226.

160. Jens M. Bruun, Jørn W. Helge, Bjørn Richelsen and BS. Diet and exercise reduce lowgrade inflammation and macrophage infiltration in adipose tissue but not in skeletal muscle in severely obese subjects. Am J Physiol Metab. 2005;290:E961-E967.

161. Richard L. Bradley, Justin Y. Jeon, Fen-Fen Liu and EM-F. Voluntary exercise improves insulin sensitivity and adipose tissue inflammation in diet-induced obese mice. $\mathrm{Am} \mathrm{J}$ Physiol Metab. 2008;295(3):E586-E594.

162. Lopresti AL, Hood SD, Drummond PD. A review of lifestyle factors that contribute to 
important pathways associated with major depression: Diet, sleep and exercise. $J$ Affect Disord. 2013;148(1):12-27. doi:10.1016/j.jad.2013.01.014

163. Song MR, Lee YS, Baek JD, Miller M. Physical Activity Status in Adults with Depression in the National Health and Nutrition Examination Survey, 2005-2006. Public Health Nurs. 2012;29(3):208-217. doi:10.1111/j.1525-1446.2011.00986.x

164. Stephens T. Physical activity and mental health in the United States and Canada: Evidence from four population surveys. Prev Med (Baltim). 1988;17(1):35-47. doi:10.1016/00917435(88)90070-9

165. Thomas M. DiLorenzo, Eric P. Bargman, Renee Stucky-Ropp GSB, Peter A. Frensch and TL. Long-Term Effects of Aerobic Exercise on Psychological Outcomes. 1999;28(1):7585.

166. Vallance JK, Winkler EAH, Gardiner PA, Healy GN, Lynch BM, Owen N. Associations of objectively-assessed physical activity and sedentary time with depression: NHANES (2005-2006). Prev Med (Baltim). 2011;53(4-5):284-288. doi:10.1016/j.ypmed.2011.07.013

167. L.B. D, M.B. P, A.C. U, M.W. O, J.A.J. S. Exploring exercise as an avenue for the treatment of anxiety disorders. Expert Rev Neurother. 2012;12(8):1011-1022. doi:10.1586/ern.12.73

168. Chaouloff F. Effects of acute physical exercise on central serotonergic systems. Med Sci Sports Exerc. 1997;29(1):58-62.

169. Liu W, Xu Y, Lu J, Zhang Y, Sheng H, Ni X. Swimming exercise ameliorates depressionlike behaviors induced by prenatal exposure to glucocorticoids in rats. Neurosci Lett. 2012;524(2):119-123. doi:10.1016/j.neulet.2012.07.011

170. Campeau S, Nyhuis TJ, Sasse SK, et al. Hypothalamic pituitary adrenal axis responses to low-intensity stressors are reduced after voluntary wheel running in rats. $J$ Neuroendocrinol. 2010;22(8):872-888. doi:10.1111/j.1365-2826.2010.02007.x

171. Broocks, A., Schweiger A. PKM. The influence of semistarvation-induced hyperactivity on hypothalamic serotonin metabolism. Physiol Behav. 1991;50(2):385-388.

172. Broocks, A., Meyer, T., George A et al. Decreased neuroendocrine responses to metachlorophenylpiperazine (m-CPP) but normal responses to ipsapirone in marathon runners. Neuropsychopharmacology. 1999;20(2):150-161.

173. Broocks, A., Meyer T., Gleiter $\mathrm{CH}$ et al. Effect of aerobic exercise on behavioral and neuroendocrine responses to meta-chorophenylpiperazine and to ipsapirone in untrained healthy subjects. Psychopharmacology (Berl). 2001;155(3):234-241.

174. Khanzada FJ, Soomro N, Khan SZ. Association of Physical Exercise on Anxiety and Depression Amongst Adults. J Coll Physicians Surg Pak. 2015;25(7):546-548. doi:07.2015/JCPSP.546548

175. Ho RT, Wang C-W, Chan CH, Ng S-M, Chan CL, Chan JS. Managing stress and anxiety through qigong exercise in healthy adults: a systematic review and meta-analysis of randomized controlled trials. BMC Complement Altern Med. 2014;14(1):674-679. doi:10.1186/1472-6882-14-8

176. Bartholomew JB, Morrison D, Ciccolo JT. Effects of acute exercise on mood and wellbeing in patients with major depressive disorder. Med Sci Sports Exerc. 2005;37(12):2032-2037. doi:10.1249/01.mss.0000178101.78322.dd

177. Lu J, Holmgren A. The thioredoxin antioxidant system. Free Radic Biol Med. 2014;66:7587. doi:10.1016/j.freeradbiomed.2013.07.036 
178. Lee S, Kim SM, Lee RT. Thioredoxin and Thioredoxin Target Proteins: From Molecular Mechanisms to Functional Significance. Antioxid Redox Signal. 2012;18(10):1165-1207. doi:10.1089/ars.2011.4322

179. Mustacich D, Powis G. Thioredoxin reductase. Biochem J. 2000;346:1-8. doi:10.1007/978-3-642-22236-8_3

180. Benhar M, Forrester MT, Hess DT, et al. American Association for the Advancement of Science (Continued). Am Nat. 2002;23(274):935-939. doi:10.1086/275028

181. Netto LES, Antunes F. The Roles of Peroxiredoxin and Thioredoxin in Hydrogen Peroxide Sensing and in Signal Transduction. Mol Cells. 2016;39(1):65-71. doi:10.14348/molcells.2016.2349

182. Silva-Adaya D, Gonsebatt ME, Guevara J. Thioredoxin System Regulation in the Central Nervous System: Experimental Models and Clinical Evidence. Oxid Med Cell Longev. 2014;2014:1-13. doi:10.1155/2014/590808

183. Patwari P, Chutkow WA, Cummings K, et al. Thioredoxin-independent regulation of metabolism by the $\alpha$-arrestin proteins. J Biol Chem. 2009;284(37):24996-25003. doi:10.1074/jbc.M109.018093

184. Minn AH, Hafele C, Shalev A. Thioredoxin-interacting protein is stimulated by glucose through a carbohydrate response element and induces $\beta$-cell apoptosis. Endocrinology. 2005;146(5):2397-2405. doi:10.1210/en.2004-1378

185. Chen, J., Saxena, G., Mungrue, I.N., Lusis, J. A., and Shalev A. A Critical Link Between Glucose Toxicity and B-Cell Apoptosis. Diabetes. 2008;57(April):938-944. doi:10.2337/db07-0715.ER

186. Lane T, Flam B, Lockey R, Kolliputi N. TXNIP shuttling: missing link between oxidative stress and inflammasome activation. Front Physiol. 2013;4(March):3-5. doi:10.3389/fphys.2013.00050

187. Reich E, Tamary A, Vogt Sionov R, Melloul D. Involvement of thioredoxin-interacting protein (TXNIP) in glucocorticoid-mediated beta cell death. Diabetologia. 2012;55(4):1048-1057. doi:10.1007/s00125-011-2422-z

188. Bharti V, Tan H, Chow D, et al. Glucocorticoid Upregulates Thioredoxin-interacting Protein in Cultured Neuronal Cells. Neuroscience. 2018;384:375-383. doi:10.1016/j.neuroscience.2018.06.001

189. Mohamed IN, Hafez SS, Fairaq A, Ergul A, Imig JD, El-Remessy AB. Thioredoxininteracting protein is required for endothelial NLRP3 inflammasome activation and cell death in a rat model of high-fat diet. Diabetologia. 2014;57(2):413-423. doi:10.1007/s00125-013-3101-z

190. Abderrazak A, Syrovets T, Couchie D, et al. NLRP3 inflammasome: From a danger signal sensor to a regulatory node of oxidative stress and inflammatory diseases. Redox Biol. 2015;4:296-307. doi:10.1016/j.redox.2015.01.008

191. Dostert C, Pétrilli V, Bruggen R Van, Steele C, T B. Innate immune activation through Nalp3 inflammasome sensing of asbestos and silica. 2008;320(5876):674-677.

192. Branyan KW, Devallance ER, Lemaster KA, et al. Role of Chronic Stress and Exercise on Microvascular Function in Metabolic Syndrome. Med Sci Sports Exerc. 2018;50(5):957966. doi:10.1249/MSS.0000000000001531

193. Wang J, Chan WG, Haut SA, Krauss MR, Izac RR, Hempfling WP. Determination of total N-nitroso compounds by chemical denitrosation using CuCl. J Agric Food Chem. 2005;53(12):4686-4691. doi:10.1021/jf0481709 
194. Hou J, Schindler U, Henzel WJ, et al. An Interleukin-4-Induced Transcription Factor : IL4 Stat and Steven L . McKnight Published by: American Association for the Advancement of Science Stable URL : https:/www.jstor.org/stable/2884613 JSTOR is a not-for-profit service that helps scholars, researchers, and students discover, use, and build upon a wide American Association for the Advancement of Science is collaborating with JSTOR to digitize, preserve and extend access to Science An Interleukin-4-Induced Transcription Factor : IL-4 Stat. 2019;265(5179):1701-1706. 